\title{
La Révolution, les fêtes et leurs images
}

Spectacles publics et représentation politique (Paris, 1789-1799)

Revolution, Festivals and their Images: Public Spectacles and Political

Representation (Paris, 1789-1799)

\section{Guillaume Mazeau}

\section{OpenEdition \\ Journals}

Édition électronique

URL : http://journals.openedition.org/imagesrevues/4390

DOI : 10.4000/imagesrevues.4390

ISSN : 1778-3801

\section{Éditeur :}

Centre d'Histoire et Théorie des Arts, Groupe d'Anthropologie Historique de l'Occident Médiéval,

Laboratoire d'Anthropologie Sociale, UMR 8210 Anthropologie et Histoire des Mondes Antiques

\section{Référence électronique}

Guillaume Mazeau, «La Révolution, les fêtes et leurs images », Images Re-vues [En ligne], Hors-série

6 | 2018, mis en ligne le 20 juillet 2018, consulté le 30 janvier 2021. URL : http://

journals.openedition.org/imagesrevues/4390; DOI : https://doi.org/10.4000/imagesrevues.4390

Ce document a été généré automatiquement le 30 janvier 2021.

\section{(c) (1) \&}

Images Re-vues est mise à disposition selon les termes de la Licence Creative Commons Attribution -

Pas d'Utilisation Commerciale 4.0 International. 


\section{La Révolution, les fêtes et leurs images}

Spectacles publics et représentation politique (Paris, 1789-1799)

Revolution, Festivals and their Images: Public Spectacles and Political

Representation (Paris, 1789-1799)

\section{Guillaume Mazeau}

«Le premier jour de la Révolution fut un jour de fête", proclame le journal L'Abeille, en juillet 1790. Quoi de plus naturel que l'association entre la fête et l'idéal révolutionnaire? Jusque dans la seconde moitié $\mathrm{du} \mathrm{xx}^{\mathrm{e}}$ siècle, le couple s'est plutôt bien porté. Ravivé en mai 68 , prolongé ensuite dans la culture de gauche, le mariage fut célébré en grande pompe vingt et un ans plus tard, en 1989, lors du Bicentenaire de la Révolution française : la «fête révolutionnaire " fut alors désignée comme la forme la plus évidente et consensuelle des commémorations, comme si la fête incarnait la révolution, et réciproquement ${ }^{1}$. Cherchant dans la fête le moment où les rapports de domination peuvent être subvertis, les études littéraires et les sciences sociales avaient, dans la décennie précédente, souligné la porosité entre fête et révolte, insistant sur les potentialités révolutionnaires des moments festifs, en particulier à travers le modèle du carnaval ${ }^{2}$. Dans le même temps, dans le sillage de Guy Debord et de Michel Foucault, la fête avait été analysée comme un des vecteurs d'une nouvelle société du spectacle ou comme un des dispositifs de contrôle des corps ${ }^{3}$. Écrivant dans ce contexte précis, les historiennes Mona Ozouf et Rosemonde Sanson sont alors venues tempérer l'opposition binaire entre fête émancipatrice et fête répressive, pointant les singularités de la «fête 
révolutionnaire » comme rituels de fondation et institutions sociales s'inscrivant dans le temps long des continuités et lents "transferts de sacralité ». Avec le scepticisme révolutionnaire qui gagnait les années 1970, l'utopie de la fête libératrice, rêvée par Rousseau dès 1758 , brillait de ses derniers feux ${ }^{4}$.

2 «Plantez au milieu d'une place un piquet couronné de fleurs, rassemblez-y le peuple et vous aurez une fête. Faites mieux encore : donnez les spectateurs en spectacle, rendezles acteurs eux-mêmes, faites que chacun se voie et s'aime dans les autres afin que tous soient mieux unis", avait affirmé le philosophe dans la Lettre à d'Alembert sur les spectacles, devenue, à titre posthume, le manifeste de la "fête révolutionnaire " $^{5}$. Presque un siècle plus tard, Michelet avait décrit la Fête de la Fédération du 14 juillet 1790 comme un véritable « miracle » : unis par la fête et «transfigurés dans la lumière de Juillet » les fédérés auraient ainsi immédiatement retrouvé, selon l'historien, leur nature humaine commune ${ }^{6} . .$. Parce qu'il abolissait la frontière entre ceux qui regardent et ceux qui agissent, concrétisant l'utopie de la participation directe sans représentation, le modèle rousseauiste de la fête a longtemps esquissé le tableau d'une humanité harmonieuse et enfin rendue à elle-même. Plus modéré, l'article de l'Encyclopédie avait quant à lui prôné une "participation sage, juste et utile » du peuple aux réjouissances et solennités publiques, afin que ce dernier soit vraiment reconnu non comme une simple multitude, mais comme "le vrai trésor des rois ${ }^{7}$. Pourtant, au même moment et surtout après 1789 , d'autres voix s'étaient élevées pour dénoncer les fêtes comme des moments de chaos et de la régression sauvage : c'est à travers les motifs des orgies et cortèges dionysiaques que l'imagerie contrerévolutionnaire avait alors porté ses coups les plus durs, inaugurant un combat culturel de long terme ${ }^{8}$. Ce discours eut en effet sa longue portée : les critiques récemment dirigées contre le climat de «festivisation » qui, depuis mai 68 jusqu'à Nuit Debout, révélerait la corruption morale de toute utopie radicale, proviennent de cet imaginaire contre-révolutionnaire, lui-même fondé sur le discours répressif tenu par l'Eglise au $\mathrm{xVIII}^{\mathrm{e}}$ siècle $^{9}$. Ainsi, qu'on la relie aux idéaux émancipateurs ou au déclin de la civilisation, investie d'enjeux qui la dépassent, la fête semble ainsi consubstantielle à la notion même de révolution.

3 Et pourtant, leur association n'est pas seulement le fruit des imaginaires politiques. Comme pendant d'autres crises de la période moderne, le moment révolutionnaire se traduit par une nette augmentation du nombre des fêtes, non seulement parce que celles-ci compensent facilement l'effondrement des autres institutions sociales, mais parce que la Révolution perturbe la notion de "représentation » dans tous ses aspects. C'est sur ce point que je voudrais insister ici, à travers une optique d'histoire politique et culturelle des représentations sociales. Avec d'autres dispositifs spectaculaires, les fêtes et leurs images tentent de remédier aux régimes de visibilité qui légitimaient la société d'ordres, mais qui étaient devenus opaques, comme si leur représentation publique ne correspondait plus à ce qu'ils étaient réellement. De ce fait, comme les pièces de théâtre, les fêtes se trouvent directement confrontées aux conflits récurrents de la révolution en cours et en particulier à la notion de juste représentation ${ }^{10}$.

Il faut donc éviter de regarder ces fêtes d'un œil trop familier : tenant à la fois du rituel, $\mathrm{du}$ spectacle et de la performance, mêlant cérémonies publiques et réjouissances populaires, imprégnés de sacré et associés aux rythmes économiques des communautés, ces moments de la vie collective étaient alors bien plus nombreux, divers et importants qu'aujourd'hui ${ }^{11}$. Je les considérerai ici comme des événements 
indissociablement esthétiques et politiques, comparables à des "photographies » des normes collectives, mais aussi à des principes actifs de la transformation sociale ${ }^{12}$. J'analyserai ici en même temps les fêtes et leurs représentations figurées : en tant que spectacles, les fêtes produisent des images instantanées ou plus tardives, tissant avec les événements un rapport complexe et souvent différent des sources écrites, c'est-àdire les programmes, les articles de journaux et les comptes rendus imprimés, ces derniers étant rendus obligatoires sous le Directoire. En insistant sur les sources graphiques, c'est la dimension sensible, peut-être aussi moins directement imbibée des discours normatifs sur la régénération collective, que je souhaite débusquer ici.

Ce point de vue induit des biais importants. Faute de sources suffisantes, je dirai peu de la manière dont les fêtes ont été vécues et ressenties, mais ce biais n'est guère propre à la culture visuelle de la fin du XVIII ${ }^{\mathrm{e}}$ siècle : elle s'étend sur la majorité des productions culturelles ${ }^{13}$. Je garderai également la prudence sur la question du «pouvoir des images ", plus souvent postulé que prouvé : l'étonnante multiplication des estampes augmente-t-elle leur impact sur les événements ou les banalise-t-elle, leur conférant un air de déjà-vu, les rendant même presque de fait invisibles? La duplication et leur diffusion des images augmentent-t-elles l'aura de la fête, ou la banalisent-elles au contraire, vidant cette dernière de son énergie première $?^{14}$ Ces questions resteront, pour l'essentiel, sans réponse claire. Issu des collections numérisées de la Bibliothèque nationale de France et du musée Carnavalet, ce corpus d'images parisien, majoritairement axé sur les fêtes nationales et politiques, ne saurait en outre épuiser le vaste foisonnement festif de la fin du XVIII ${ }^{\mathrm{e}}$ siècle.

\section{Les fêtes ou l'art du déjà-vu}

\section{Inerties, reprises et continuités}

6 Mona Ozouf l'a amplement montré : après 1789 , les fêtes ne rompent qu'en partie avec les habitudes ${ }^{15}$. C'est d'ailleurs en partie leur rôle : comme d'autres institutions sociales, elles comptent parmi les amortisseurs des crises de l'histoire. Ceux qui les mettent en scène, les dessinent, les peignent ou les gravent ont souvent en tête d'anciens cadres qu'ils superposent à ce qu'ils voient, croient voir ou interprètent a posteriori. Par ailleurs, la lenteur et la répétition des scénographies festives font partie des attendus de ces rituels momentanés qui dialoguent avec le temps long et l'histoire de basse intensité. Alors que tout bascule, ces spectacles continuent, souvent avec les mêmes formes, de jouer les mêmes fonctions de vérification (au sens de "faire voir la vérité d'une chose ${ }^{16}$ ) de la légitimité du pouvoir et de la solidité des liens sociaux. La « fête » n'a d'ailleurs rien d'un mot subversif: dans les mots du xvIII ${ }^{\mathrm{e}}$ siècle, le terme est avant tout associé aux "solennités » ou aux "réjouissances ", ou même associé à la célébration de Dieu et du roi ${ }^{17}$. Rarement spontanés, toujours décryptés et analysés par leurs protagonistes mêmes, ces rituels collectifs visent aussi à " pré-voir » et à conjurer l'imprévu : ils contribuent aux multiples modes informels et collectifs de la prévoyance politique antérieures à la statistique ${ }^{18}$. C'est pourquoi la majorité des fêtes jouent leur rôle: celui de faire "reconnaître ", c'est-à-dire à la fois "voir à nouveau » et « légitimer », les corps et pouvoirs de la société d'ordres.

7 L'ossature principale des fêtes officielles change donc peu: les formes les plus fréquentes restent le défilé et le cortège, tableaux mobiles dans lesquels la société 
organique déplie ses corps dans la cité ${ }^{19}$. Souvent présentée comme la première fête de la Révolution, la procession d'ouverture des Etats généraux (4 mai 1789) ne surprend ainsi personne : elle s'inscrit pleinement dans la tradition de la solennité monarchique. Répétitives, figurant le temps long des hiérarchies sociales, les images du défilé reprennent d'ailleurs des standards visuels autorisés: le défilé en serpentin, les emblèmes et attributs des ordres, les couleurs de la monarchie, mais aussi les spectateurs statiques et obéissants, légitimant par leur présence et leur regard la puissance du spectacle octroyé, donnent l'image d'un régime sûr de lui-même et de la stabilité de ses codes visuels. Publiée en 1789, L'Accomplissement du vœu de la nation montre le défilé du clergé suivi de la noblesse, du roi et des princes devant la foule civilisée et polie des riches spectateurs versaillais. Agrémentée d'une légende précise et numérotée permettant d'identifier les groupes successifs, l'image arrêtée sur le passage des deux premiers ordres exclut le Tiers Etat de l'image idéale du royaume (fig. 1) ${ }^{20}$. Une partie des traditions et « retours à l'ordre » visuels sont fabriqués. Ridicules dans leurs habits de cérémonie sombres et passés de mode, les députés du Tiers constituent les cibles principales de cette soumission par le signe ${ }^{21}$.

Fig. 1

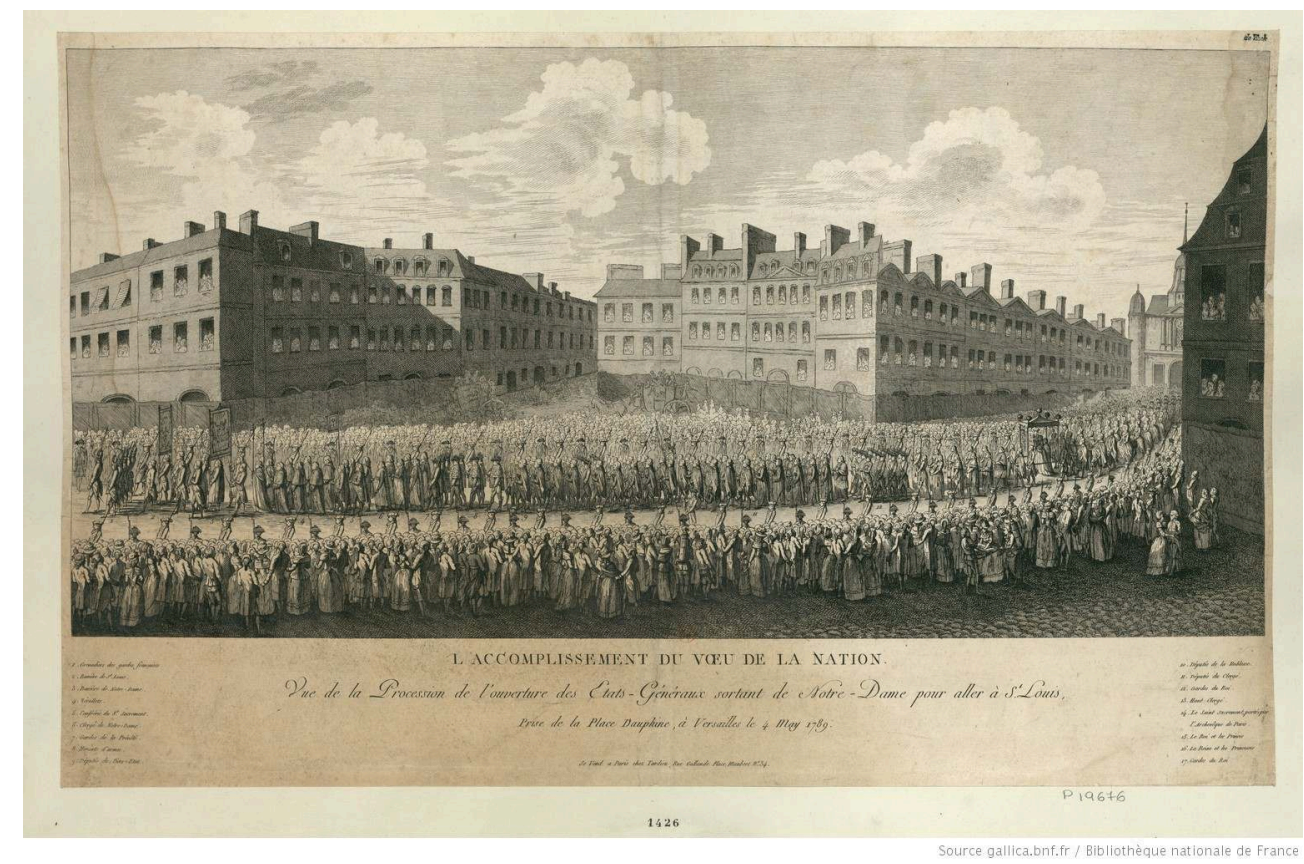

ANONYME, L'Accomplissement du vœu de la nation : vue de la procession de l'ouverture des Etats-généraux sortant de Notre-Dame pour aller à St Louis, prise de la place Dauphine, à Versailles, le 4 may 1789, eauforte, col. ; 29,5 x 59,5 cm, Paris, chez Tardieu, 1789, BNF.

8 Même après le printemps 89 , la plupart des fêtes s'inscrivent dans ces anciens dispositifs. Au fil des mois, ces rangs et préséances s'effacent progressivement, mais d'autres apparaissent, révélant les degrés de la nouvelle société capacitaire, dans laquelle les élus, les gardes nationaux et autres corps institués de la société civique prennent la première place. Dans la plupart des images de la Fête de la Fédération, les bannières des bataillons de gardes nationaux sont mises en valeur. Elles actualisent la tradition de l'héraldique et de la blasonnerie, utilisées par les corps municipaux, proposant ici de nouveaux pictogrammes symbolisant ces nouveaux corps représentatifs de la nation. Le besoin de reconnaissance et de nouveaux codes de 
représentation est si fort que Raymond Augustin Vieilh de Varennes, lui-même Vainqueur de la Bastille puis garde-magasin général des démolitions de la forteresse, leur consacre une série spécifique: sur chaque image, un garde national porte fièrement le drapeau de son bataillon, dont la taille est exagérément agrandie, l'emblème devenant le véritable sujet du portrait ${ }^{22}$. Ainsi, la Fête de la Fédération est en quelque sorte vécue comme l'épiphanie visuelle du nouvel ordre politique né un an plus tôt, le 14 juillet 1789 .

Fig. 2

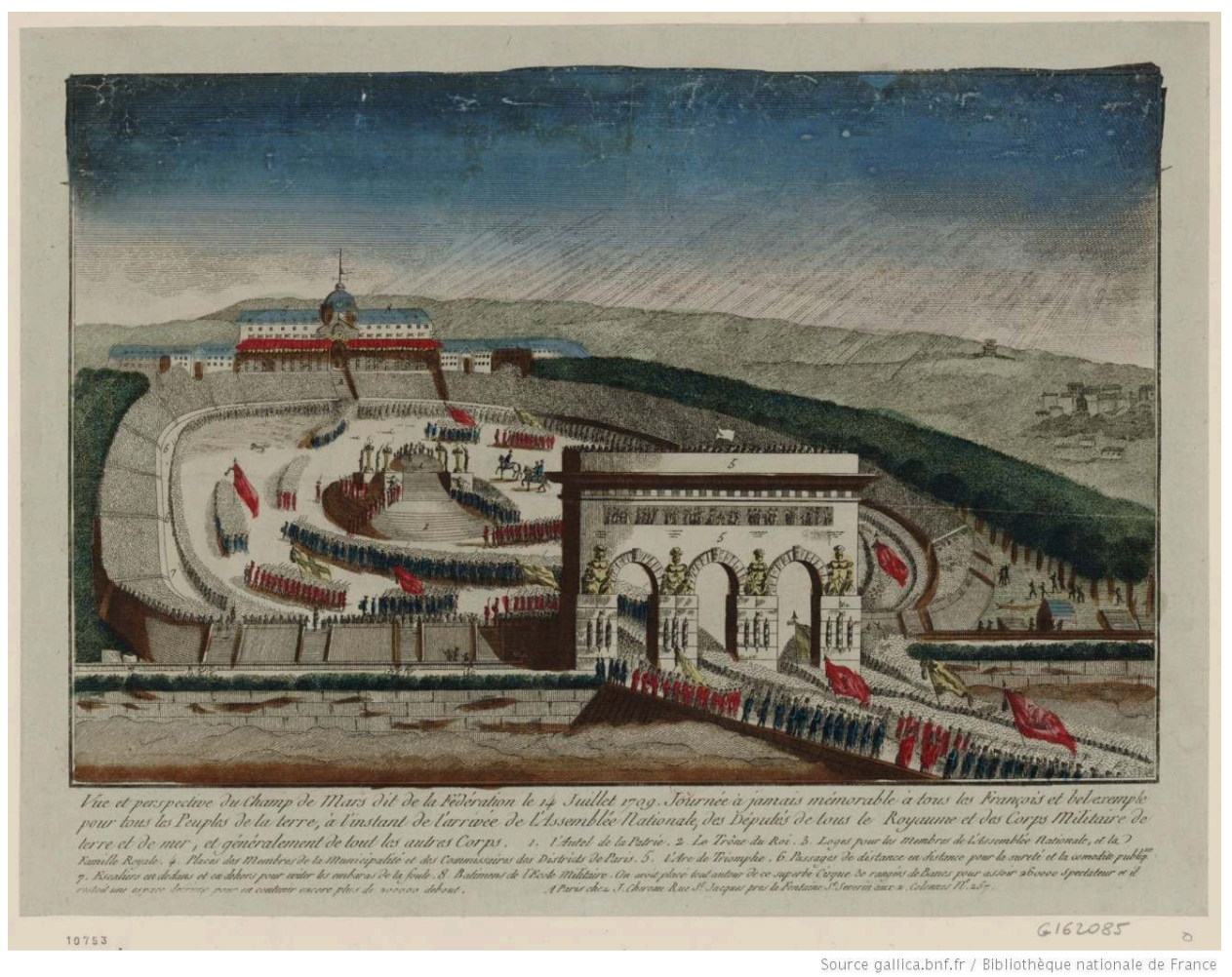

Anonyme, Vue et perspective du Champ de Mars dit de la Federation le 14 juillet 1709 [i.e. 1790], : journée a jamais memorable à tous les français et bel exemple pour tous les peuples de la terre, à l'instant de l'arrivée de l'Assemblée nationale, des deputés de tous le royaume et des corps militaire de terre et de mer, et généralement de tout les autres corps..., eau-forte, col. ; 26,5 × 40 cm, Paris, Chereau, 1790, BNF.

9 La plupart des images de l'été 1790 insistent ainsi sur les fêtes d'ordre : omniprésents, attirant des foules nombreuses, les jeux et réjouissances populaires sont pourtant effacés au profit des fêtes officielles ${ }^{23}$. Pendant l'été 1790 , les représentations des bals de la Bastille, de l'Hôtel de Ville et des Champs-Elysées ne totalisent que $20 \%$ du corpus et sont reléguées dans les arts considérés comme mineurs, décorant les assiettes, les éventails, panneaux de bois, papiers-peints ou dessus de boîte ${ }^{24}$. Autant qu'elles dérangent la "culture des apparences » de l'Ancien Régime, les fêtes parisiennes et leurs images réinstallent donc un ordre visuel qui marginalise le peuple ${ }^{25}$. Les stéréotypes des élites urbaines, marquées par une «culture métropolitaine » cosmopolite et éduquée, imposent donc leurs codes dans les spectacles festifs de la Révolution ${ }^{26}$. Héritées de la longue tradition de la veduta italienne, mais aussi des paysages urbains propres et aérées de la ville utile des Lumières, les «vues » d'optique, panoramiques ou dites " générales » des fêtes révolutionnaires, souvent prises en grand angle ou en plongée, sont les héritières des anciens ordres visuels, fondés sur l'autorité 
de l'œil de la Providence, de celui du roi ou plus récent, du regard policé que posent les élites urbaines sur la ville ${ }^{27}$. Parmi bien d'autres, la gravure en couleur Vue et perspective du Champ de Mars dit de la Federation (...) offre une vue panoramique et surplombante dont la composition met en valeur l'Ecole militaire, l'Arc de Triomphe et l'immense Cirque national, les hommes n'apparaissant que comme les jouets minuscules d'un événement plus grand qu'eux (fig. 2). Prise en diagonale depuis le dessus des gradins en direction de l'autel et de l'Arc de Triomphe, la Fédération générale des Français au Champ de Mars, le 14 juillet 1790, donne quant à elle le sentiment presque cinématographique de plonger rapidement dans un espace aussi vaste qu'animé par une énergie collective (fig. 3).

Fig. 3

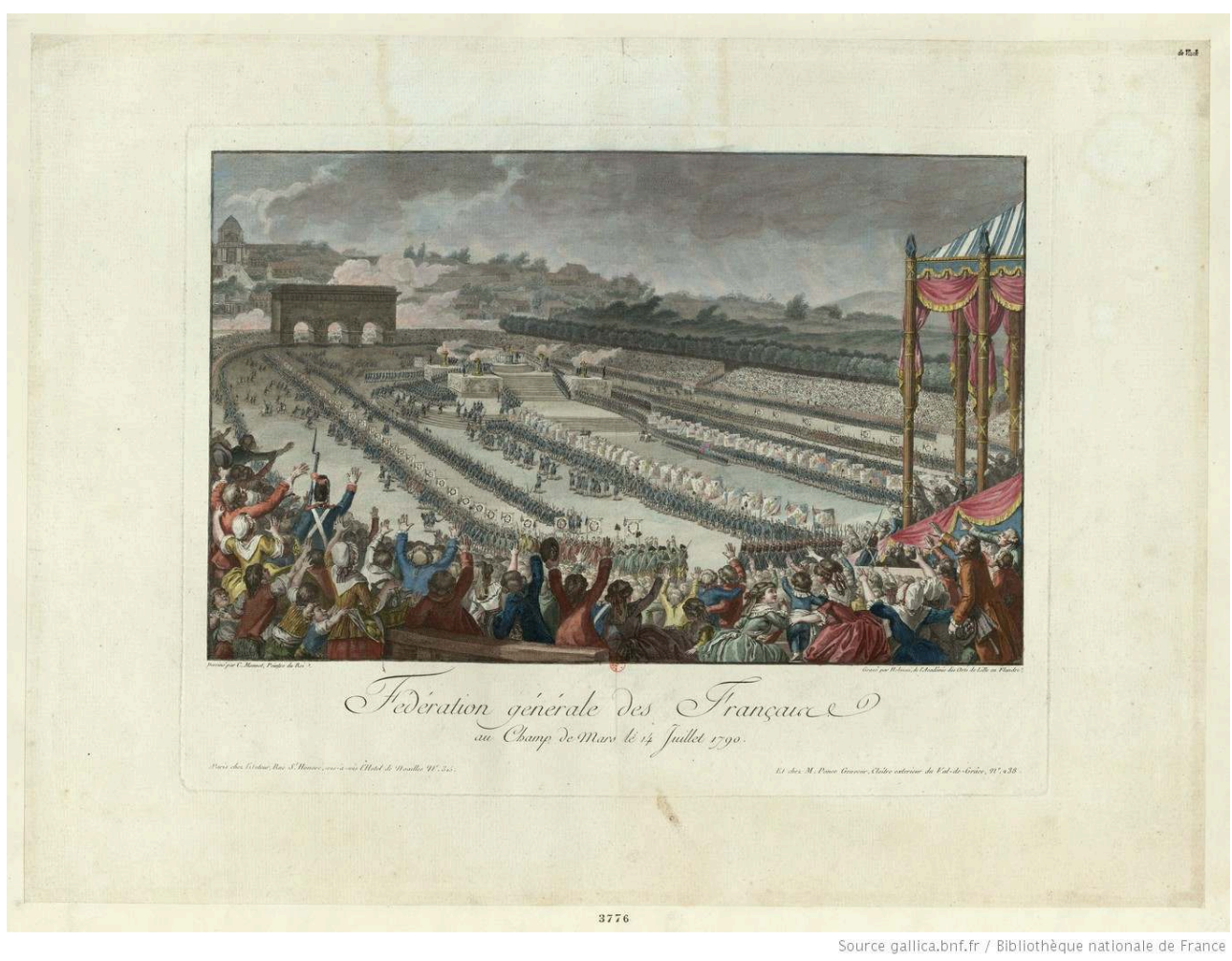

Charles monnet (dess.), Isidore Stanislas helman (grav.) et Antoine Jean duclos (grav.), Fédération générale des Français au Champ de Mars, le 14 juillet 1790 : [estampe] / Dessiné par C. Monet, Peintre du Roi ; gravé par Helman, de l'Académie des Arts de Lille en Flandre, À chez l'Auteur Et chez M. Ponce Graveur, eau-forte, burin, col. ; 27,5 x 44 cm, 1790 (détail), BNF.

Impressionner pour modeler : reposant sur l'idée selon laquelle les spectacles et les artifices peuvent façonner l'opinion des foules émotives et sensibles, bien des fêtes de la Révolution héritent des dispositifs du «Roi-machine ${ }^{28}$. Chargées d'effets et d'instruments spectaculaires, les plus grandes fêtes recourent aux machines d'architecture, aux tableaux vivants, mais aussi aux « hystoires » et autres « mystères » jadis organisés par les guildes municipales, les autorités religieuses ou même le pouvoir monarchique ${ }^{29}$. Cette continuité visuelle redouble celle des conditions matérielles de ces fêtes officielles à portée nationale. Il y a certes des nouveaux venus : une partie des sculpteurs, dessinateurs et peintres employés pour l'organisation des grandes scénographies urbaines de la Révolution viennent du petit monde de l'art et de l'artisanat et trouvent là une occasion inespérée d'accéder à une certaine 
reconnaissance ${ }^{30}$. Mais la plupart d'entre eux ont appris à travailler dans les structures de formations de l'Ancien Régime, qui marquent souvent les fêtes de leur esthétique classique. Tout un monde s'affaire, recourant aux compétences établies des architectes et artisans parisiens, mobilisant des réseaux professionnels connus (comme celui des artificiers, dominé depuis longtemps par les frères Ruggieri $\left.{ }^{31}\right)$, s'appuyant sur une logistique et une infrastructure disponible : sous le Directoire et surtout à partir de 1796, le stock des objets et décors servant aux fêtes sont conservés dans le dépôt des Fêtes Nationales, situé dans l'hôtel des Menus Plaisirs qui, sous l'Ancien Régime, servait déjà d'entrepôt pour les spectacles royaux ${ }^{32}$.

11 Formellement conservatrices, beaucoup de fêtes de la Révolution ont probablement peu surpris ni cherché à surprendre. Les réemplois, répétitions et déjà-vus y sont nombreux, amortissant peut-être la sensation de rupture ou de désorientation historique. Ainsi, l'autel de la patrie de la Fête de la Fédération (14 juillet 1790) est recyclé lors de la célébration des soldats de Châteauvieux (15 avril 1792), dont certains décors proviennent eux-mêmes de la translation des restes de Voltaire au Panthéon (11 juillet 1791) ${ }^{33}$. De la même manière, la Montagne de la Fête de l'Être Suprême (10 juin 1794) est réutilisée pour la Fête de la Victoire quelques mois plus tard ${ }^{34}$. Quant aux temples de la Raison, qui accueillent certaines fêtes républicaines à partir de l'automne 1793, ils viennent souvent d'anciennes églises dont les décors intérieurs ne sont que des maquillages rapides et superficiels $s^{35}$. Constants, ces reprises et camouflages restent aussi peu connus que les impressions qu'ils laissent, ou non, sur le public. Galvanisés par la croyance en l'avènement du monde nouveau, motivés par la volonté de créer des communautés sensibles, les rapports écrits des fêtes cherchent constamment à masquer ces traditions et continuités des fêtes de la Révolution. Les images les révèlent davantage. De ce fait, ce que les contemporains ont vu et décrit relève plutôt du mélange confus des formes, un étonnant bricolage que le graveur allemand Jean Gorges Wille, présent lors de la Fête de l'Unité à l'été 1793, raconte avec quelque surprise, curiosité et enthousiasme ${ }^{36}$.

Etonnante si l'on croit à l'illusion de la table rase révolutionnaire, cette relative inertie des formes festives n'est pourtant pas nouvelle. Elle est même consubstantielle au rapport complexe que ces institutions sociales entretiennent avec le temps, y compris dans un contexte de crise. Qualifiées a posteriori de "révolutionnaires ", les fêtes de la décennie 1790 sont de ce point de vue décevantes: rares moments de pause et de rassemblement en dehors des messes, ces rituels collectifs aident à redessiner l'espace et à reconfigurer le temps, en un mot à relier, rassurer et amortir l'angoisse de la brisure. Produites pour être rangées accrochées ou même encadrées, les images des fêtes, présentes sur les estampes ou les assiettes décoratives, participent à diffuser un imaginaire révolutionnaire consensuel et partagé au sein des foyers. Véritables institutions domestiques, les représentations des fêtes semblent d'ailleurs être plus nombreuses que bien d'autres thèmes dans les images privées. Certaines d'entre elles s'inscrivent explicitement dans de longues traditions politiques et visuelles. C'est le cas de celles qui rejouent les "Entrées royales", ces "grands théâtres » mobilisés pour maintenir, célébrer la symbolique royale ou compenser le déclin de la puissance monarchique ${ }^{37}$. Réalisées dans le contexte de l'effondrement du pouvoir, les entrées de Louis XVI à Paris (17 juillet et 6 octobre 1789), mais surtout celle du 21 juin 1791, sanctionnant son retour forcé après la fuite avortée, sont accompagnées de rassemblements plus ou moins spontanés visant à réajuster les modes de 
représentation royaux à chaque nouvelle crise de la monarchie. Plus inédites, les diverses fêtes de la Fédération, célébrant l'union de la nation autour de la loi et du roi, reprennent les codes des Entrées royales mais en renversent la signification : ici, ce sont les gardes nationaux qui, en défilant sous les monuments éphémères, simulent l'«Entrée du peuple » dans la cité sous ses nouveaux totems, mais loin des barrières et murailles, considérées comme les cicatrices architecturales des injustices fiscales du passé38. Après 1795 , ces cortèges et entrées, effectués par les Directeurs à cheval, renouent davantage avec les traditions antérieures, fondées sur le modèle prestigieux du triomphe militaire.

Fig. 4

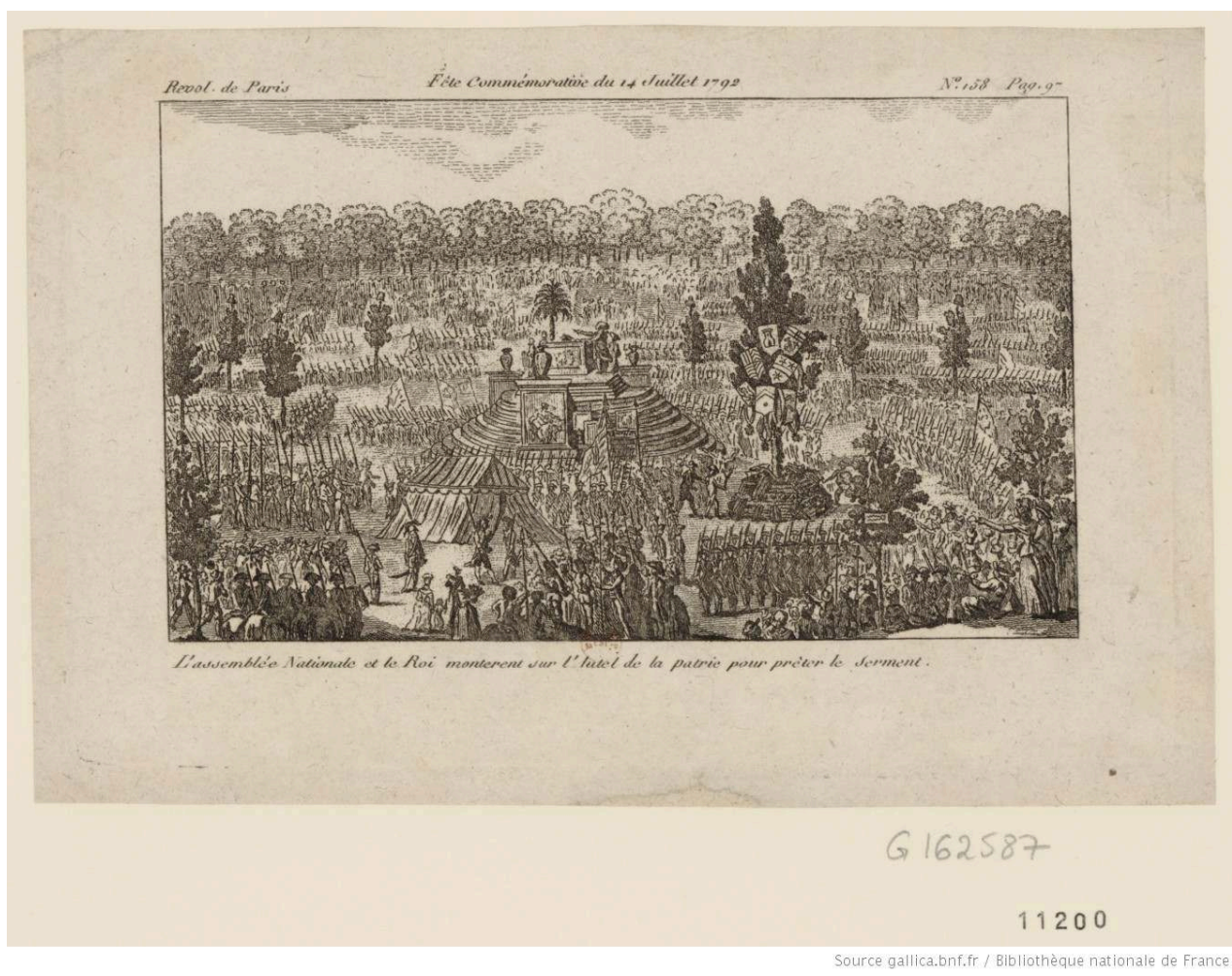

DALENCOUR, Fête commémorative du 74 juillet 7792 : l'Assemblée nationale et le Roi monteront sur l'autel de la patrie pour prêter le serment, eau-forte ; 9,5 × 15,5 cm (tr. c.), Paris, imprimerie des Révolutions de Paris, 1792, BNF.

Plutôt que de figurer de nouvelles utopies prospectives, beaucoup d'images des fêtes parisiennes empilent donc les temporalités comme des palimpsestes visuels : en 1789 et 1790, alors que les figures et thèmes révolutionnaires inondent le marché des estampes, les images d'anciennes fêtes royales continuent de se vendre. Souvent, elles sont l'occasion de comparer Louis XVI au «bon» Henri IV, vu comme plus conciliant que son héritier, dont la statue de la place Dauphine avait d'ailleurs attiré les fêtes et protestations de l'été $1788^{39}$. Plus tard, lorsqu'ils s'appuieront sur les fêtes pour propager l'adhésion dans les Républiques sœurs européennes, les Français sauront recourir à ce métissage des traditions visuelles. En Italie, après 1796, les événements organisés dans les nouvelles Républiques marient ainsi les habitudes spectaculaires des fêtes baroques à l'austérité des fêtes républicaines françaises. À Naples, en janvier 1799, l'état-major français organise très pragmatiquement les miraculeuses et populaires liquéfactions de la statue de saint Janvier, présenté par Championnet comme le 
nouveau protecteur de la Grande Nation, afin de faire adhérer le peuple revêche des lazzaroni à la République parthénopéenne ${ }^{40}$. Faites de réemplois, de citations et de traditions empilées, les images des fêtes se présentent ainsi souvent comme les supports d'un "art de la mémoire ", destiné à transmettre un cliché souvenir ${ }^{41}$ : c'est particulièrement le cas des gravures présentant les «fêtes commémoratives » du 14 juillet, destinées à construire une communauté affective dans le souvenir de l'unité apparente de l'été 1790. En 1792, Dalencour livre une description figurée à la fois exhaustive et condensée du déroulé de la fête du 14 juillet, l'œil du spectateur étant invité à passer d'une scène à l'autre, recomposant lui-même les épisodes successifs de l'événement (fig. 4). Autrement dit, la reconnaissance de stéréotypes et de clichés correspondant à des habitudes et à des traditions festives est un des effets recherchés non seulement par les organisateurs des fêtes, mais aussi par les « petits pinceaux » qui les représentent, ou encore par les clients qui les achètent puis les conservent ou les exposent chez eux. Les images des fêtes de la Révolution visent en tout cas souvent à fixer celles-ci dans les mémoires. Le 13 décembre 1790, le Journal de Paris décrit ainsi la gravure fermant un livre intitulé La petite Lutèce devenue grande fille, en partie consacrée à la Fête de la Fédération (14 juillet 1790) : l'image «rappelle cette superbe fête aux yeux de ceux qui l'ont vue, et la trace, avec vérité, aux yeux de ceux qui en ont été privés $»^{42}$.

\section{La Révolution trouble-fête?}

Évidemment, tout ne se réduit pas aux continuités : la crise révolutionnaire se traduit par une brusque inflation des spectacles publics, dont les formes se réinventent à l'ombre des traditions de long terme ${ }^{43}$. Contrairement à leur image d'Épinal, beaucoup de fêtes de la Révolution apparaissent en réalité bien peu "festives ", selon l'acception contemporaine du mot. Au-delà des instants fugaces où surgissent des moments d'enthousiasme ou de joie, au-delà aussi des réjouissances organisées, les fêtes de la Révolution ainsi que leurs images ressemblent plus souvent à des rituels didactiques ou à des mises en scène bien réglées. Pourtant, la plupart du temps, rien n'est vraiment comparable aux fêtes de l'Ancien Régime. Il ne s'agit en effet plus de soumettre par le spectacle mais de donner confiance et d'éduquer. Les révolutionnaires français croient en effet que les fêtes constituent un des outils capables de faire progresser les hommes ${ }^{44}$. Pendant la Révolution qui avait secoué les Provinces-Unies de 1781 à 1787, les partis Orangistes et patriotes s'étaient déjà entre-déchirés sur ce qui, de loin, pourrait sembler anecdotique et qui, pourtant, interroge les moyens par lesquels les rapports sociaux peuvent, ou non, être corrigés ${ }^{45}$. Or de Thouret et Mirabeau (1791) à La Réveillère-Lépeaux, auteur d'un fameux rapport en mai $1797^{46}$, la plupart des révolutionnaires choisissent les fêtes, avec l'école, comme l'un des principaux outils d'une politique de civilisation du peuple, considéré comme trop sensible aux superstitions et sujet aux mauvaises influences ${ }^{47}$. Pour beaucoup, les fêtes doivent aussi devenir les creusets symboliques de la réduction des inégalités. Elles doivent créer du lien, contribuer à l'invention d'une fraternité civile et assurer la cohésion d'une nation particulièrement fragilisée par la Révolution: pour Billaud-Varenne, l'expérience collective ressentie lors des fêtes doit exhumer le "sens commun » à tous les hommes ${ }^{48}$.

De même que les arts, chargés de donner une "direction morale » à la nation, les fêtes sont pensées comme des "institutions sociales》 destinées à éduquer le peuple ${ }^{49}$. Présente dès 1790, cette conception pédagogique culmine lors du Directoire 
(1795-1799), qui érige la politique festive en véritable système voué à la "régénération". Après 1795 , cette dernière constitue l'une des missions de la $5^{\mathrm{e}}$ division du ministère de l'Intérieur, connue sous le nom de direction générale de l'Instruction publique, pourvue de tous les outils d'une vaste politique de régénération, c'est-à-dire, dans l'esprit des républicains, les écoles, les bibliothèques et les musées. Sept grandes fêtes nationales doivent rythmer le calendrier annuel, consacrées à la Fondation, à la République, à la Jeunesse, aux Époux, mais aussi à la Renaissance, à l'Agriculture, à la Liberté et aux Vieillards). Leurs dates sont définies par le décret sur l'Instruction publique du 25 octobre 1795 (3 brumaire an IV) : il s'agit alors d'asseoir la République sur des socles à la fois locaux (ce sont les autorités départementales qui en sont chargées) et stables, susceptibles de changer les habitudes. Ces fêtes sont aussi chargées de défendre la tonalité politiquement et économiquement libérale de la Constitution de 1795, fondée sur la vitalité de l'agriculture, du commerce ainsi que sur le nouvel ordre familial, établi par la réforme du mariage $(1792)^{50}$. Chargées de charrues décorées et d'autres symboles du monde paysan, les images de la Fête de l'Agriculture promeuvent ainsi la prospérité agraire et le libre commerce ${ }^{51}$. Vêtues de blanc, les femmes mariées dans l'année sont appelées à défiler en blanc, couronnées de fleurs et ornées de rubans tricolores. Peu regardés et peu suivis, ces spectacles bien ordonnés ne parviennent toutefois guère à compenser les tensions issues de la guerre civile, avivées par la politique de répression politique et la dérégulation commerciale menées depuis l'été 1794.

Fig. 5

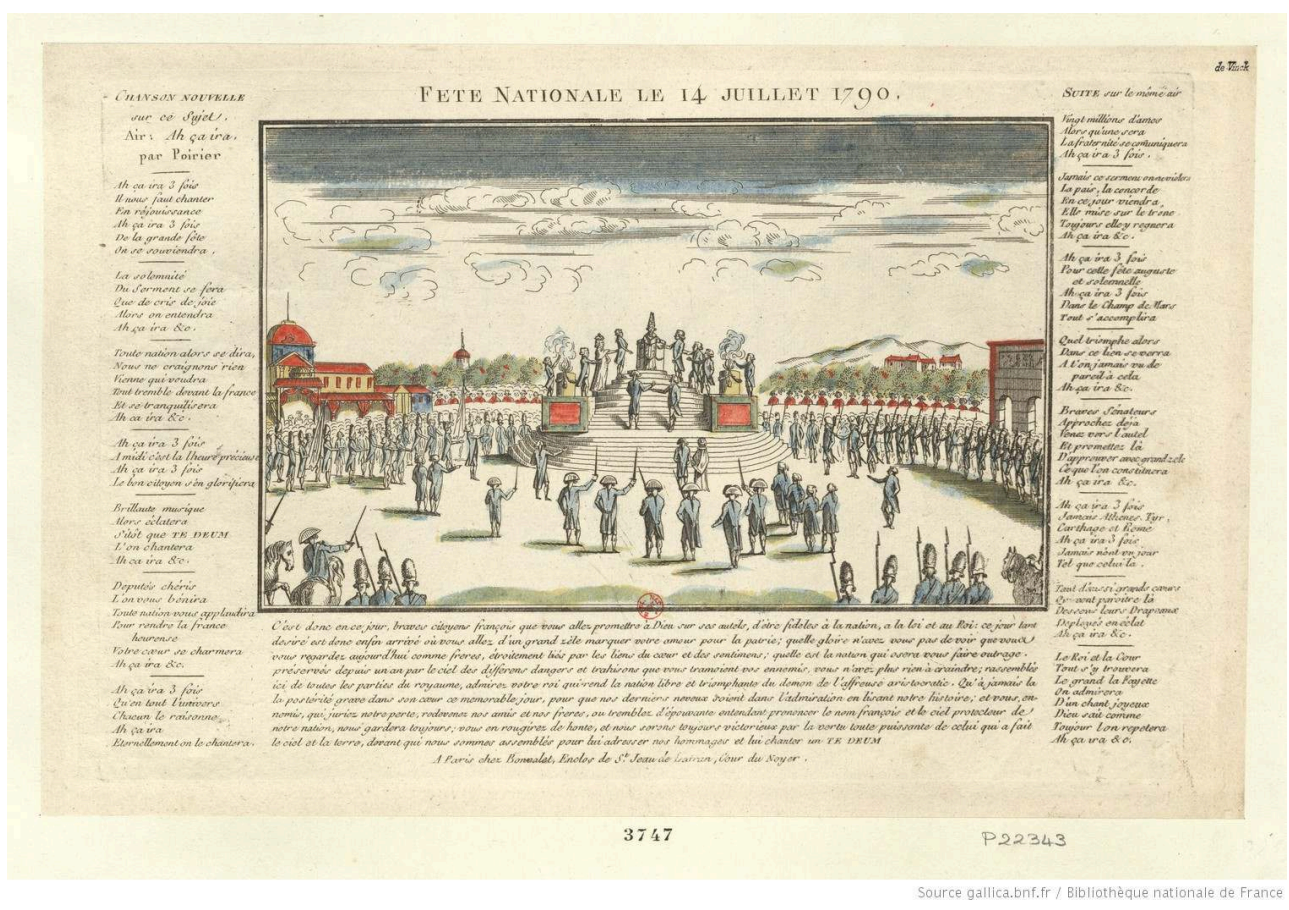

anonyme, Fete Nationale le 14 juillet 1790.., eau-forte, col. ; 23,5 x 36 cm, Paris, 1790, BNF. 
Fig. 6

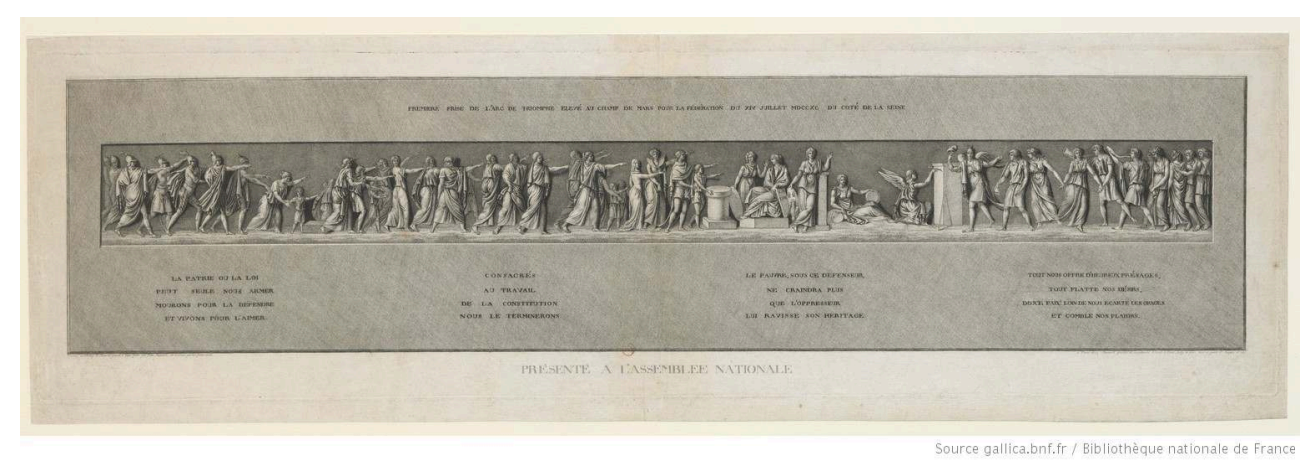

Jean-Baptiste Félix MASSARD, Premiere frise de l'arc de triomphe elevé au Champ de Mars pour la Fédération du XIV juillet MDCCXC du coté de la Seine : presenté l'Assemblee nationale : [estampe] / dessiné au Champ de Mars et gravé a l'eau-forte par Felix Massard ; et terminé par son frere ainé, eau-forte, roulette ; 19,5 x $70 \mathrm{~cm}$ (élt d'impr.), Paris, chez Massard, 1790, BNF.

Autant que les fêtes elles-mêmes, leurs images constituent des vecteurs de pédagogie qui interdisent de leur accorder une trop grande confiance documentaire. Ces images visent à promouvoir la Révolution et/ou la République jusque dans les maisons, comme l'attestent le nombre de dessus de boîtes, d'assiettes patriotiques, de papiers peints ou de panneaux décoratifs, qui brodent les paysages du quotidien ${ }^{52}$. Parfois saturées de devises, de symboles politiques et de commentaires moraux, les clichés des fêtes reviennent particulièrement souvent pour illustrer les almanachs, les textes de chansons et même les calendriers républicains, eux-mêmes utilisés comme des supports ordinaires de pédagogie collective. Sous le dessin du serment prêtée sur l'autel de la patrie, la gravure intitulée Fete [sic] nationale le 14 juillet 1790 (...) une légende explique la signification du geste, elle-même encadrée par un chant composé sur l'air du Ça Ira de Poirier (fig. 5). Beaucoup d'autres images sont également encadrées de chansons ou d'extraits de discours ${ }^{53}$. Axés sur le récit des épisodes du printemps et de l'été 89 , les bas-reliefs de l'autel de la patrie de la Fédération sont par exemple gravés et largement diffusés après le 14 juillet 1790 , pour que ceux qui ne les ont pas vus puissent $\mathrm{y}$ avoir accès. Sur une estampe longue de 70 centimètres, destinée à être dépliée, Jean-Baptiste Félix Massard fait accéder aux détails d'une frise qui n'était destinée à être aperçue que de loin: consacrés au serment et à l'apologie de la constitution alors en cours de rédaction, les motifs antiques appellent à mourir pour défendre la patrie et à aimer la loi (fig. 6). Spécialisé dans ce genre d'estampe, Massard récidivera l'année suivant au sujet du char servant à la translation des cendres de Voltaire au Panthéon, preuve que les vastes scénographies ne comblent pas le besoin de tout voir : certains acheteurs aiment scruter les détails des scénographies, méditer sur le sens véritable de la fête et conserver des supports de mémoire ${ }^{54}$. Lors de la Fête de l'Être Suprême en 1794, plusieurs estampes enrichissent la représentation de la cérémonie d'un calendrier républicain de l'an III, afin de marquer le nouveau temps commun (fig. 7). 
Fig. 7

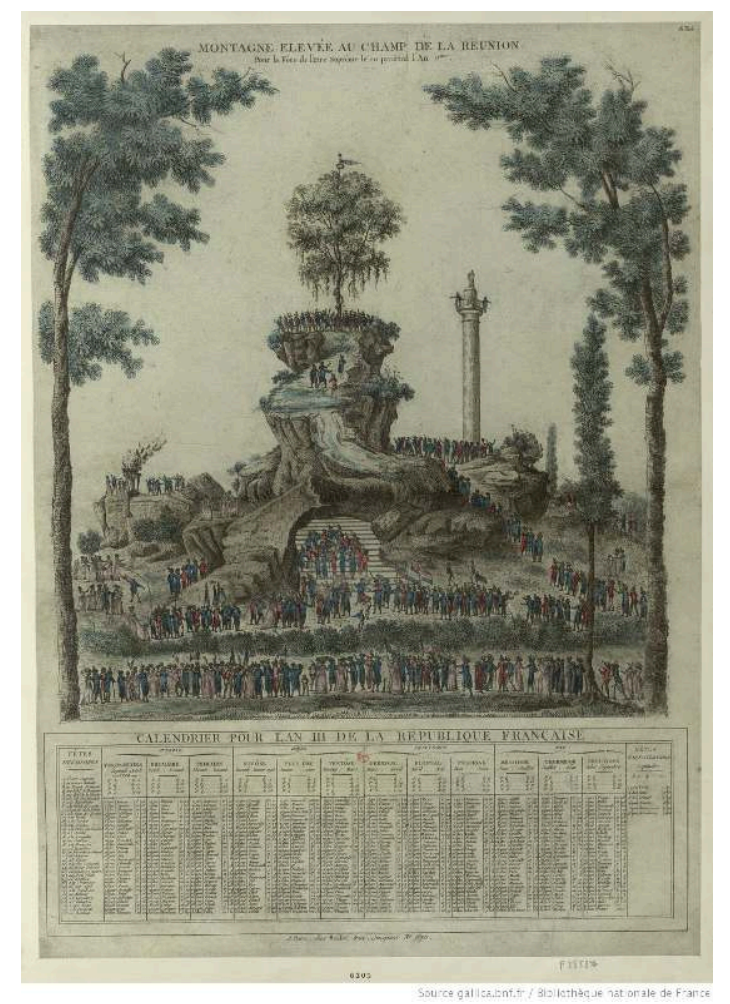

anonyme, Montagne élevée au champ de la réunion: Pour la Fête de l'Etre Suprême le 20 prairial l'An 2.me, eau-forte, 70,5 x 50,5 cm, Paris, chez Basset, 1794, BNF.

Or ces visions ne sont pas neutres : elles visent en général à faire de la Révolution une fête. L'enjeu est loin d'être futile dans la guerre des images que se livrent les camps en présence : pendant la campagne de promotion du serment civique de 1790-91, incitant les citoyens à s'engager publiquement en faveur de la Révolution, certaines estampes montrent les communautés rassemblées devant les chaumières, les tas de fumier ou les églises, unies par la chorégraphie des bras levés. Ces images circulent comme des armes de combat, participant à relancer ou à entretenir l'enthousiasme des débuts, contribuant à combattre le premier scepticisme et la défiance et, par contrecoup, à isoler un camp du refus. Très diffusée, l'estampe dessinée par Derozier et gravée par Génisson, "dédiée aux bons villageois", en constitue le cliché idéal typique : rassemblés sous le calvaire, les habitants lèvent leurs bras, leurs bâtons, leurs fusils et leurs chapeaux en direction du prêtre et des officiers municipaux, alors que s'éloigne un couple d'aristocrates (fig. 8). Pendant l'été 1790 et dans les mois qui suivent, les images de la Fédération se focalisent ainsi sur la joie et les fraternisations, mettant en scène la libre et joyeuse adhésion du peuple, fabriquant une image aussi consensuelle que fabriquée ${ }^{55}$. Images animées, elles-mêmes fixées par des images immobiles, les fêtes de la Révolution valent mille discours. Nommé au Comité d'Instruction Publique en octobre 1792 pour organiser les fêtes civiques, Jacques-Louis David affirme, le 17 janvier suivant : « nos ennemis, vaincus par les armes, le seront aussi par les arts $»^{56}$. 
Fig. 8

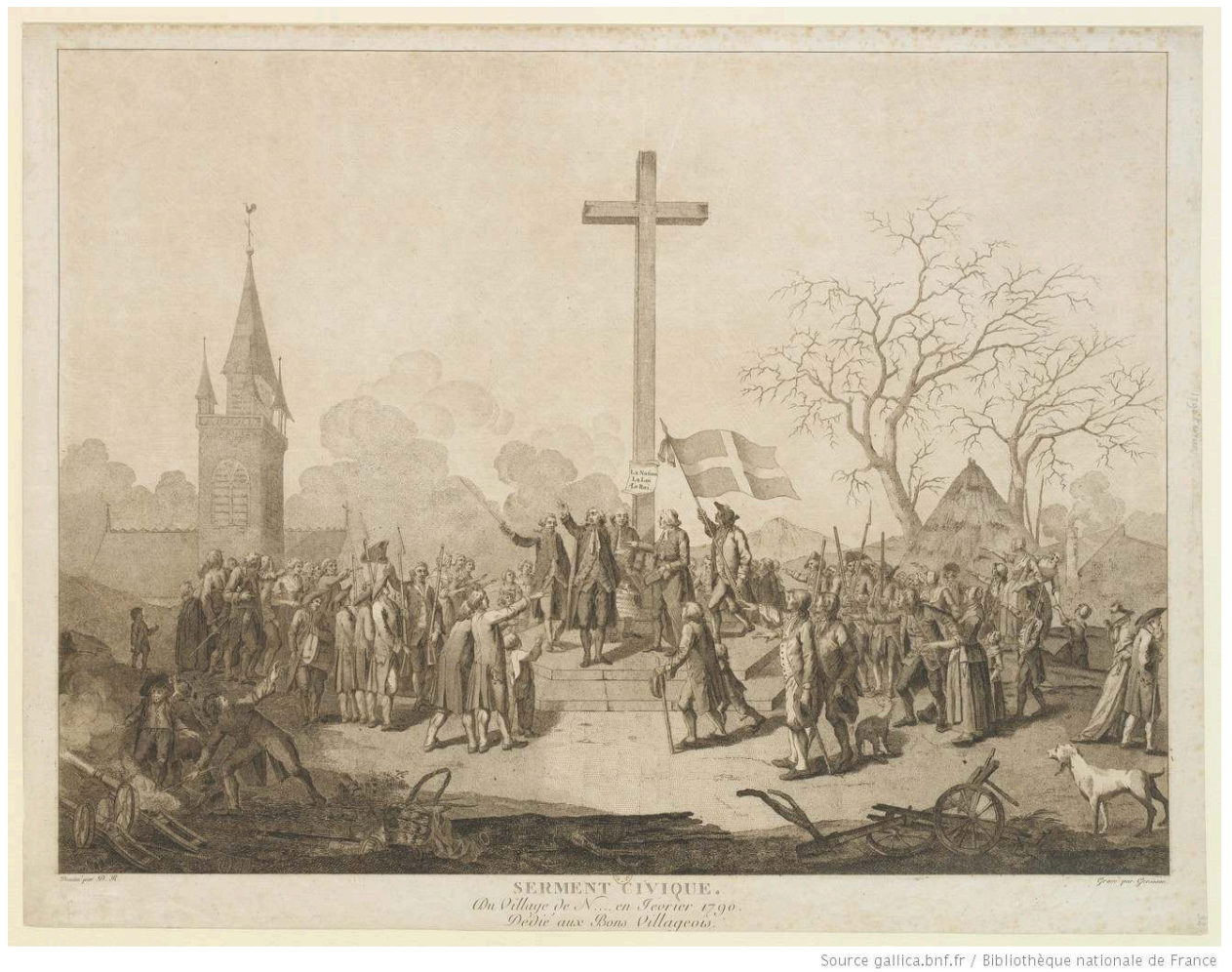

derozier (dess.), génIsson (grav.), Serment civique : Du Village de N.... en Février 1790 : Dédié aux Bons Villageois, estampe à l'eau-forte, pointillé, col. ; 41 x 55 cm, Paris, 1791, BNF. 
Fig. 9

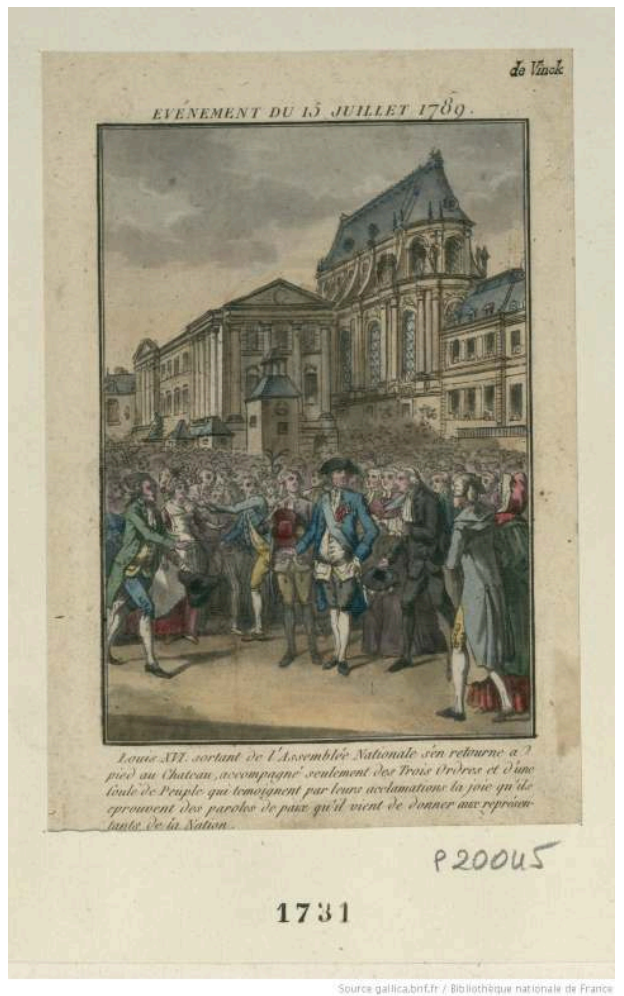

Jean François JANINET, Evénement du Quinze juillet 1789, eau-forte, manière de lavis, $13 \times 9 \mathrm{~cm}$, Paris, $1789, \mathrm{BNF}$.

Parce qu'elles se trouvent au cœur des dispositifs spectaculaires du pouvoir, les fêtes et leurs images testent de nouvelles formes de représentation. Au moins jusqu'à l'été 1790, elles participent largement à moderniser l'image de la monarchie. D'abord célébré comme le " Restaurateur de la liberté française », Louis XVI est ainsi représenté en gloire lors de sa visite à l'Assemblée nationale (15 juillet 1789) ou, deux jours plus tard, à l'Hôtel de Ville de Paris, bains de foule décrits comme des moments de fusion des corps du roi et du peuple, réalisant l'idéal impossible et inavoué de la fête royale, dans un tout nouveau contexte. Dans son Evénement du quinze juillet 1789, Jean-François Janinet traduit ce sentiment de rupture : à peine sorti à pied de l'Assemblée, Louis XVI est entouré par une foule épaisse et enthousiaste, dont son entourage peine à contenir les ardeurs. Si le roi demeure dans la posture classique de ses portraits en pied, il se tient désormais au milieu de ses sujets (fig. 9). Cette humanisation du corps royal culmine dans les images des travaux de terrassement du Champ de Mars censés préparer la Fête du 14 juillet 1790, le monarque partageant la sueur des anonymes dans un élan de labeur commun. Sur une estampe anonyme, Louis XVI, revêtu d'une simple veste à jabot blanc, donne ainsi le premier coup de pioche, accompagné de plusieurs membres de son entourage. Le roi figure au premier plan, mais l'image rompt avec le portrait en majesté (fig. 10). Pourtant, au même moment, d'autres images continuent à magnifier le roi. Surtout, les fêtes et leurs images imposent les nouveaux corps de la nation dans le nouvel ordre visuel commun : les édiles municipaux, les membres de la garde nationale et les députés, en sont les véritables héros. Redoublant les grandes collections de portraits politiques qui se constituent dès $1789^{57}$, les fêtes et leurs images permettent d'habituer le regard aux visages des nouveaux fondés de pouvoir et, parfois, 
de les reconnaître ${ }^{58}$. Elles exercent donc un rôle fondateur dans l'établissement du nouveau régime représentatif, fondé sur une nouvelle culture visuelle de la reconnaissance physique du charisme politique, tout en explorant les porosités entre célébrité et popularité.

Fig. 10

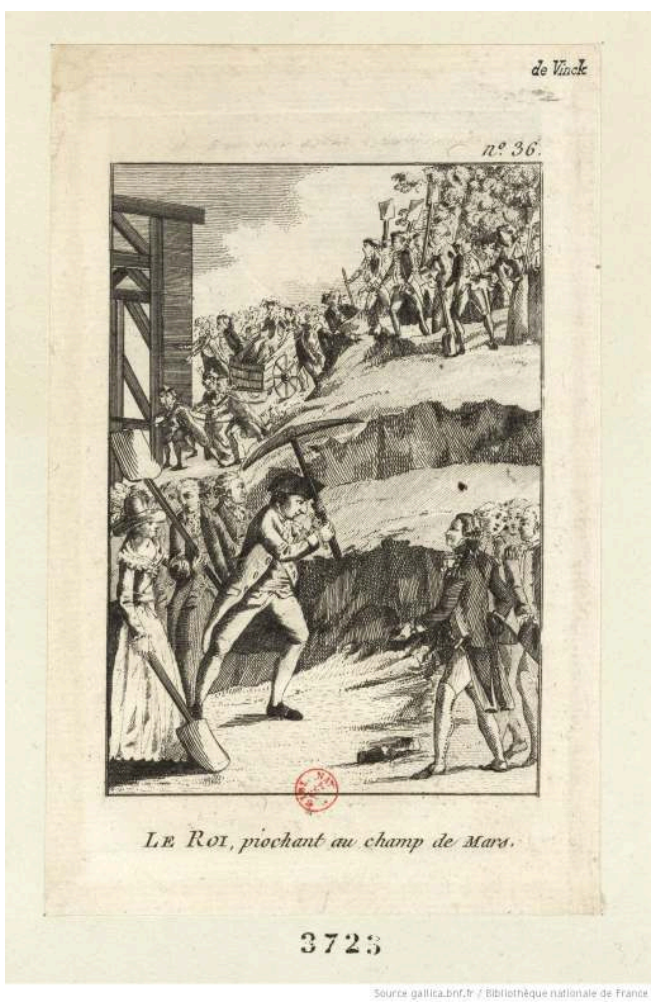

ANONYME, Le roi piochant au Champ de Mars, eau-forte ; 12,5 x 8,5 cm (tr. c.), Paris, 1790, BNF.

En effet, c'est un tout petit cercle qui est mis à l'honneur. Assez représentative du nouveau Hall of fame constitué par les images des fêtes, l'estampe intitulée La Fédération faite le 14 Juillet 1790 présente une vue classique du Champ de Mars, mais celle-ci est encadrée par des allégories patriotiques, un calendrier de l'année 1791 et surtout par des portraits de Bailly, Thouret, Camus, Lafayette, Alexandre de Lameth et l'abbé Sieyès, considérés comme les pères fondateurs de la constitution en cours de rédaction (fig. 11). Les arts décoratifs comme les éventails, les assiettes, les papiers peints ou les meubles historiés valorisent le couple Bailly et Lafayette, dont les visages, introduits dans la mondanité, sont les plus reconnus ${ }^{59}$. Les fêtes suivent les évolutions de la représentation politique: sous le Directoire, dans le cortège de la Fête des Victoires, les hommes forts du pouvoir exécutif défilent en bon ordre, vêtus de leurs habits de cérémonie, riches et sophistiqués, leurs corps raide incarnant la distance que la République tente désormais d'instaurer entre le peuple et ses élus ${ }^{60}$. Mais dès 1790 , on se presse pour pouvoir figurer sur le tableau de la nouvelle famille politique : réfugiés en France depuis 1787, les patriotes hollandais obtiennent d'assister à la fête de la Fédération en tant que "délégation étrangère " ${ }^{61}$. Comme avant, les citoyens ordinaires vont aussi à la fête pour figurer dans la grande parade urbaine. Les images viennent d'ailleurs souvent après coup pour corriger l'éventuelle mauvaise visibilité des signes d'identification politique et sociale. 
Fig. 11

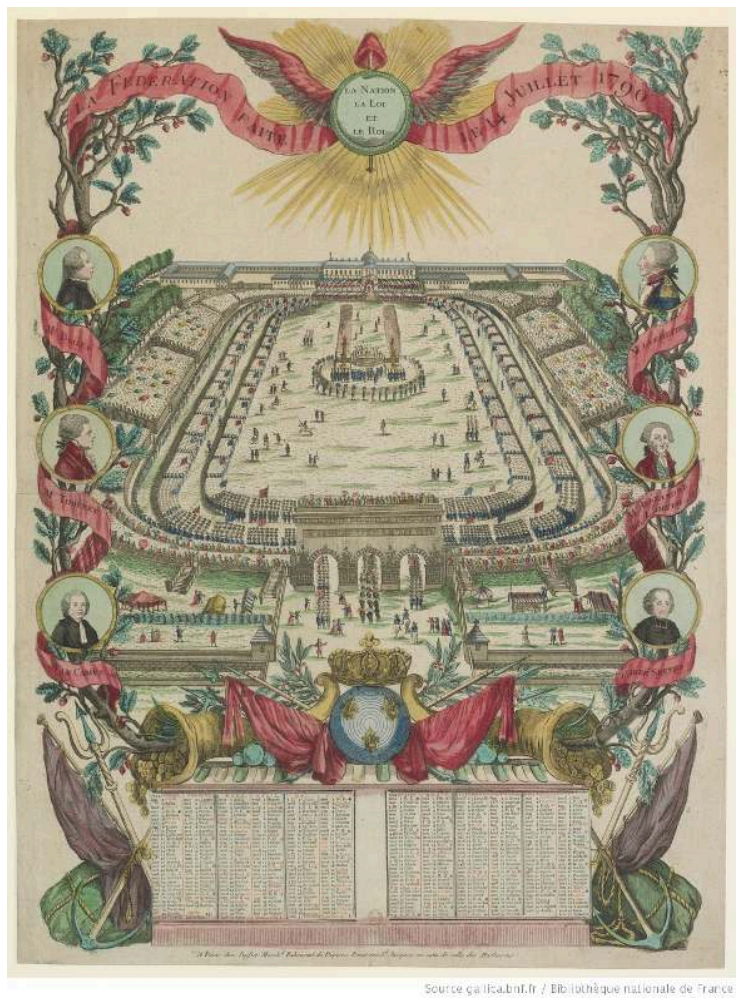

anonyme, La Fédération faite le 14 Juillet 7790 : la Nation la Loi et le Roi, eau-forte, col. ; 66,5 x 47,5 cm, Paris, chez Basset, 1789, BNF.

Mais la Révolution se méfie des fêtes. Parce que tout rassemblement populaire, de surcroît festif, est ressenti comme une menace potentielle, les fêtes sont très policées. La législation et règlements se multiplient donc pour les encadrer ou les interdire. Dès l'été 89 , les salles de spectacle sont fermées. Six mois plus tard, en janvier 1790, le carnaval est supprimé, avant que le travestissement ne soit officiellement interdit le 29 octobre 1793. Et même lorsqu'elles ont bien lieu, les fêtes de la période révolutionnaire se démarquent par leur style austère et "sévère", opposé à l'imaginaire des ostentatoires « fêtes galantes ", mais aussi à la magnificence dramatisée du baroque et du rococo de la monarchie absolue. Autant dus aux restrictions économiques et aux contraintes de l'urgence qu'au recours aux modèles antiques, la simplicité néoclassique et l'«art pauvre» des fêtes révolutionnaires doivent donc être également compris comme des manifestes esthétiques, politiques et moraux. Le " formalisme buté » dont parle Mona Ozouf vient en partie de cette esthétique de la fragilité et de l'invisible ${ }^{62}$. Dans les foules révolutionnaires, les sceptiques prennent en effet rapidement leurs distances avec les dispositifs trop spectaculaires ou sophistiqués, parfaitement conscients du piège politique qui leur est tendu. Avant le 14 juillet 1790, les feux d'artifice sont ainsi accusés de ne rechercher que l'admiration des spectateurs, ainsi réduits à la passivité. Comme Marat, le journaliste radical Loustalot n'a pas de mots assez durs pour dénoncer ce " peuple d'idolâtres qui ne voit, dans cette fête, que M. de la Fayette puis le roi, et qui ne se voit pas lui-même $»^{63}$. Pour Babeuf, la fête ne fait qu'assurer la pérennité de la culture des "apparences », liée au goût du secret et du caché $^{64}$. 
Fig. 12

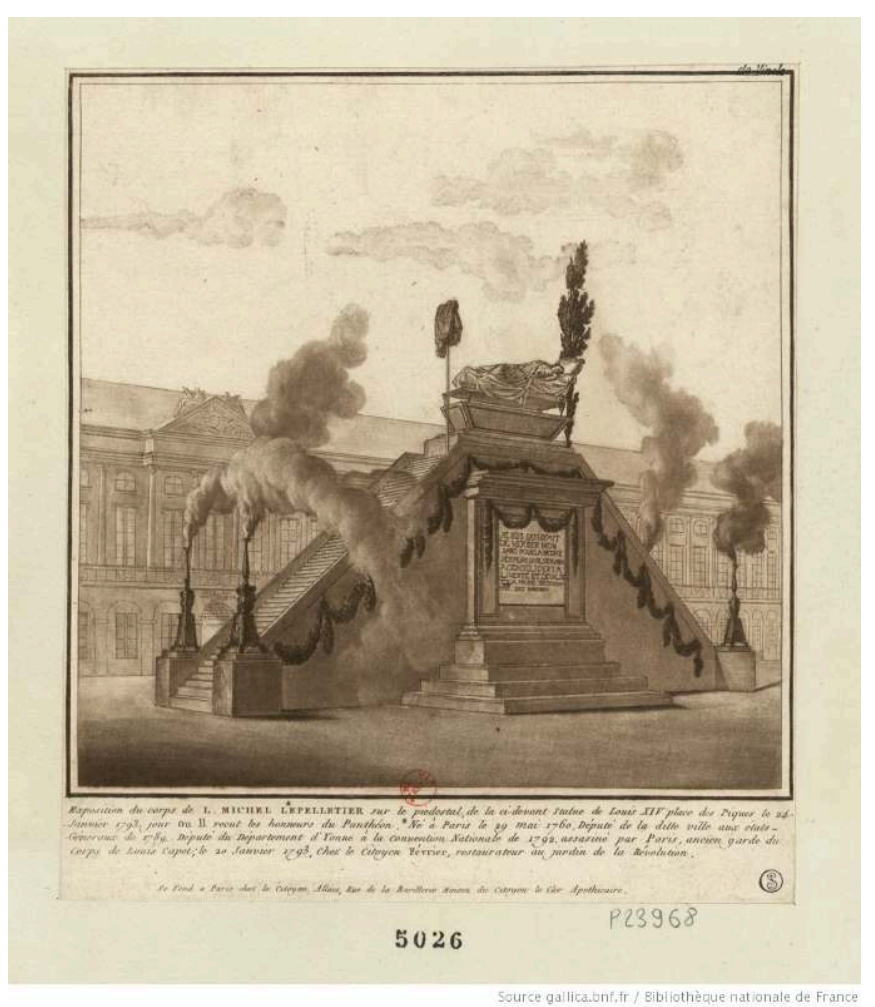

Louis-Jean altals, Exposition du corps de L. Michel Lepelletier sur le piédestal de la ci-devant statue de Louis XIV place des Piques..., eau-forte, $17 \times 17$ cm, Paris, 1793, BNF. 


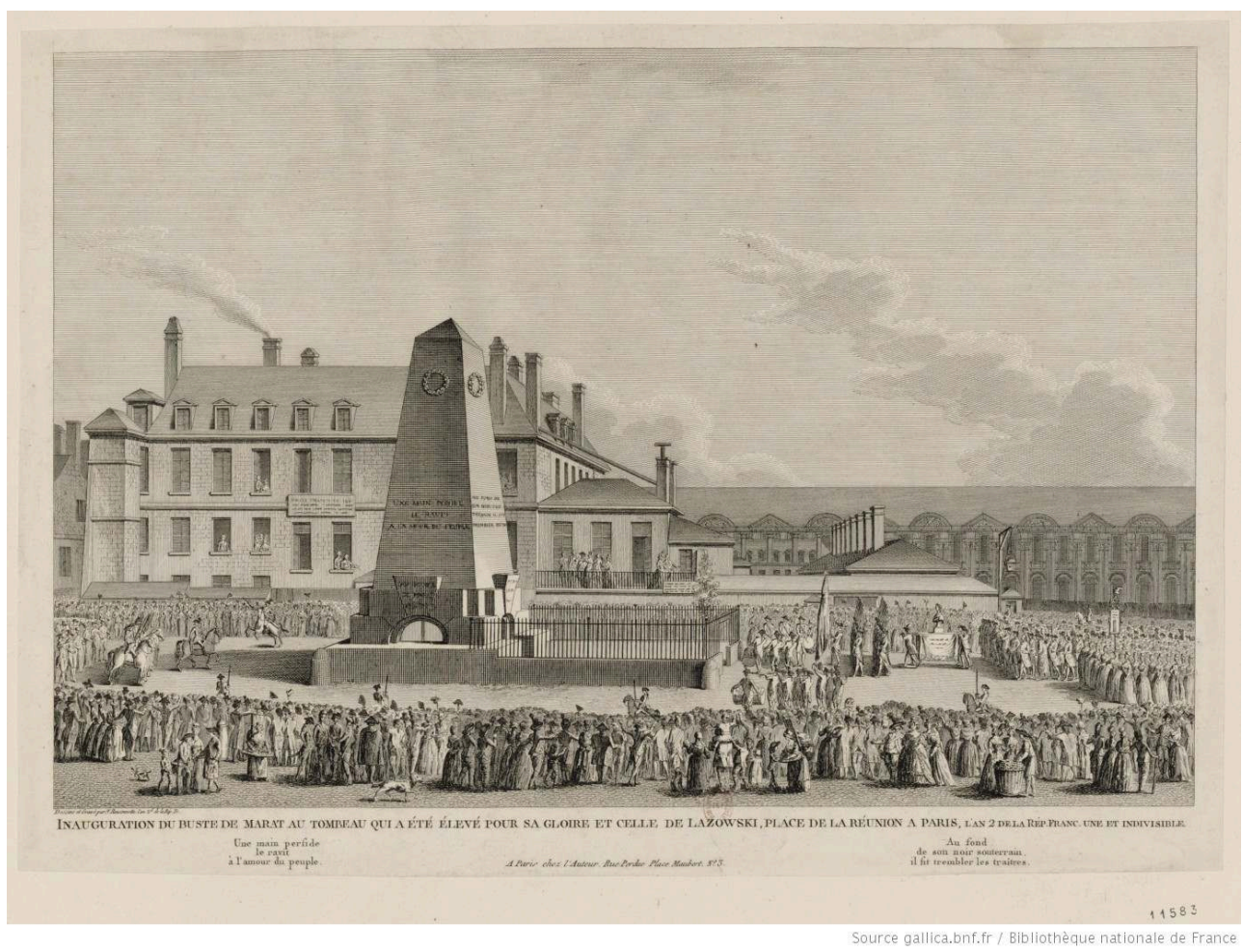

Nicolas RANSONNETTE, Inauguration du buste de Marat au tombeau qui a été élevé pour sa gloire et celle de Lazowski, place de la Réunion à Paris, eau-forte, burin ; 28,5 x 41 cm, Paris, 1793 ou 1794, BNF.

Malgré cette hésitation à séduire, les fêtes n'évacuent toutefois pas toute forme de partage des affects. Très fréquentes, les fêtes funèbres rappellent que dès l'été 1789 , une manière de braver les menaces consiste à célébrer les morts et à se rassembler autour d'eux ${ }^{65}$. Cette volonté d'émouvoir apparait particulièrement lors des grandes pompes funèbres visant à produire du consensus : « [0]n peut décrire l'appareil de cette marche triomphale ; mais il n'est pas possible de rendre les impressions diverses", avoue l'auteur anonyme de l'estampe représentant l'honneur rendu aux mânes de Voltaire ${ }^{66}$. Organisées le 16 juillet 1793, les funérailles de Marat montrent que plus la mort envahit le quotidien de la guerre civile, plus les pompes funèbres se teintent d'éléments festifs, des accessoires aux gestes en passant par le voix ${ }^{67}$. De l'automne 1793 au printemps 1794, les fêtes des martyrs prennent l'apparence de spectacles complets, mêlant les mises en scène grandioses des corps souffrants, les chants et les parfums d'encens. Exposé en janvier 1793 devant l'hôtel du ministre de la Justice sur un piédestal de la place des Piques ayant jusqu'ici accueilli la statue de Louis XVI, le cadavre de le Peletier, entouré d'un arbre de la liberté et de sa tunique ensanglantée, est magnifié par d'épaisses volutes d'encens, s'échappant des quatre coins du monument. Sur une des estampes représentant la scène, il est possible de lire que le sang du martyr servira de révélateur, permettant à ceux qui le regarderont de "reconnaître" les ennemis de la patrie (fig. 12). Sur une estampe représentant l'inauguration de la pyramide élevée en l'honneur de Marat et Lazowski sur la place de la Réunion, l'ambiance n'est pas morbide mais joyeuse: le dessinateur Nicolas Ransonnette ne manque pas de décrire les vendeurs d'eau et autres marchands ambulants qui parcourent la foule des spectateurs composée d'hommes, de femmes mais aussi d'enfants (fig. 13). Tiraillés entre la gravité des cérémonies funèbres et 
l'enthousiasme des fêtes patriotiques, ces spectacles de la mort politique traduisent bien l'hybridité des registres esthétiques dans lesquels les contemporains cherchent à panser les blessures de la guerre civile et à façonner des communautés sensibles.

Fig. 14

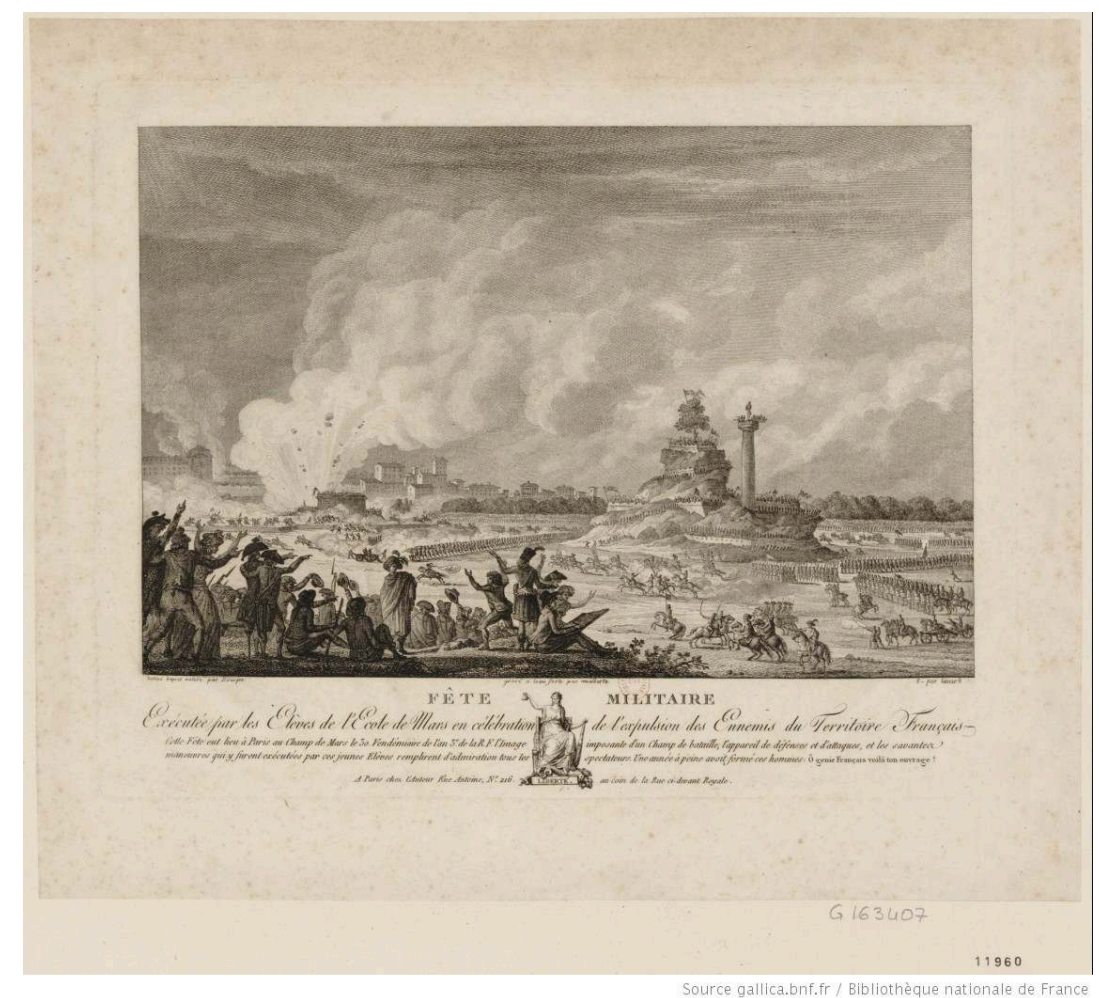

Ferdinand воuruot (dess.), Jean-Baptiste lí́nARd (grav.) et Georges malbeste (grav.), Fête militaire, eauforte, $23 \times 29,5 \mathrm{~cm}$, Paris, chez l'auteur, 1794, BNF.

Les fêtes de la Révolution se signalent par une autre singularité : elles présentent un visage de plus en plus militaire, surtout après 1797 . Qu'est le 14 juillet 1790 , la fête la plus représentée de toute la Révolution, sinon un immense défilé de soldats? Qu'ont fait les spectateurs, à part regarder d'un œil distrait et incertain les bannières des fédérés ? Organisée le 21 octobre 1794 (30 vendémiaire an III), la fête exécutée par les élèves de l'Ecole de Mars pour fêter la fin - provisoire - de l'invasion du territoire, est une véritable démonstration de force militaire: les estampes traduisent le caractère spectaculaire des explosions et des simulations de guerre. Sur une de ces images, les vastes manœuvres, déployant l'énergie virile des jeunes soldats cavalant au milieu de gigantesques nuages de fumée, mimant le combat sous de dangereuses projections d'explosifs, « remplirent d'admiration tous les spectateurs » (fig. 14). Sous le Directoire, la militarisation des fêtes se renforce et revêt un tout autre sens : ce n'est plus la prise d'armes citoyenne qui est valorisée : adhérer à la République, c'est désormais rendre hommage à l'ordre policier et militaire, c'est obéir aux gradés, en particulier aux généraux, assimilés à des "Grands Hommes", comme le montre la cérémonie organisée en l'honneur du général Hoche en septembre 1797 ou le transfert des cendres de Turenne aux Invalides trois ans plus tard, dans des mises en scènes bien plus ordonnées $^{68}$. La mise en place du régime libéral est aussi un retour à l'ordre visuel néoclassique, omniprésent sur les images de la fête pour la fondation de la République 
(22 septembre 1796) : illustrateur des Fastes du peuple français (1796), L. F. Barreau représente les Directeurs qui, tels des proconsuls, s'apprêtent à couvrir de lauriers quelques blessés de guerre. Reconnaissables à ses longues colonnes, l'hôtel des Invalides est rempli d'une foule nombreuse (fig. 15) ${ }^{69}$.

Fig. 15

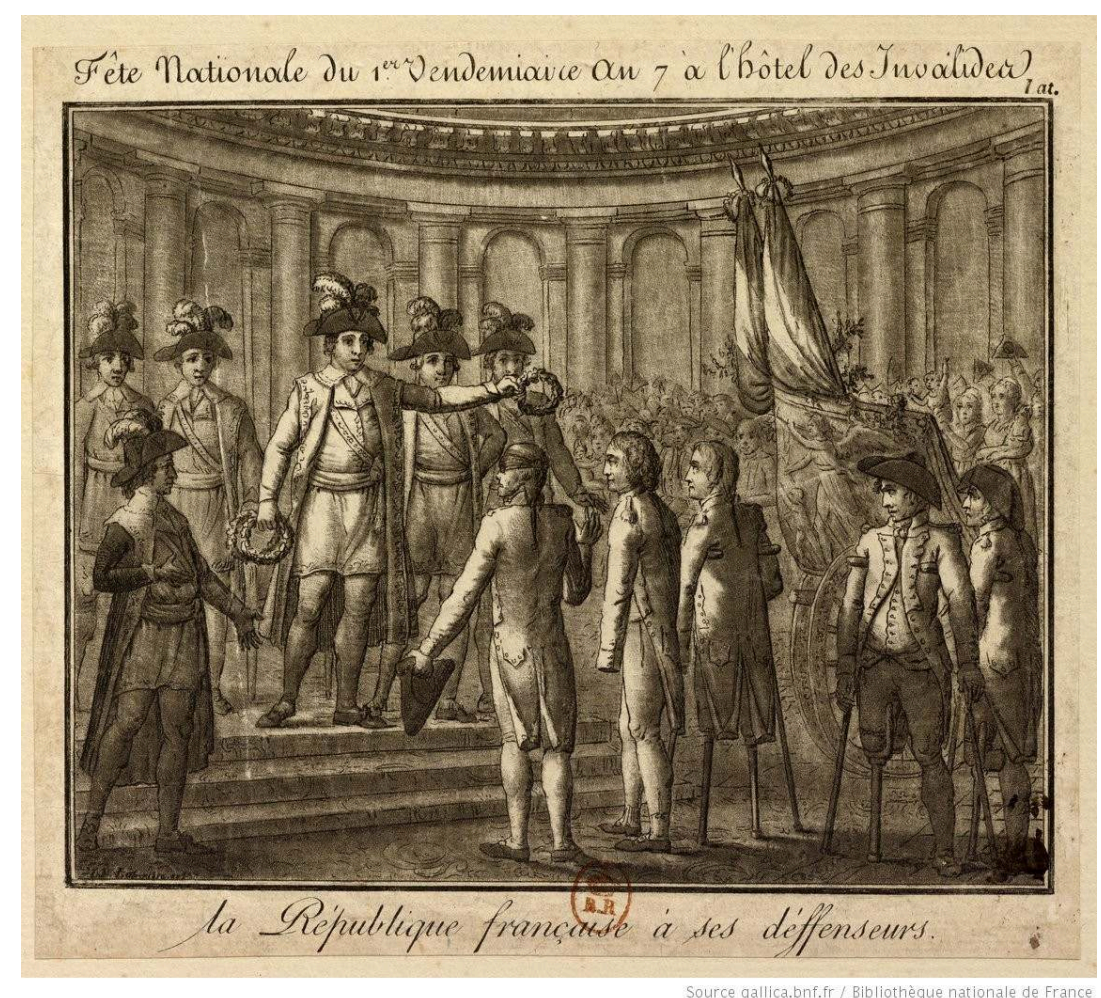

L. F. LABrousse, Fête nationale du 7.er vendemiaire an 7 à l'Hotel des Invalides : la République française à ses déffenseurs [sic], eau-forte, outils ; 12 × 15,5 cm, Paris, 1798

Dernière étrangeté, par rapport aux clichés les plus courants : les fêtes de la Révolution sont aussi profondément religieuses. À Paris comme ailleurs, les monuments des fêtes sont, avant les obélisques et arcs de triomphe, les "autels de la patrie», meubles principaux du culte civique à partir de $1790^{70}$. À Paris, l'autel de la patrie occupe souvent le centre des images des fêtes ${ }^{71}$. Recyclées en Temples de l'héroïsme (comme le Panthéon), en Temples de la Raison après l'automne 1793, abritant la théophilanthropie en 1797, les églises parisiennes polarisent une part importante des rituels collectifs. Dans l'univers des gestes, les prestations de serment et les processions participent de ce «transfert de sacralité » dont parle Mona Ozouf, venant des rituels catholiques, même si les gestes et le contexte dans lesquels ils sont effectués les font parfois changer de signification $^{72}$. Dans la Procession de la Déesse Raison d'Eugène Béricourt, les jeunes filles des meilleures familles jacobines rappellent à la fois les religieuses processionnaires de l'Ancien régime et les vestales de l'Antiquité : encadrées par des gardes nationaux, vêtues de blanc, elles portent la statue de la déesse, mais aussi une pyramide, un petit monument militaire, ainsi qu'une bannière représentant une victoire militaire. Transformées en objets d'admiration et de vertu, elles portent, dans ce mélange de traditions plus ou moins inventées, l'image de la nouvelle religion civique, saturée de codes sexués (fig. 16). 
Fig. 16

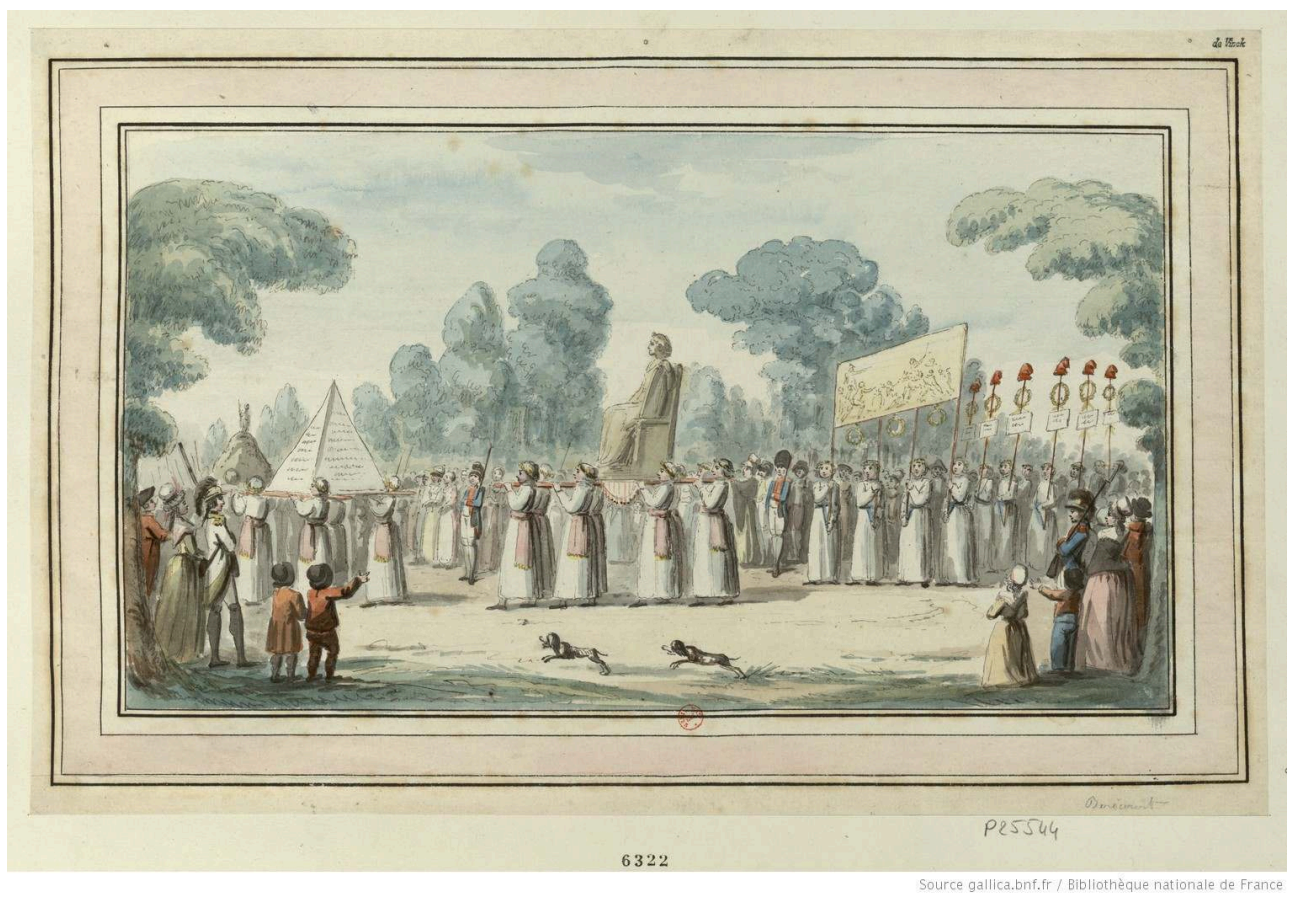

Eugène béricourt, Procession de la déesse Raison, aquarelle, coul. ; 19,5 × 35,5 cm, Paris, 1793, BNF.

Contrairement aux idées reçues, les fêtes parisiennes de la Révolution ne recourent donc à l'irrévérence ou même au rire et à la joie qu'avec prudence et parcimonie. La fameuse "gaîté française ", associée au "caractère national » et qui, jadis, appuyait la promotion de l'« esprit français» des élites éclairées, s'avère désormais encombrante : c'est la joie populaire, issue des émotions «naturelles » qui doit désormais s'exprimer, mais celle-ci porte évidemment son lot de dangers ${ }^{73}$. Malgré cette profonde réticence de la Révolution à l'égard des formes joyeuses, l'imagerie contre-révolutionnaire, appuyée par certaines représentations patriotes idéalisées, réussit le tour de force consistant à associer la fête révolutionnaire au rire voire au sarcasme ${ }^{74}$. Dans le Repas fraternel en l'honneur de la Liberté du peintre conservateur Eugène Béricourt (1794), le banquet donné par les sans-culottes laisse place aux beuveries et aux libations censées prouver le manque de civilité du peuple (fig. 17). Ainsi, plus on la cherche, plus la « fête révolutionnaire » s'avère plus proche qu'il n'y paraît des traditions antérieures. 


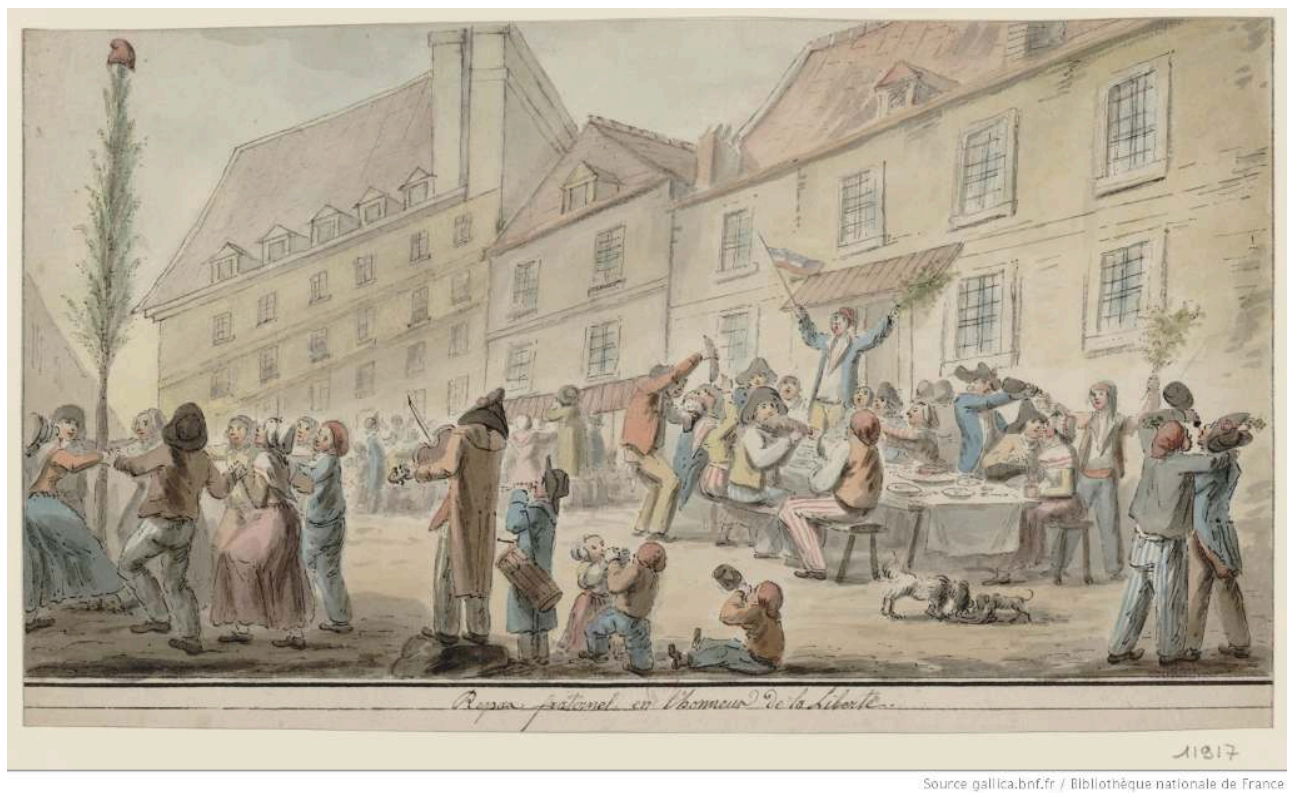

Eugène béRIcourt, Repas fraternel en l'honneur de la liberté, plume, lavis, aquarelle, coul. ; 20 × $38 \mathrm{~cm}$, Paris, 1794, BNF.

\section{Faire spectacle de la Révolution : un enjeu politique}

On sait peu de choses sur les manières dont ils étaient utilisés. Mais en 1790, il était possible d'acheter des éventails peints en l'honneur de la Fête de la Fédération. En dépliant les dix-huit brins, il était possible de progressivement dérouler le panorama du Cirque national et de lire les explications entourant l'image ${ }^{75}$. Ainsi, ni les fêtes ni leurs images ne renvoient jamais tout-à-fait aux «formes accoutumées ", comme il était d'usage de parler des grandes cérémonies publiques sous la monarchie absolue. La nouveauté tient d'abord dans la surprenante spectacularisation du pouvoir : s'il semble superflu d'organiser des fêtes en période de grave crise politique, celles-ci voient pourtant leur nombre et leur importance augmenter, à tel point que les images de fêtes en viennent parfois à résumer la Révolution elle-même. La nouveauté vient aussi des expériences collectives qu'elles sont censées provoquer, fondées sur le «partage du sensible $»^{76}$. D'où vient l'importance des fêtes et leur imagerie ? Probablement du rôle croissant des formes symboliques et des rituels dans la régulation des tensions collectives, au moment où se disloque l'ancien régime des représentations. La question du degré de sincérité des populations est donc, comme le signale Nicolas Mariot, une mauvaise question: les fêtes sont des institutions sociales évidemment normatives, mais elles recèlent aussi une part d'ouverture et d'innovation, de même qu'elles reposent sur un système de croyances complexe. Il est de ce fait souhaitable de voir les images des fêtes autrement que comme d'authentiques instantanés ou, dans un excès contraire, comme des simulacres ne disant rien de vrai du réel ${ }^{77}$. Les fêtes et leurs images font partie des nouveaux arts politiques informels, reposant sur la mobilisation du sensible et des affects. 


\section{Politiques du sublime}

grande énergie collective : « rappelez-tous la fédération du 14 juillet 1790, dit Merlin de Douai aux députés à l'automne 1794, les travaux qui l'ont précédée dans le Champ-deMars, leur activité non interrompue pendant plusieurs jours, la diversité de leurs mouvements, celles des machines qui y étaient employées, les flammes tricolores, les feuillages; le mélange de tous les âges, de tous les sexes, de toutes les professions travaillait avec un zèle égal, racontant, riant, chantant; des gens arrêtés entre ceux qui couraient, d'autres qui buvaient, mangeaient, se reposaient et dormaient entre ceux qui travaillaient.... $»^{78}$.

L'instabilité des formes, les machines et matériaux éphémères des décors et des chars, l'usage du dessin, de l'aquarelle et du pastel, la prédominance de l'estampe, les mille et une techniques anti-monumentales utilisées pour figurer rompent avec les lourds instruments et codes visuels empesés de la société d'ordre. Plus fragiles et volatiles, les techniques et les formes disent quelque chose des nouvelles incertitudes du temps historique. L'énergie et la fluidité des fêtes accompagnent l'incertitude et le changement politiques. Tableaux vivants d'une société en mouvement, les défilés se révèlent plus mobiles, plus légers et moins cérémonieux qu'auparavant. Réalisées par des dessinateurs et graveurs souvent peu réputés et volontiers maladroits au regard des normes académiques, les images des fêtes rompent en outre avec les formes reconnaissables, stables et maîtrisées de l'Ancien Régime. Alors qu'en 1770, les images officielles du mariage du Dauphin étaient confiées à la virtuosité du dessinateur officiel des Menus Plaisirs du roi Moreau Le Jeune, vingt ans plus tard, les estampes célébrant la Fête de la Fédération (1790) sont le fait de multiples artistes autoproclamés et plus ou moins adroits, profitant de la Révolution pour briser le marché de l'art et donnant, par la même occasion, une vision alternative des événements. Cette instabilité de papier, qui confine parfois à la laideur, traduit la recherche de l'anti-monumentalité : les fêtes de la Révolution mettent en œuvre une " politique du provisoire " (Richard Taws), liée au sentiment de volatilité qui accompagne la crise révolutionnaire, mais qui traduit aussi la nouvelle morale politique dans laquelle les systèmes de représentation perdent leur autorité et deviennent révisables. Les nombreuses lumières des lampions et bougies, les pétards, les fleurs, les décors de carton expriment la nouvelle fragilité des existences et le caractère temporaire des choses et même du pouvoir, dont le mandat des députés, limité à deux ans seulement, est la traduction la plus visible. Transmettre l'énergie du feu et de la lumière sur le papier: en 1790, une modeste estampe à l'aquatinte montre la foule dansant devant l'Hôtel de Ville devant les mots du serment de la Fédération, reproduits en lettres de feu sur la façade du bâtiment ${ }^{79}$. L'arbre de la liberté reste quant à lui le symbole le plus courant de la matérialité périssable et éphémère qui constitue les fêtes révolutionnaires: présent sur beaucoup d'images, volontiers chargé de rubans et d'emblèmes divers, il inspire dès 1789 une estampe intitulée Bon mai ou la vraie fête des bonnes gens ${ }^{80}$. 
Fig. 18

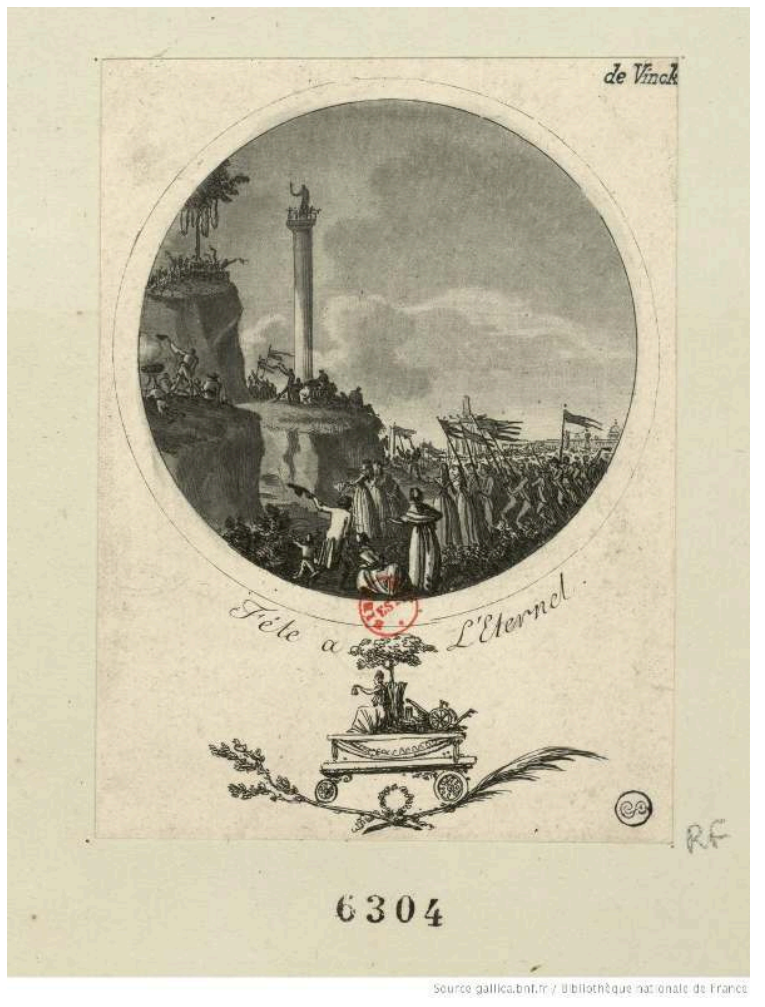

ANonyme, Fête à l'Éternel, eau-forte, outils, 14,5 x 11 cm, chez Boulay, Paris, 1794, BNF.

Fig. 19

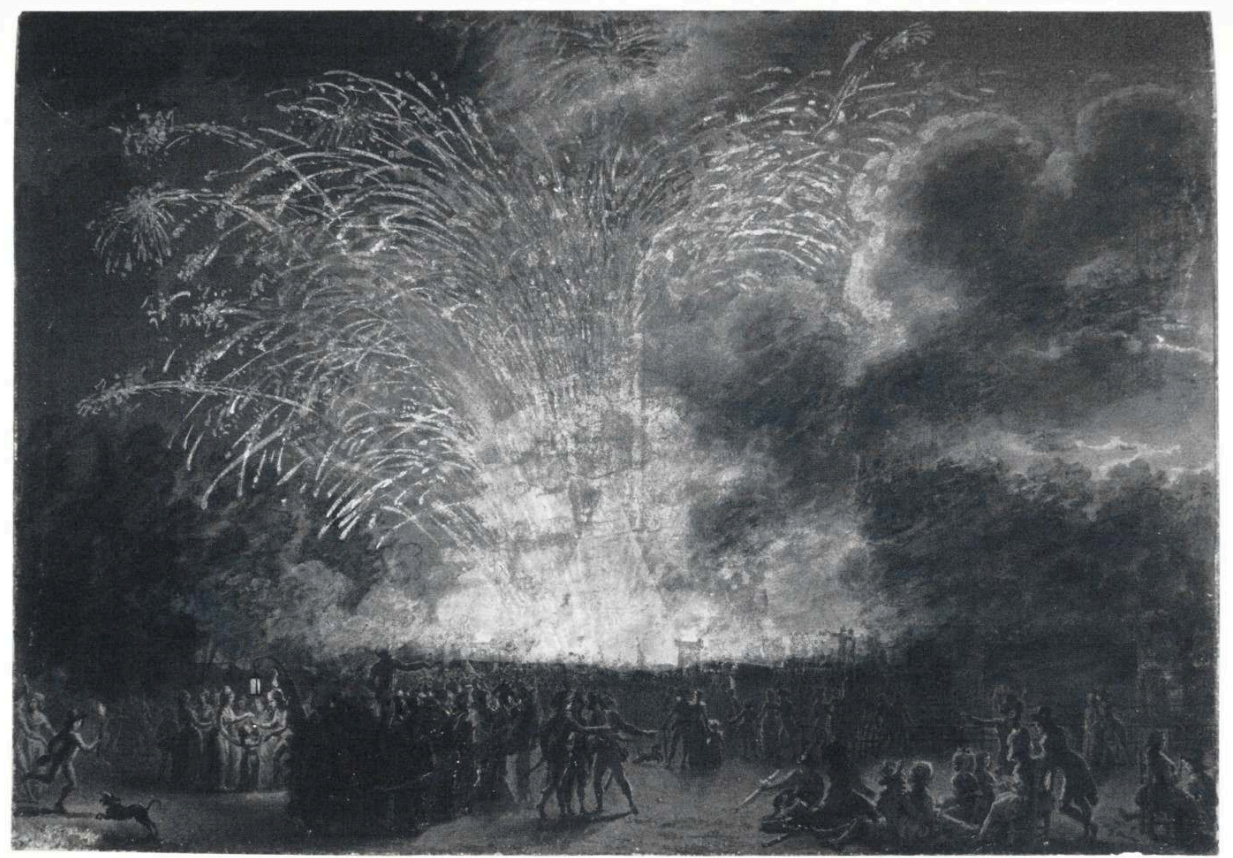

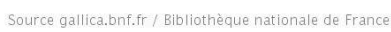

Paul grégolre, Feu d'artifice tiré à Paris en 1792, dessin lavé à l'encre de Chine et gouache blanche, 42 x 59,8 cm, Paris, 1792, BNF. 
Les gestes figurant sur beaucoup d'images expriment un sentiment de libération des énergies, des corps et des mouvements. C'est le cas dans les nombreux défilés qui peuplent le corpus des images : héros d'un jour spontanément promenés dans la rue, marcheurs en colère ou baignés d'enthousiasme, les corps en mouvement traduisent un sentiment de libération émotive. L'ambiance est parfois dramatique, la force des éléments venant souligner l'importance de l'événement : dans la Fête à l'Éternel (1794), le vent fait flotter les bannières portées par les spectateurs et donne un souffle particulier à la célébration (fig. 18). Les bras levés de ceux qui prêtent serment ou qui brandissent leurs chapeaux, les bouches ouvertes des chansons, des cris et slogans proférés à l'unisson, les corps engagés dans les danses et les jeux populaires, les explosions des feux d'artifice qui crèvent le ciel nocturne, les flammes vacillantes des bougies allumées en signe de réjouissance : une multitude de gestes et de signes exhibés lors des fêtes tentent de trouver des formes correspondant à ce que le soulèvement et l'émancipation provoquent dans les corps et les esprits. La fête et son image se pensent comme des spectacles totaux, conjuguant, par le biais de la représentation visuelle, le son et l'image ${ }^{81}$. Lorsqu'il représente le Feu d'artifice tiré à Paris en 1792, Paul Grégoire associe l'explosion spectaculaire des jets lumineux à l'énergie collective qui mobilise la foule des spectateurs, comme électrisés par l'expérience partagée (fig. 19). Les réjouissances accompagnant la "libération des barrières", le $1^{\mathrm{er}}$ mai 1791 , sont l'exemple-type de cette esthétique de la libération. Jean Duplessis Bertaux dessine les convois de marchandises passant par la barrière de la Conférence comme sous un Arc de Triomphe, les marchandes et marchands étant jugés sur les tonneaux ou les animaux de traits en portant des branches d'arbres en signe de joie, en buvant du vin et en célébrant l'événement par des gestes d'enthousiasme ${ }^{82}$. Métaphore des vertus supposées du « libre commerce », les mouvements et la mobilité des fêtes des périodes « capacitaires » de la Révolution (1789-92 et après 1794) montrent que l'esthétique se met au service d'une vision libérale du monde, comme on le voit dans la Vue de la prise d'eau du canal du Caire, et de la fête annuelle célébrant l'ouverture de la digue, probablement effectuée vers 1799 (fig. 20). Ces déploiements d'énergie peuvent aussi servir à intimider. Ainsi, une image intitulée Les Aristocrates désespérés d'apercevoir la Fête du 14 Juillet au Champ de Mars montre les Contre-Révolutionnaires comme frappés de convulsions à la simple vue de la joie des patriotes (fig. 21). Le spectacle de la fête exerce alors une force magique : il terrorise et terrasse les ennemis de la nation. 


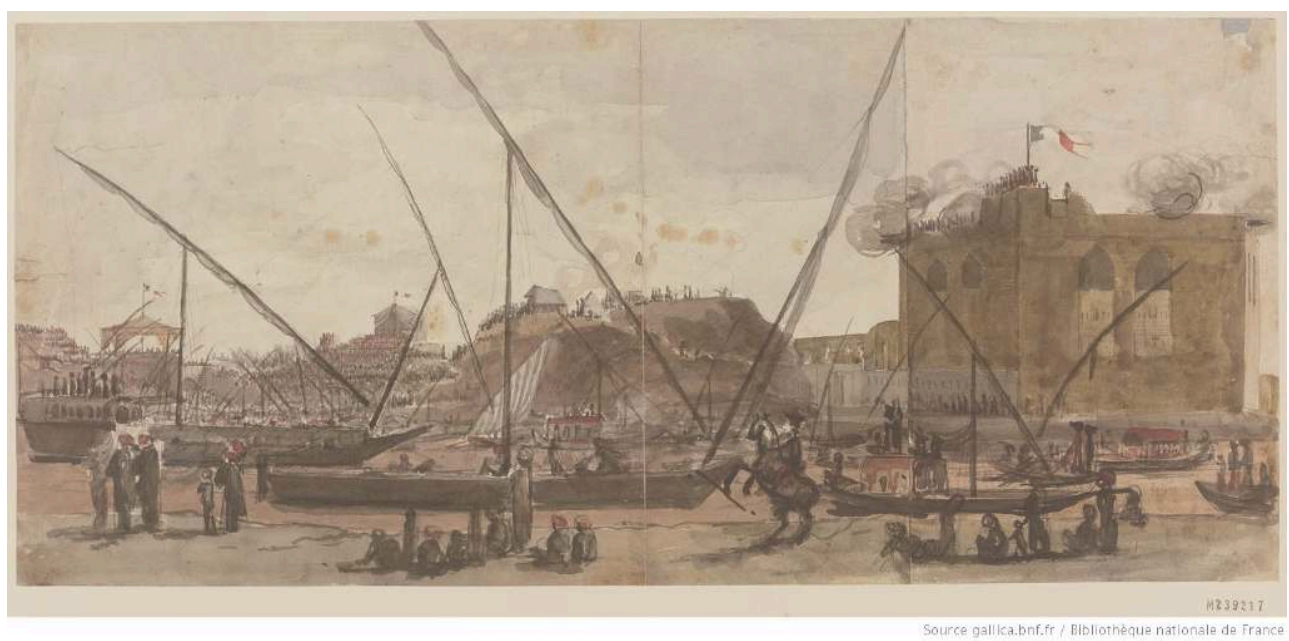

André DUtertre, Vue de la prise d'eau du canal du Caire, et de la fête annuelle célébrant l'ouverture de la digue, aquarelle et crayon, 25,1 x 56,1 cm, Paris, 1799, BNF.

Explorés par ces déplacements festifs, de nouveaux paysages politiques se dessinent sur les images des fêtes, faisant surgir une ville utopique ou éphémère ${ }^{83}$ : le choix de certains lieux, comme la Bastille, vieille prison d'Etat, ou le Champ de Mars, ancien terrain d'exercices militaires, ou encore le jardin des Tuileries, près de l'ancien palais royal, font de la fête une occupation symbolique voire une conquête de territoires interdits que les images viennent, après coup, attester et légitimer. " Ici l'on danse »: les estampes des illuminations champêtres et des réjouissances publiques sur les ruines de la Bastille au cœur de l'été 1790 traduisent combien la joie se nourrit de la satisfaction de la «prise ». Mais les images des fêtes permettent aussi d'explorer les confins urbains. Peu à peu, les cortèges s'éloignent du centre des cités anciennes, passant par les faubourgs, approchant des barrières, s'arrêtant dans les espaces vastes et dégagés, rompant avec la "bonne ville» du passées. Changeant de point de vue, les images rivalisent avec les vues classiques des villes de l'Ancien Régime, issues de la tradition des tableaux de siège, de la veduta italienne ou des vues d'optique. C'est en effet désormais l'espace mobile et ouvert, celui des promenades et des faubourgs, qui constitue le nouveau centre de gravité de la cité patriote. Les fêtes ne servent plus à promouvoir les lieux de la monumentalité des centres urbains, attachés aux autorités et aux élites sociales. C'est du moins le message que leurs images tentent d'imposer, effaçant une réalité plus banale: la continuité de bien des lieux anciens des fêtes parisiennes comme l'Hôtel de Ville, le Palais Royal ou les boulevards, mais aussi le resserrement, sous le Directoire, des lieux de la fête autour du Champ de Mars, du Champ de la Réunion ou des Champs Élysées : les cortèges continuent alors de rythmer et de célébrer l'urbanisme monumental parisien ${ }^{85}$. 


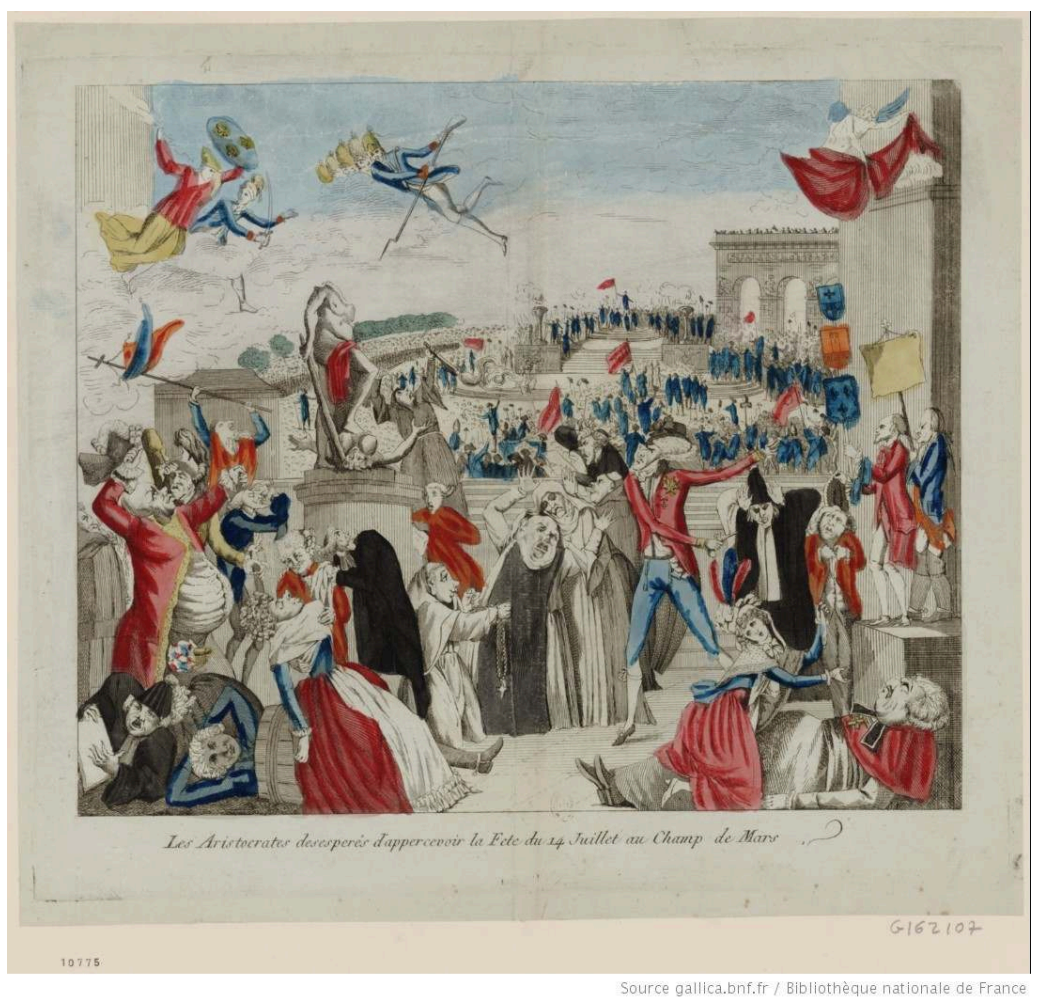

ANONYME, Les Aristocrates désespérés d'apercevoir la fête du 14 juillet au Champ de Mars, eau-forte, col. ; $33 \times 38 \mathrm{~cm}$, Paris, 1790, BNF.

« La divinité de la République est la liberté, son temple est l'Univers; c'est sous la voûte céleste que doit se célébrer son culte. Nos places publiques seront désormais nos salles de concert », affirme Sarrette en $1793^{86}$. Sur la plupart des images des fêtes, le ciel n'est pas un décor mais forme un écran sensible, sur lequel il serait possible de deviner les signes de l'avenir. La plupart du temps bleus et dégagés, les ciels des estampes traduisent la bienveillance de l'Être Suprême et laissent aussi entrevoir le soleil, gage de régénération ${ }^{87}$. Plus rarement sombres et nuageux, ils suggèrent au contraire l'échec de la Révolution ou annoncent la fin du monde. Organisés comme des spectacles, les lancers d'aérostats expriment de la même manière l'importance du soulèvement et de l'élévation céleste dans l'esthétique de la Révolution, accompagnant le mouvement des obélisques et des colonnes. Mais ils sont aussi vécus comme de terribles et incertaines tentatives des hommes à défier la nature, symbolisant le défi prométhéen de la Révolution : blessant plusieurs personnes, l'explosion du ballon lancé le 18 juillet au Champ de Mars est décrite par plusieurs estampes comme un événement malheureux, rappelant la catastrophe du 30 mai 1770, lorsque les ratés du feu d'artifice du mariage du Dauphin avaient provoqué plus d'une centaine de victimes ${ }^{88}$. 


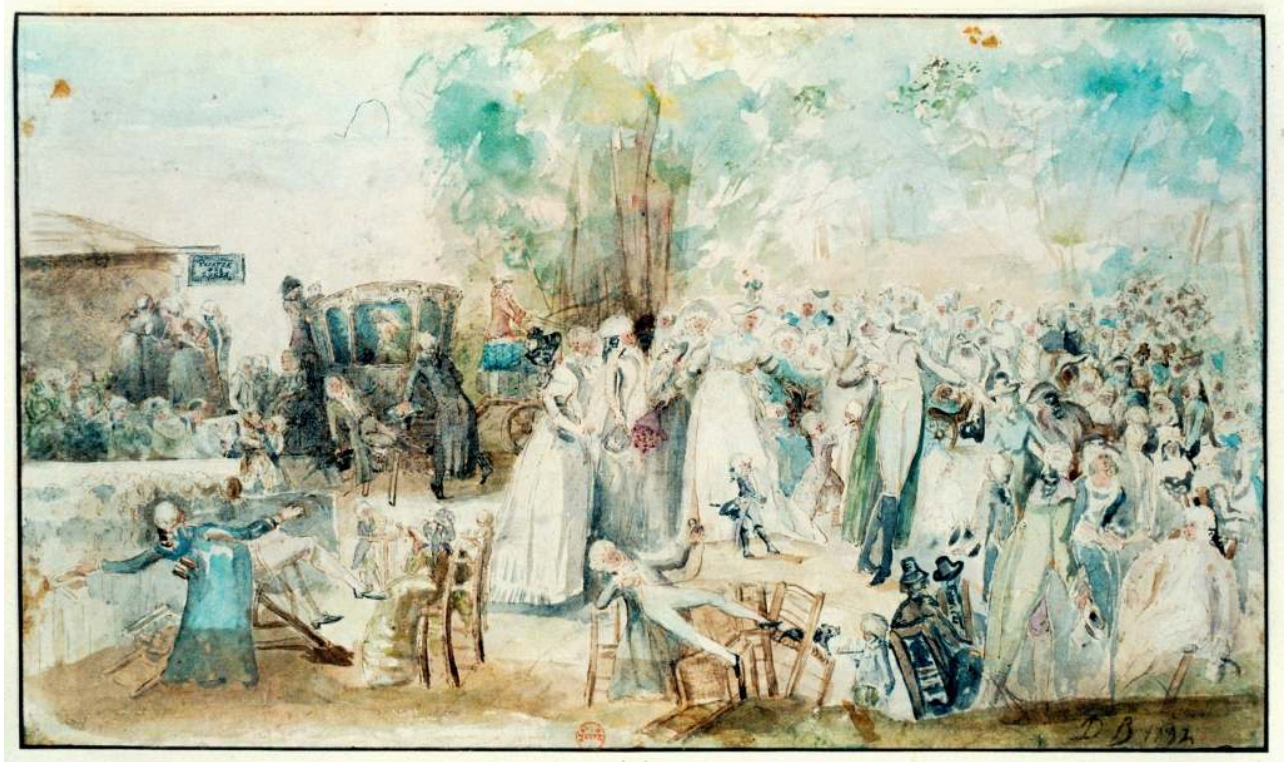

Philibert Louis deBucourt, La fête des Loges dans la forêt Saint-Germain, Dessin à la plume et encre brune, aquarelle, $23,5 \times 36,5 \mathrm{~cm}$, Paris, 1792, BNF.

31 Ces paysages modelés par les fêtes de la Révolution sont évidemment très politiques ${ }^{89}$. En 1792, Philibert-Louis Debucourt livre une aquarelle de La Fête des loges dans la forêt de Saint-Germain, montrant l'archétype de la "bonne fête " bourgeoise, située au cœur d'un sous-bois, libérée des artifices de la ville (fig. 22). Les grandes plaines dégagées et aplanies aux marges des villes, les montagnes artificielles ou les rangées d'arbres replantés par dizaines pour l'occasion, dont les essences (chênes et peupliers) sont méticuleusement sélectionnées pour leur association à l'idée de liberté, traduisent quant à elles le discours du « retour à la nature » et le rejet du «luxe » artificiel de la société de cour. Les fêtes prennent souvent l'aspect de spectacles verts. Certaines images se concentrent sur les nouveaux paysages, créés pour l'occasion, comme les estampes sur les décorations élevées pour la fête de l'Être Suprême, insistant sur les rochers, l'arbre de la liberté, au sommet de la montagne, et les buissons en friche ${ }^{90}$. La focalisation des dessinateurs sur le motif de la montagne, dont le volume et la hauteur sont en général plus exagérés que leurs modèles de terre ou même de bois, traduit le désir de montrer que l'énergie collective et la volonté politique peuvent domestiquer le sublime et changer l'ordre de la nature ${ }^{91}$. Se réduisant à une levée de terre en général pelée, à peine arborée ou sculptée par quelques rochers, surplombant une vaste plaine, la «montagne ", comme celle du Champ de Mars, s'impose donc comme le paysage " naturel» de la communauté nationale, suggérant le soulèvement du peuple ${ }^{92}$ voire son élévation au sommet des éléments naturels ${ }^{93}$. Par ses capacités paroxystiques, ce recours au sublime permet de rejouer la fiction d'une Révolution-Création, née du feu fondateur, redonnant rituellement naissance à la communauté civique : une estampe de Louis Jean Allais réalisée à l'occasion de la Fête de la Réunion du 10 août 1793 représente ainsi la Constitution sortant d'une Montagne au milieu de la lave, en plein orage (fig. 23). L'accumulation des parfums forts et entêtants, des couleurs vives et associées, mais aussi des musiques et des chants a capella, le bric-à-brac des symboles et des objets, la recherche du gigantisme des volumes et des espaces, traduisent une volonté d'«impressionner » et de susciter un paroxysme émotif, proche de la définition 
que donnait Burke du sublime en 1757 : « tout ce qui est propre à exciter les idées de la douleur et du danger, c'est-à-dire tout ce qui est en quelque sorte terrible, tout ce qui traite d'objets terribles, tout ce qui agit d'une manière analogue à la terreur, est une source du sublime ; ou, si l'on veut, peut susciter la plus forte émotion que l'âme soit capable de sentir ${ }^{94}$.

Fig. 23

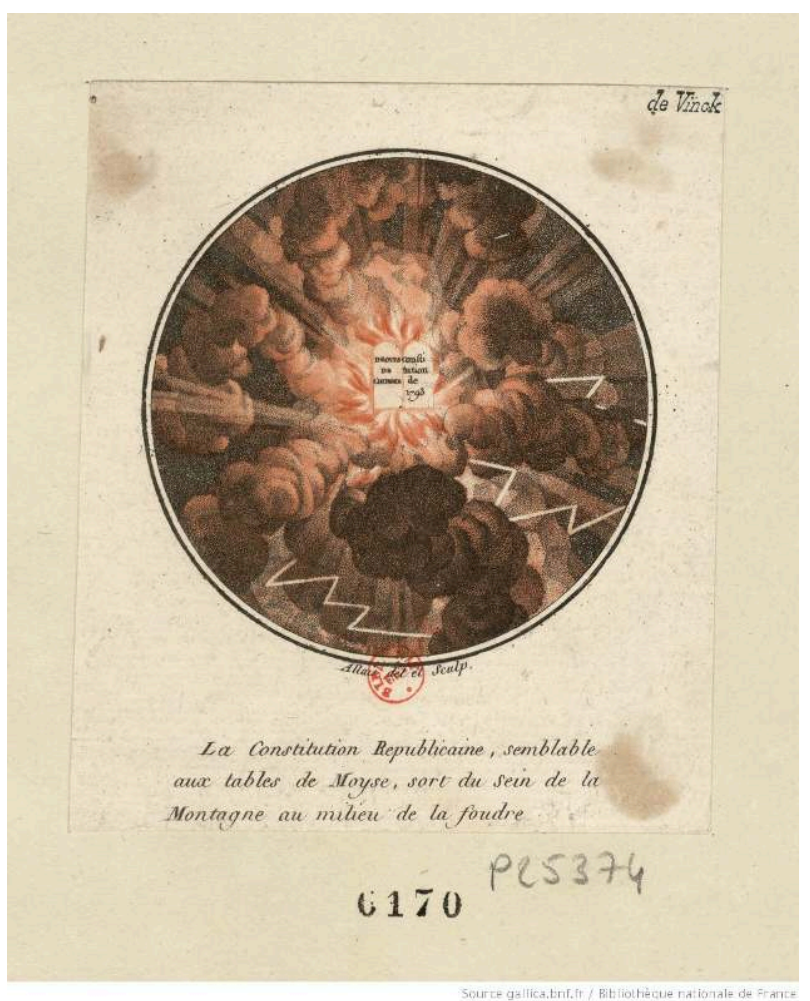

Louis Jean alcals, Constitution républicaine, semblable aux tables de Moyse, sort du sein de la Montagne au milieu de la foudre : Fete de l'unité et indivisibilité de la Republique française, célébrée le 10 août 1793 l'an 2.me de la Re.que f.aise une et indi.ble, eau-forte, pointillé, outils, coul. au repérage ; $13 \times 20 \mathrm{~cm}$, Paris, 1793, BNF.

Les architectes des fêtes le savent parfaitement. Comme le souligne Quatremère de Quincy, « la grandeur physique est une des principales causes de la valeur et de l'effet de l'architecture", car elle est capable selon lui de créer un fort sentiment d'admiration. Boullée pense également que l'efficacité pédagogique des monuments vient en partie de leur dimension: "c'est de l'effet de leurs masses que naissent les sensations " $^{95}$. Évoquant la fête du 14 juillet 1801, Boullée affirme aussi qu'un édifice public doit être « un vrai poème capable d'exciter dans le cœur des spectateurs des sentiments analogues à sa destination $»^{96}$. La force massive des volumes et des lignes néoclassiques, traduites par les monuments éphémères tels que les arcs de triomphe, les colonnes colossales ou les statues, sont ainsi choisies pour leur capacité à impressionner de manière simple, claire et vertueuse, à l'opposé des complexes torsions du baroque et du rococo, associées au luxe et à la tricherie des formes extérieures ${ }^{97}$. Produites après les fêtes, les images visent parfois à ancrer ces monuments, même éphémères, dans une mémoire de papier, comme les médaillons intitulés Monumens [sic] nationaux élevés pour la fête de la Fraternité, célébrée le 10 août 1793 : consacré à un événement précis de la fête, chacun de ces médaillons de papier, 
véritables monuments visuels, retrouve l'étymologie du mot, dérivé du latin « monere ", signifiant notamment « rappeler ", « remémorer » (fig. 24).

Fig. 24

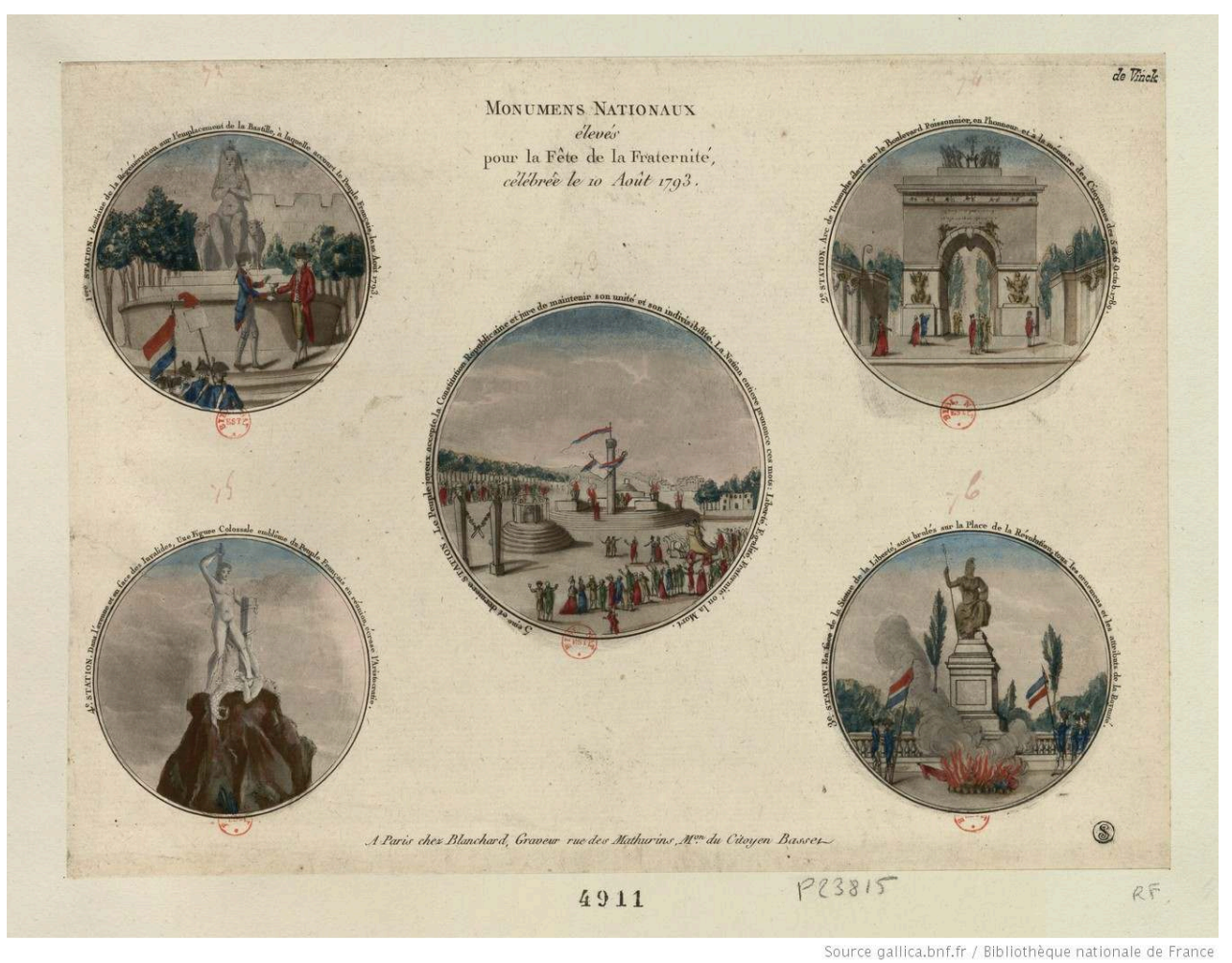

Auguste blanchard, Monuments nationaux élevés pour la Fête de la Fraternité, célébrée le 10 août 1793, eau-forte, $20 \times 27 \mathrm{~cm}$, Paris, 1793, BNF.

Dépouillés des éléments d'architecture qui, auparavant, sculptaient et solidifiaient les gerbes de feu, certains feux d'artifice expriment désormais la capacité de la Révolution à trouer la nuit, à civiliser la nature primitive et à rassembler les populations par leur énergie dynamique et lumineuse. Peu représentés, ces instants par nature difficiles à fixer, expriment pourtant la singularité de l'expérience politique que les révolutionnaires tentent de créer lors des fêtes, fondée sur le partage des émotions intenses, le subtil mélange de sublime, de sobriété, de fugacité et de monumentalité. 


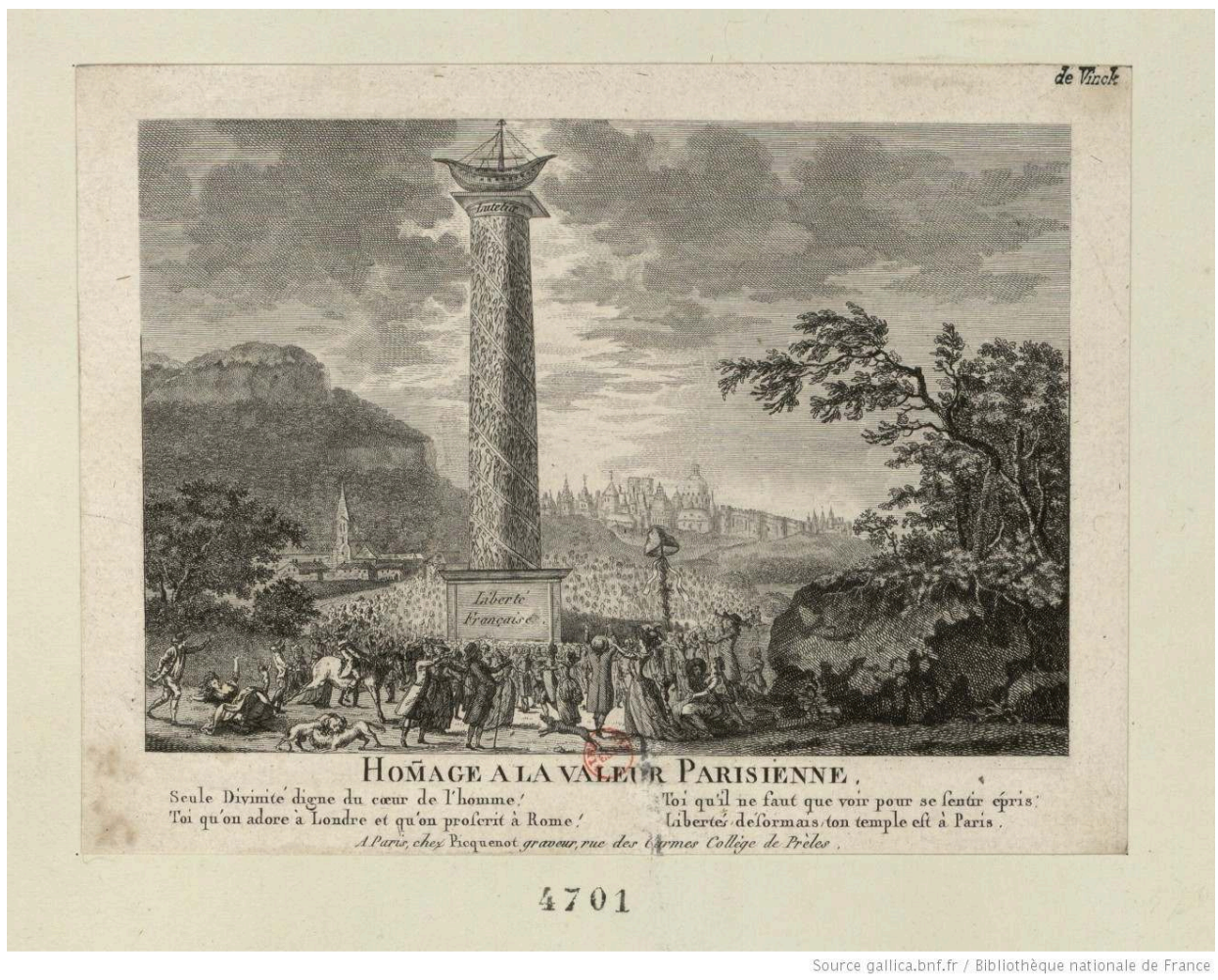

Michel PICQUENOT, Hommage à la valeur parisienne, Estampe à l'eau-forte ; 11 x 16 cm, Paris, vers 1791, BNF.

Spectaculaires, les fêtes se destinent aussi aux patriotes européens et même américains, devenant de véritables vitrines internationales de la Révolution française. Ces moments jouent logiquement un rôle dans la diplomatie informelle : depuis longtemps, les fêtes servent aussi à exprimer la sympathie entre les États, à rassurer ou, selon les contextes, à intimider les puissances étrangères. Sous la Révolution, ce rôle se renforce encore. Consciemment organisée sous le regard des Européens, la Fête de la Fédération est ainsi une véritable démonstration d'unité et de force militaire, visant à faire de Paris la capitale des Révolutions, visant aussi à exprimer la force, l'ordre et la «tranquillité » d'un moment que les chancelleries étrangères commencent à accuser de semer l'anarchie en Europe. Dans une représentation imaginaire, le graveur Michel Picquenot livre vers 1791, un Hommage à la valeur parisienne: hors de la ville, une gigantesque colonne surmontée d'un bateau et de l'inscription Lutetia est entourée d'une foule épaisse. La lettre invite les patriotes européens à visiter Paris, louée comme la ville de la Liberté : « toi qu'il ne faut que voir pour se sentir épris/Liberté désormais ton temple est à Paris » (fig. 25). En 1798, les estampes célébrant l'Entrée à Paris des œuvres d'art et des objets scientifiques pris lors des campagnes militaires visent à faire de la capitale française le centre de gravité de la civilisation européenne (fig. 26) ${ }^{98}$. Organisée sous le Directoire en mars de la même année, la Fête de la souveraineté du peuple doit, de même, en mettre plein la vue. C'est pourquoi le ministre de l'Intérieur, demande aux communes riches de ne pas se contenter d'exécuter simplement le programme, mais de rivaliser de décorations fastueuses et spectaculaires afin de « célébrer la puissance de la Grande Nation », souhaitant que le peuple puisse profiter d'un beau spectacle, ajoutant «toute l'Europe nous regarde ! $»^{99}$. 


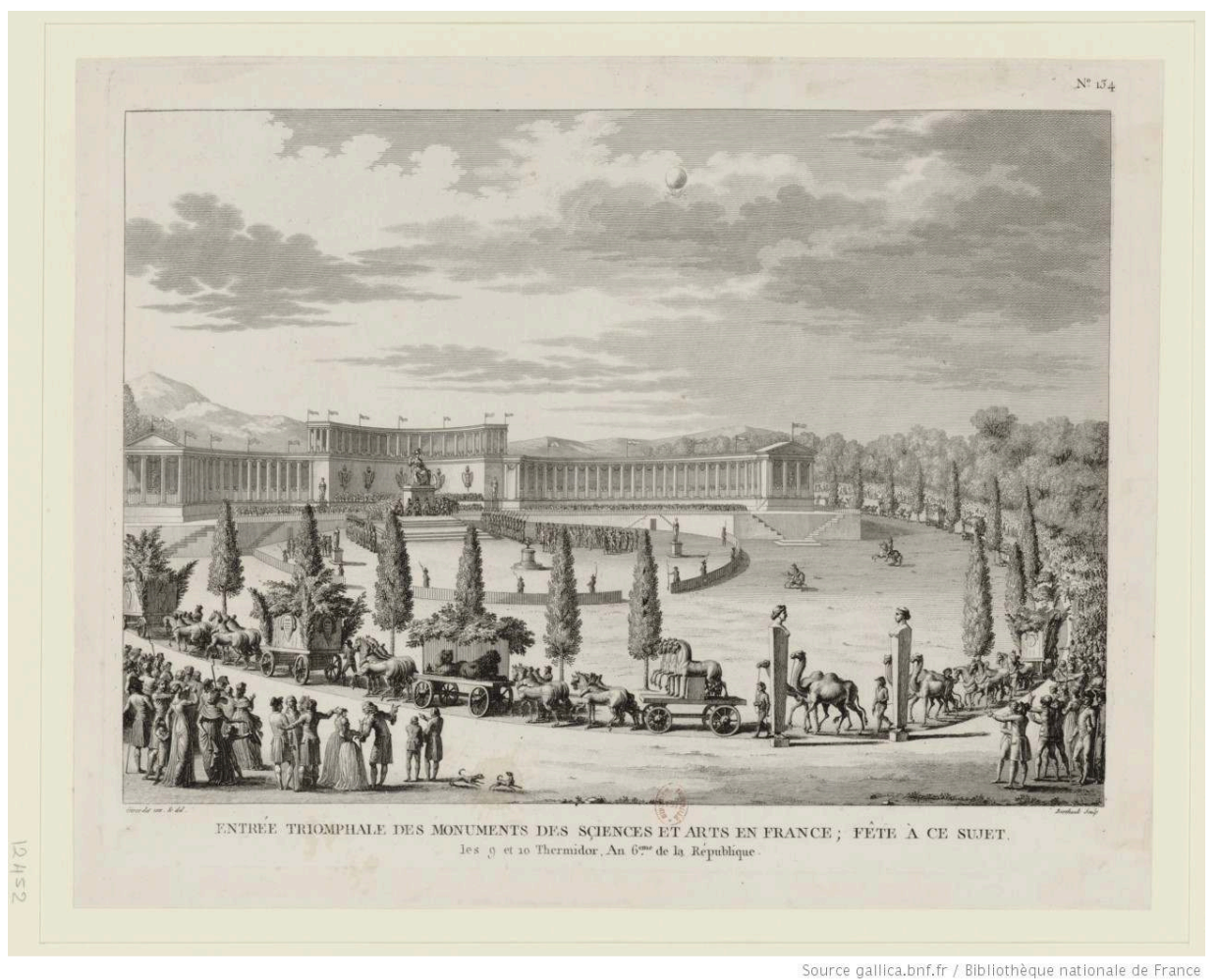

girARDEt (dess.) et berthault (grav.), Entrée triomphale des monuments des sciences et arts en France. Fête à ce sujet les 9 et 10 thermidor an 6ème de la République, gravure, 29,2 × 40,6 cm, Paris, 1798.

Vues comme des manifestes spectaculaires de la Révolution, les fêtes sont par conséquent souvent choisies pour cibles, comme le montre particulièrement l'image satirique intitulée "Bonet sans tête, arbre sans racine: vive la liberté »100. Pour certains, la prétention démiurgique ou prométhéenne des paysages révolutionnaires prouve la démesure et l'orgueil du volontarisme « jacobin » ainsi que de la table rase : perpétrés dès l'été 1792, les «attentats » visant les «mais » ou arbres de la liberté se multiplient, exploitant parfaitement les fragilités de l'« art pauvre » révolutionnaire ${ }^{101}$. En 1790, alors que la plupart des images insistent sur le beau temps de la Fête de la Fédération, niant la pluie qui a, de fait, gâché les réjouissances, certains critiquent justement cette dépendance face aux éléments naturels, dont la force de la monarchie absolue avait justement été de les soumettre ${ }^{102}$.

\section{Esthétiques de la représentation}

Toutefois, le véritable cœur organique de ces fêtes demeure le peuple assemblé. En 1790, Jean-Louis Prieur livre une vue à vol d'oiseau de la Fédération du Champ de Mars, célébrant la multitude réunie : dans ce dessin, le trait fin permet d'individualiser les silhouettes, mais de celles-ci, on n'aperçoit que les contours finement tracés, les physionomies particulières se fondant dans le grand corps mouvant de la foule innombrable qui, de ce fait, constitue le véritable sujet de l'image (fig. 27). 


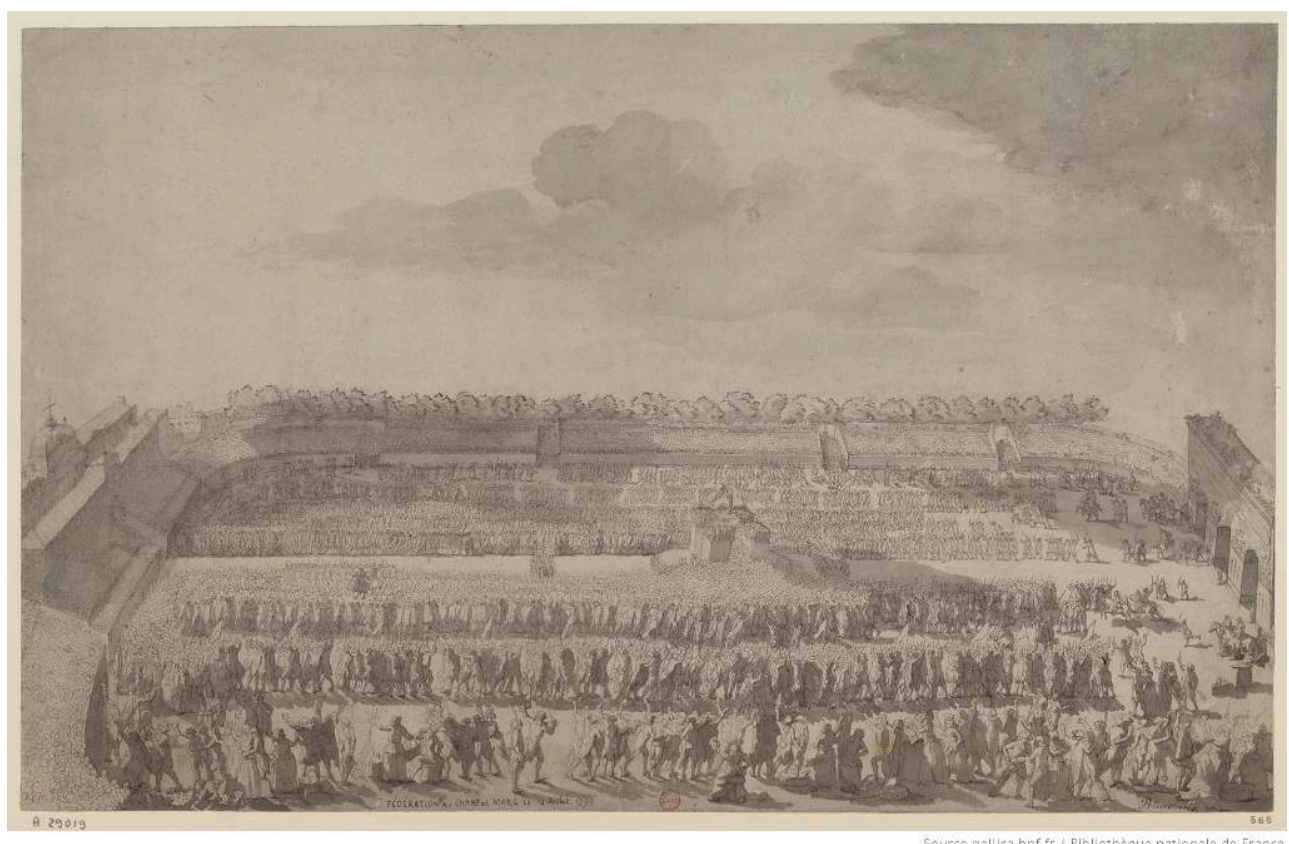

Jean-Louis Prieur, Fédération au Champ de Mars le 14 juillet 1790, dessin à la plume et lavis à l'encre de Chine ; 33 × 52,3 cm, Paris, 1790 (détail), BNF.

Dans beaucoup d'estampes, la foule spectatrice fournit la matière sensible des fêtes et devient la condition de son efficacité magique. Les corps rassemblés de la multitude festive et libérée deviennent donc un des clichés récurrents du spectacle de la Révolution, renouvelant les anciennes représentations organicistes de la société de corps $^{103}$. En marge des images habituant les yeux au régime représentatif, montrant les députés dans la salle des Menus-Plaisirs, du Manège et au Palais-Bourbon, c'est dans l'iconographie des fêtes que se déploie une esthétique de l'Assemblée, mais une assemblée particulière : celle de la nation. Aux côtés des discours et des imprimés, les images du peuple en fête se distinguent par leur capacité à figurer la nation de manière sensible, révélant leur pouvoir constituant. Diffusées en mai et juin 1794, les estampes de la Fête de l'Être Suprême célèbrent l'association des différents corps de la patrie : gravée en couleur, la Vüe [sic] du Champ de Mars le jour du 20 Prairial montre parfaitement combien c'est la réunion de plusieurs groupes bien distincts (femmes, enfants, hommes, députés) qui forme l'unité nationale (...)(fig. 28). 


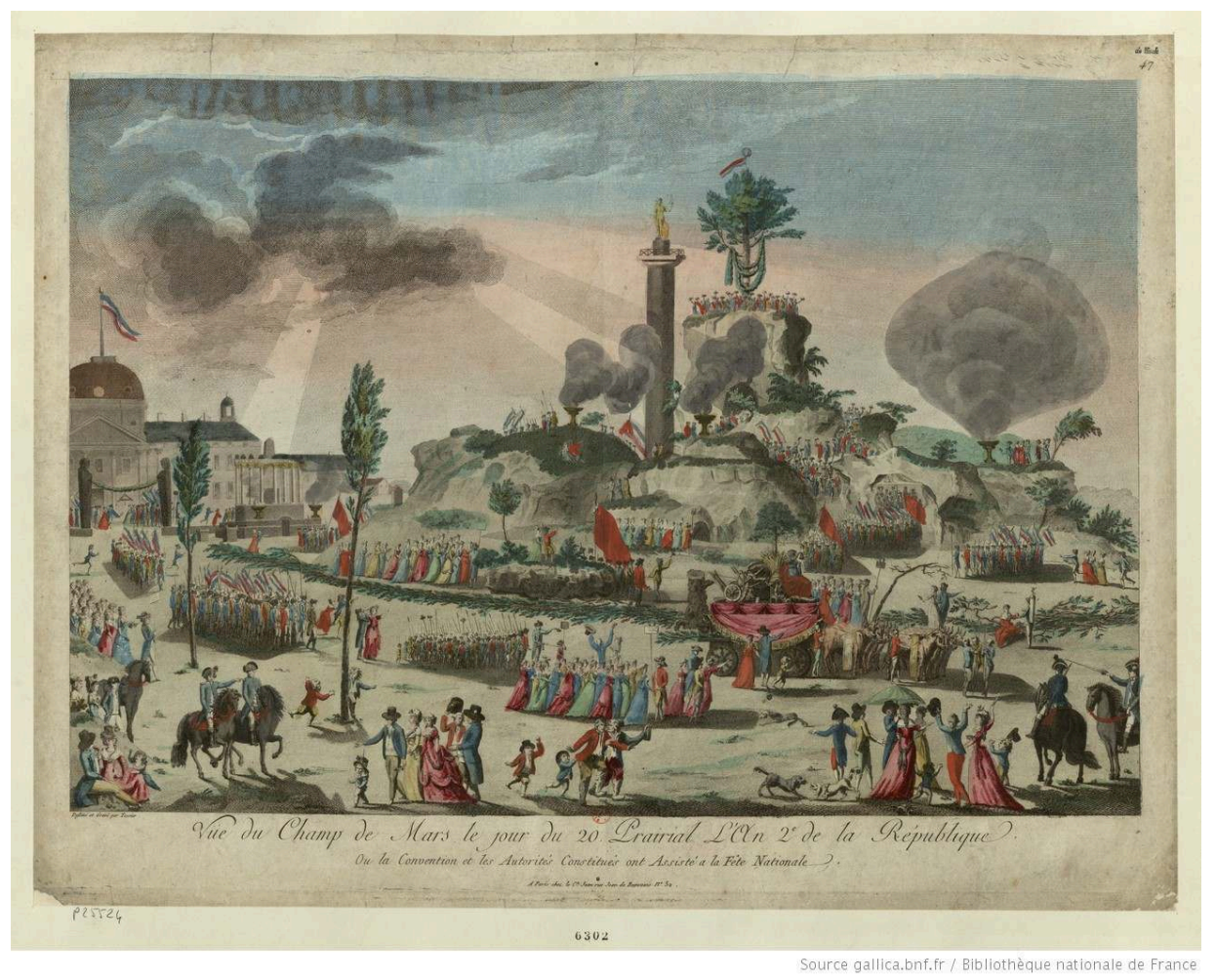

G. TEXIER, Vüe du Champ de Mars le jour du 20 Prairial l'An 2.e de la République : Ou la Convention et les Autorités Constituées ont Assisté à la Fête Nationale, eau-forte, burin, col. ; 40 x 53,5 cm (élt d'impr.), Paris, chez le C.n Jean (à Paris), 1794

En donnant le premier rôle aux populations ordinaires, la Révolution renverse le modèle de la fête de Cour ou même de la fête royale ${ }^{104}$. Comme le note Louis Sébastien Mercier après la fête de la Fédération, «dans ce jour solennel ce fut comme une expérience d'électricité. Tout ce qui touchait à la chaîne dut se ressentir de la commotion »: le simple partage de l'enthousiasme contribuerait à faire sociétét ${ }^{105}$. Les fêtes et leurs images mettent en scène la fiction politique principale de la Révolution: la grande réunion du peuple qui, dans l'ordre du spectacle, doit compenser les insuffisances de la représentation politique. Dans une vision très imaginaire, la gravure intitulée Cérémonie de la Confédération Nationale au Champ de Mars le 14 Juillet 1790 montre à quel point la foule peut faire corps avec la montagne et l'autel de la patrie, figurant la fusion de la multitude (fig. 29). Comme le note le rédacteur des Révolutions de Paris après la fête donnée en avril 1792 en l'honneur des soldats de Chateauvieux, elle-même illustrée en début de numéro : «[d]u moment qu'on se trouva rassemblé, on goûta le plaisir d'être ensemble $»^{106}$. C'est dans cet esprit que Robespierre affirme, le 7 mai 1794, un mois avant de célébrer la fête de l'Être Suprême : « rassemblez les hommes, vous les rendrez meilleurs $»^{107}$. 


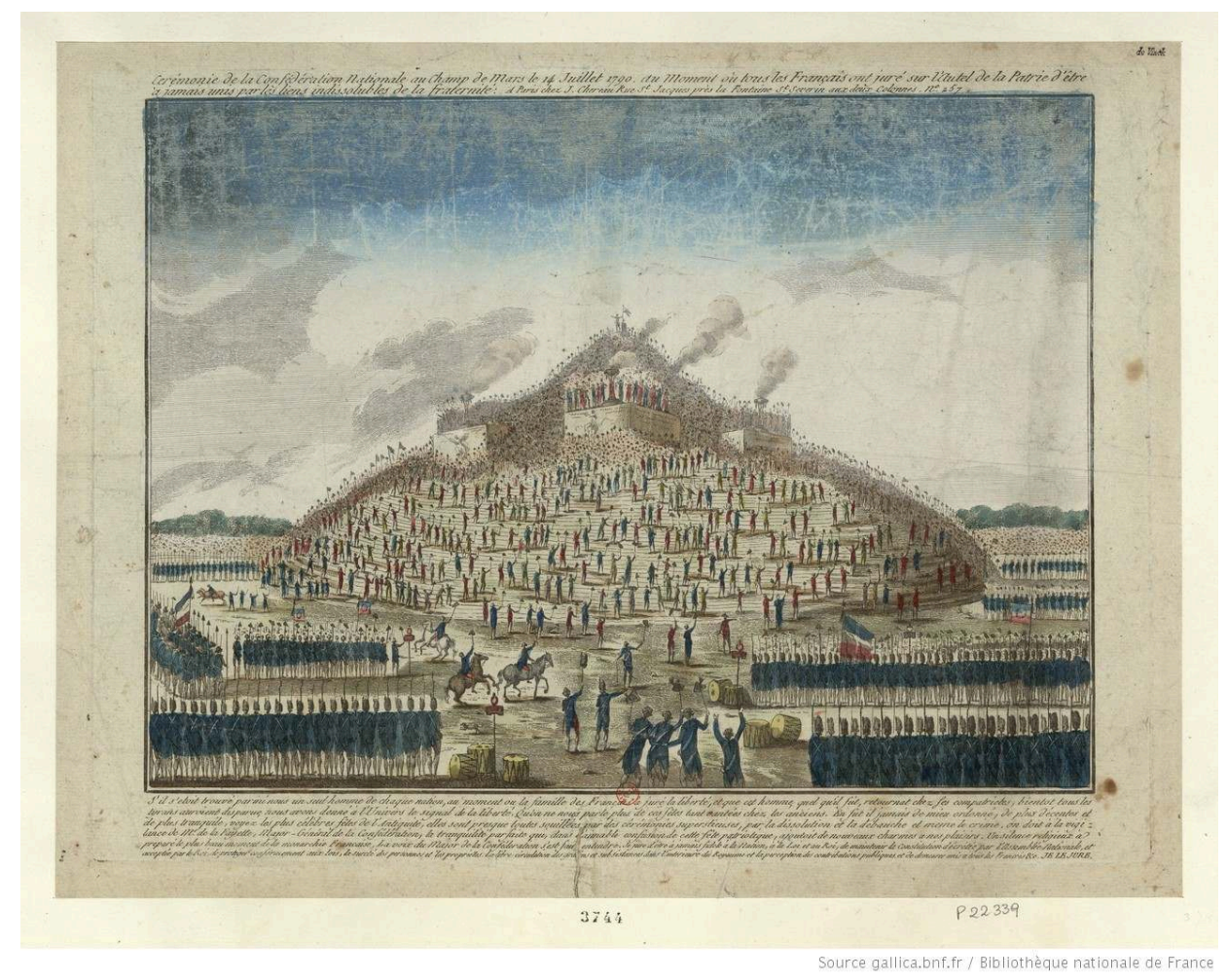

anonyme, Cérémonie de la Confédération nationale au Champ de Mars au Moment où tous les Français ont juré sur l'Autel de la Patrie d'être à jamais unis par les liens indissolubles de la fraternité : s'il s'etoit trouvé parmi nous un seul homme de chaque nation, au moment ou la famille des Français à juré la liberté, et que cet homme, quelqu'il fût, retournat chez ses compatriotes, bientot tous les tyrans auroient disparue, nous avons donné a l'Univers le signal de la liberté. Qu'on ne nous parle plus de ces fêtes tant vantées chez les anciens, Eau-forte, col., 30 × 40 cm, Paris, chez Chéreau, 1790.

La nouvelle harmonie de ce peuple bigarré est célébrée par les assemblages bariolés et presque bricolés, simulant la réunion des dissemblances. Les dessinateurs et graveurs semblent même exagérer la chamarrure des foules révolutionnaires, surlignant les couleurs éclatantes et disparates des habits, des banderoles et des décors comme pour célébrer l'hétérogénéité de la foule assemblée. « La multitude du monde, la vivacité des mouvements, la bigarrure des habits, tout concourait à la variété pittoresque de ce spectacle », affirme Louis-Sébastien Mercier dans sa description des préparatifs du Champ de Mars en juillet $1790^{108}$. Une brochure contemporaine recourt à cette même vision stéréotypée, qui ne tient pas uniquement du goût pour le pittoresque : «la vivacité des mouvements, la multitude du monde, la bigarrure des habits, tout concourt à la variété du tableau $»^{109}$. À l'instar de la mode patriote des rayures tricolore, venue d'Amérique et des Provinces-Unies, la combinaison des couleurs vives et variées traduit, dans l'ordre de la culture matérielle et sensible, l'assemblage volontaire des énergies différentes ${ }^{110}$. Le 20 septembre 1790, la pompe funèbre organisée au Champ de Mars en l'honneur des Suisses de Châteauvieux tués à Nancy pour s'être rebellés, montre un bric-à-brac hétéroclite d'objets portés comme des reliques (un modèle réduit de la Bastille, un autre d'une galère, une Déclaration des Droits de l'homme) ou brandis comme des signes politiques (bonnets, feuilles de chêne, branches de peuplier, balances de la justice, bouts de pain, faux et cœurs) ${ }^{111}$. Même si elles sont animées par le rejet du luxe et de la surcharge, les fêtes de la Révolution sont également tentées par une profusion de gestes, d'objets, de couleurs et de symboles disharmonieux, selon les 
normes du goût éclairé. Les nouveaux symboles de la révolution (pique, faisceaux et bonnet) cohabitent avec les outils du travail quotidien (charrues, faux, divers outils), les figures allégoriques (Liberté, Raison, Victoire, Egalité), les héros du passé et du présent (de Brutus à Marat) et enfin des reliques haïes de l'Ancien Régime comme la Bastille, les effigies du pape, des despotes ou d'aristocrates ou même des églises et des chaînes, portées puis rituellement détruites ${ }^{112}$.

Fig. 30

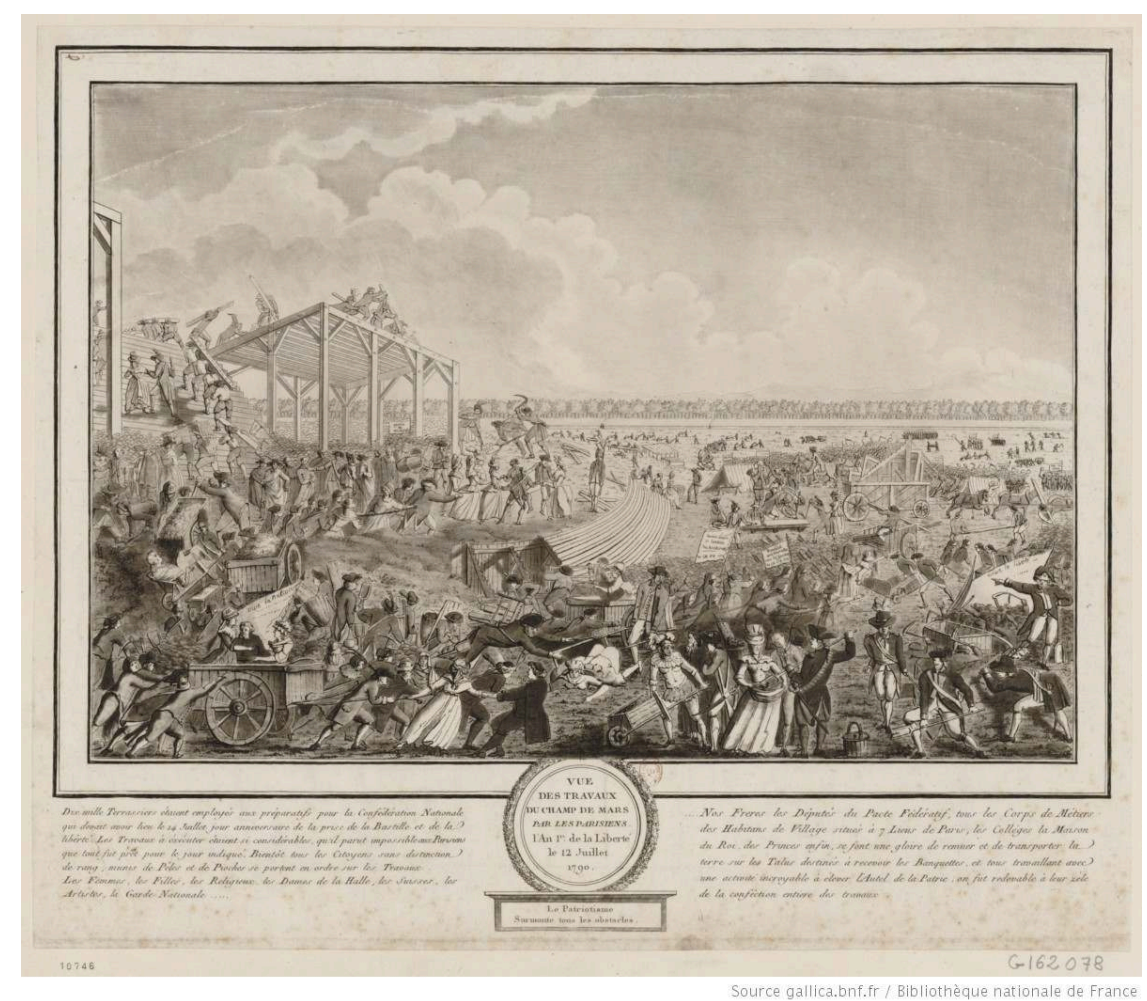

Anonyme, Vue des travaux du Champ de Mars par les parisiens l'an 7.re de la liberté le 12 juillet 1790 : le patriotisme surmonte tous les obstacles. dix mille terrassiers étaient employés aux préparatifs pour la Confédération nationale qui devait avoir lieu le 14 juillet jour anniversaire de la prise de la Bastille et de la liberté..., eau-forte, outils ; 29,5 x 42,5 cm, Lyon, Gentot, 1790.

Mais le désordre n'est pas le chaos. Le bouillonnement porte la promesse d'une nouvelle origine. Les images des fêtes populaires, des danses autour des arbres de la liberté ou des travaux collectifs célèbrent l'énergie collective et montrent les heureux effets de la liberté conquise. Dans la Vue des travaux du Champ de Mars par les parisiens (...) (fig. 30) ou dans L'Effet du patriotisme (fig. 31) les mouvements des ouvriers d'un jour, issus de toutes les classes sociales, forment un ballet aussi chaotique que coordonné, entre pelletées, travaux de force, slogans patriotes, libations et embrassades, unifiant leurs forces pour préparer la fête du 14 juillet 1790. Toutefois ces démonstrations d'enthousiasme et d'énergie sont, pour d'autres, les preuves de l'immaturité, du chaos et de l'échec assuré de la Révolution. Les caricatures britanniques donnent ainsi des fêtes françaises une vision dionysiaque, les bacchanales révolutionnaires croquées par Gillray ou Cruikshank suscitant le rire, le mépris et l'horreur du public conservateur ${ }^{113}$. Sous le Directoire (1795-1799), les fêtes de la Révolution deviennent volontiers des orgies ou des métonymies de l'enfer: dans une Fête de l'Être Suprême, la Révolution est représentée sous la figure de la Discorde, trônant sur un monceau de cadavres ${ }^{114}$. 


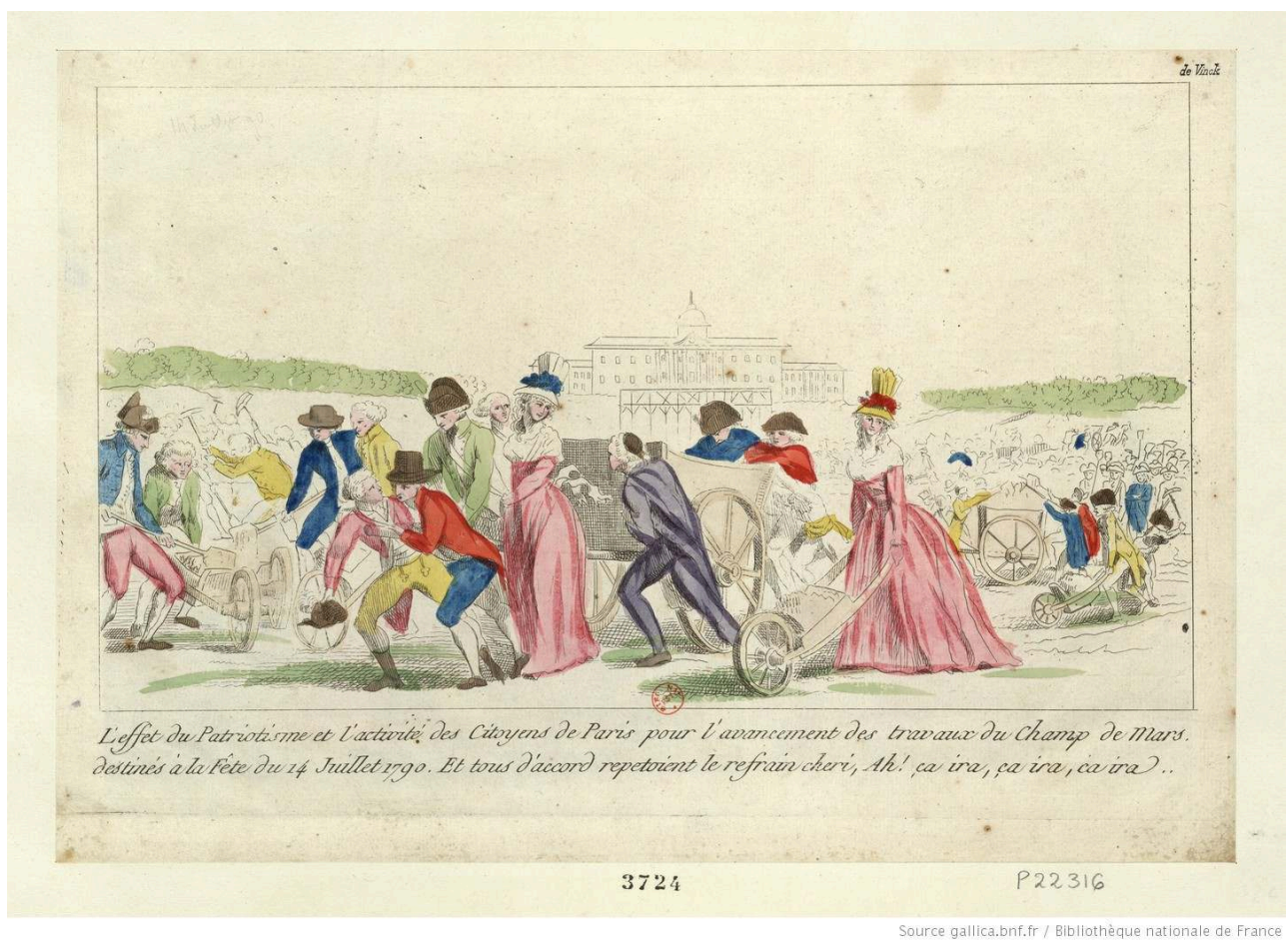

ANONYME, L'Effet du patriotisme et l'activité des citoyens de Paris pour l'avancement des travaux du Champ de Mars : destinés à la fête du 14 juillet 1790. Et tous d'accord repetoient le refrain cheri, Ah! ça ira, ça ira, ça ira, eau-forte, col. ; 22 × 34 cm (élt d'impr.), Paris, 1790, BNF.

Ce bricolage des formes exprime parfois les profondes divisions politiques, en particulier à propos des traditions religieuses. Alors qu'au printemps 1791 le transfert de Mirabeau au Panthéon se déroule dans les formes reconnues du culte catholique, celui des cendres de Voltaire (11 juillet 1791), délesté des décors du cérémonial, déchaîne quant à lui les passions. Les images exagèrent l'impression d'une confusion esthétique et d'un télescopage des temps: alors que certains artistes décrivent la fête funèbre avec une certaine précision documentaire ${ }^{115}$, la plupart des autres, emportés par la nouveauté de l'événement, transportent celle-ci aux temps des apothéoses antiques ${ }^{116}$. Au moment où la place accordée aux cultes dans la vie publique française fait plus que jamais débat, la pompe séculière, organisée au nom de la nation, fait scandale. Les cérémonies célébrées en l'honneur des martyrs de la République à l'automne 1793, les fêtes de la Raison au printemps 1794 puis les fastes de l'Être Suprême, prolongent ensuite ce coup de force esthétique, qui, fragile au regard des traditions sensibles du catholicisme, révèle le décalage entre les élites révolutionnaires, marquées par leurs utopies de "régénération ", et les populations, rétives à ces formes qu'elles ressentent comme imposées ${ }^{117}$. Lors des fêtes organisées en l'honneur de Marat, de Lepelletier et de Chalier, la vue des souffrances des martyrs doit souder les bons républicains: "Que des images vraiment saintes, vraiment solennelles parlent aux cœurs attendris ; que le corps de notre vertueux collègue, découvert à tous leurs yeux, laisse voir la blessure mortelle qu'il a reçue pour la cause du peuple (...) que les vêtements ensanglantés frappent les regards des citoyens ${ }^{118}$. De nombreuses images, inspirées du dolorisme chrétien, reprennent cette fonction. Dès 1795, le décorum catholique se réinstalle plus solidement encore. Les fêtes religieuses funèbres sont 
également saisies par les contre-révolutionnaires : à la même période, donc bien avant la politique funèbre de la Restauration, les projets visant à organiser des fêtes en l'honneur de la mort de Louis XVI peuplent l'imaginaire contre-révolutionnaire ${ }^{119}$.

Pour saisir le rôle que jouent les images des fêtes dans l'acclimatation aux nouvelles formes de représentation, il faut prêter attention à ce qui n'est que trop souvent considéré comme un élément secondaire : le public. Parce qu'elles proposent un point de vue panoramique ou à vol d'oiseau, beaucoup d'images des fêtes transforment les seconds rôles en objets principaux du regard ${ }^{120}$. Passant inaperçus dans beaucoup d'analyses d'images, les spectateurs, les promeneurs, les femmes, les danseurs et buveurs, les commerçants ambulants, les gardes nationaux, les bourgeois et les gens du peuple sont pourtant là et décrits avec une véritable précision documentaire ${ }^{121}$. Pourtant, en même temps, les images sont souvent des fictions unificatrices: emblématiques de cette recherche d'une magie du spectacle et de l'image, elles minimisent les différences sociales. Cette fiction va jusqu'à tenter, parfois, d'amalgamer la présence du peuple et sa propre représentation. Les images de la fête du 10 août 1793 forment peut-être la tentative la plus aboutie de cette utopie, tant la mise en scène brouille souvent la limite entre les spectateurs et les acteurs ${ }^{122}$.

\section{Fig. 32}

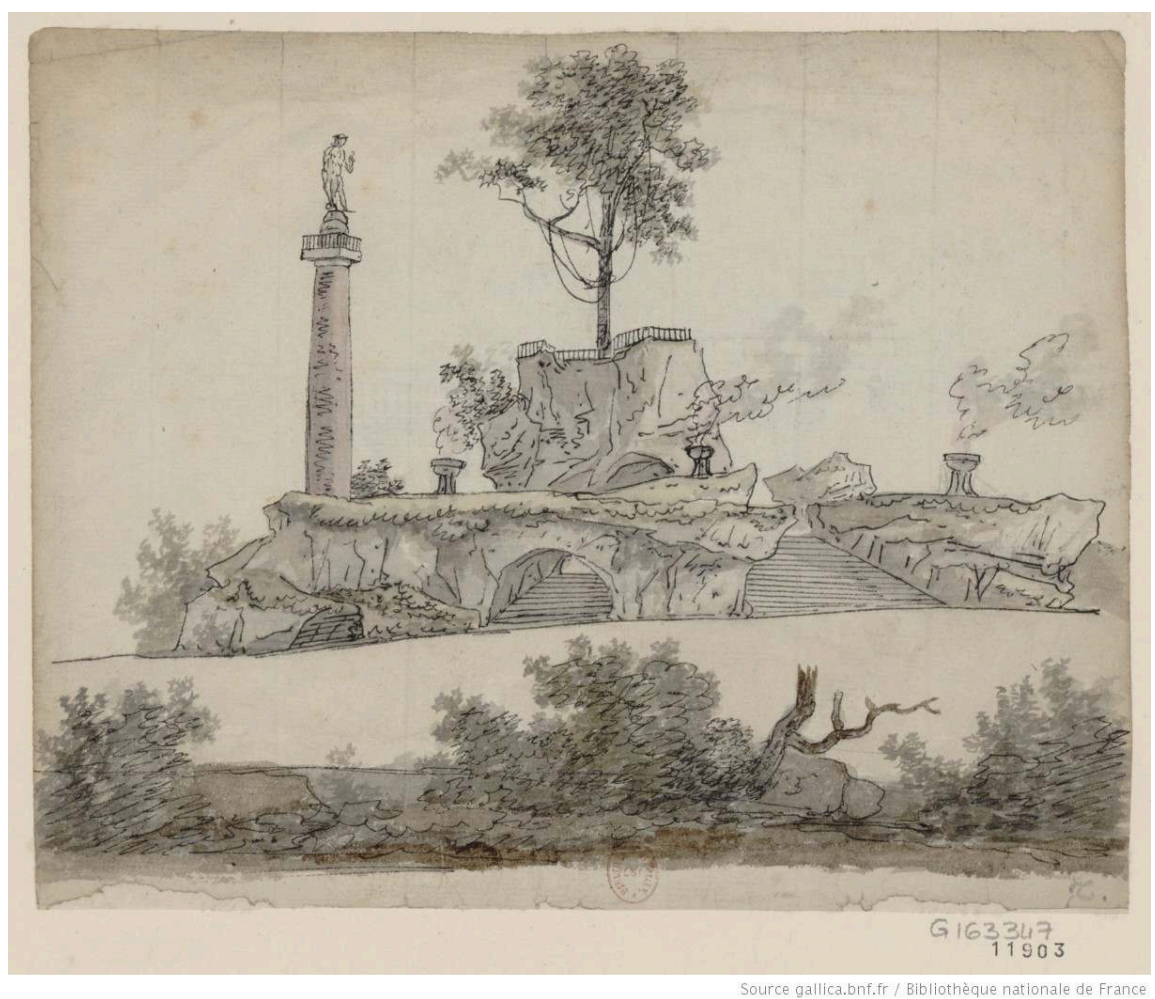

Anonyme, Décorations élevées pour la fête de l'Être Suprême, Dessin à la plume, lavis, aquarelle, couleur, $18 \times 22,5 \mathrm{~cm}$, Paris, 1794

C'est précisément lorsque cette forte attente est déçue et que le spectacle devient simulacre que la fête devient trahison. Le 10 juin 1794, la Fête de l'Être Suprême se retourne contre ses organisateurs pour avoir transgressé le tabou de la personnalisation du pouvoir. Organisée par David, la scénographie cumulant une gigantesque montagne, des chars imposants et des feux d'artifice spectaculaires, rompt 
bien trop avec la recherche de l'anti-monumentalité qui, jusque-là, avait fait la marque des fêtes révolutionnaires. Les dessins décrivant le décor traduisent le gigantisme des éléments naturels qui, par leur association, fabriquent un paysage politique étrange et monumental. Au sommet du rocher artificiel, l'arbre de la liberté, planté sur un promontoire assorti de barrières, côtoie une colonne lisse d'inspiration égyptienne surmontée d'un génie (fig. 32) ${ }^{123}$. Revêtu d'une longue robe qui le fait ressembler à un prêtre d'un culte nouveau, ou, selon certaines images, d'un habit bleu, Robespierre prend la tête du cortège, se présentant maladroitement comme un homme trop puissant ${ }^{124}$. Dans les fêtes du Directoire, en partie lors des fêtes de la Raison, les fêtes décadaires ou le culte philanthropique, la passivité du public est au contraire délibérément recherchée, le peuple étant écrasé par la présence de ses représentants et des Directeurs, vêtus de leur impressionnant costume: cette mise en scène est particulièrement emblématique dans l'image de la Fête au Champ de Mars pour la fondation de la République (1796), dans laquelle les Directeurs surplombent la grandiose apothéose antique, dans laquelle les individus sont noyés (fig. 33). Les fêtes ne sont d'ailleurs plus aussi souvent célébrées en plein air : la Maison Commune, le Temple décadaire ou de la Raison abritent désormais les rituels collectifs dans lesquels les simples citoyens sont destinés à « recevoir » passivement les « impressions » produites par les mots, les gestes et les décors. Davantage imposés, les dispositifs festifs ressemblent de plus en plus nettement à des cultes civils, visant à civiliser les classes populaires. Les images se font de plus en plus rares. Ce programme culmine avec le projet de La Réveillère-Lépeaux, visant à éviter le retour de la Révolution. Auteur d'un Essai sur les moyens de faire participer l'universalité des spectateurs à tout ce que se pratique dans les fêtes nationales (1797), le Directeur pointe du doigt des populations toujours jugées trop instables et facilement influençables. L'esthétique festive s'éloigne alors des goûts populaires et se rapproche, à nouveau, du goût des couches éduquées. Des œuvres d'art, des exemplaires de la Déclaration des Droits de l'Homme et des bustes des députés sont ainsi disposés dans les temples afin d'en imprégner l'âme des citoyens. Par l'exercice de leur regard, par le jugement de goût, les gens simples sont ainsi supposés accéder aux valeurs "supérieures" de la nouvelle République capacitaire que les promoteurs de la Constitution de 1795 souhaitent installer. 


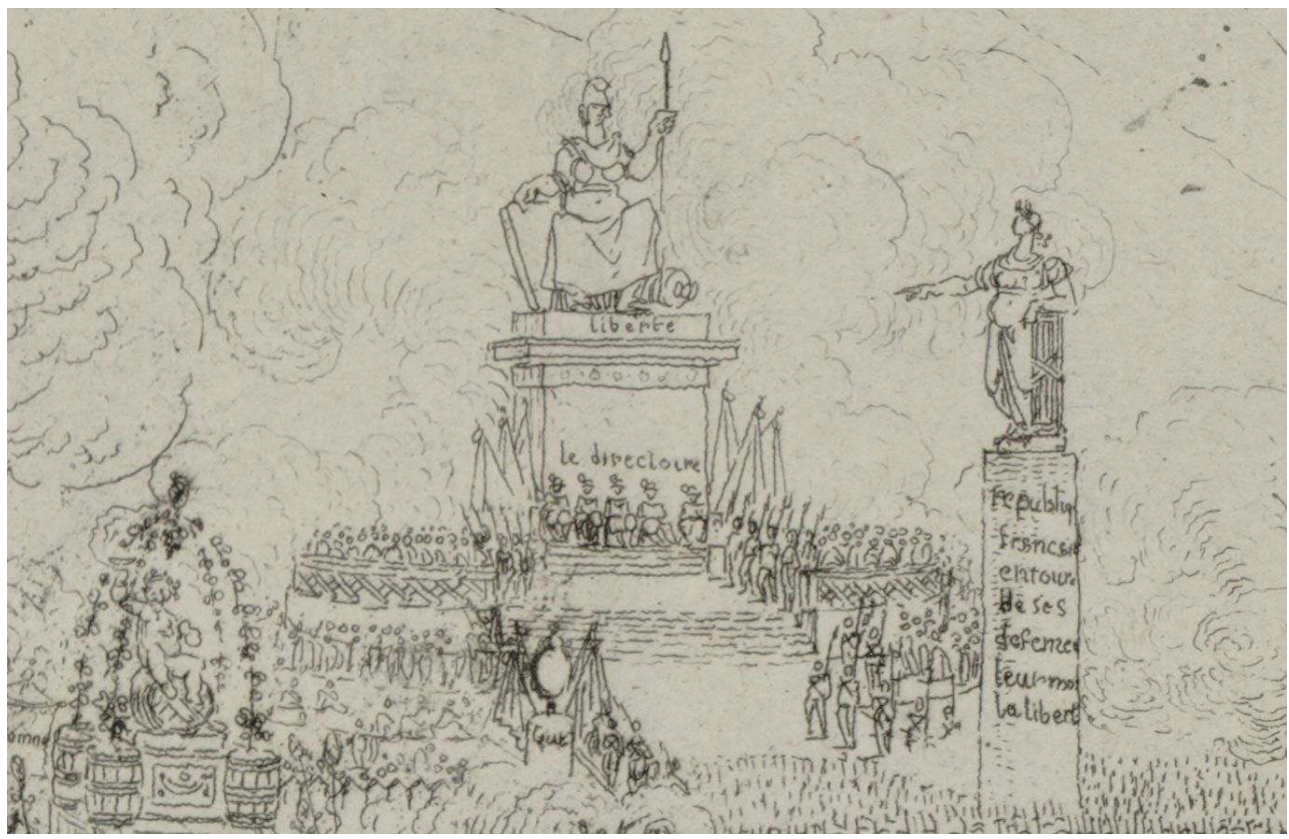

anonyme, Fête au Champ de Mars pour la fondation de la République, eau-forte, 25 × 37,5 cm, Paris, 1796 (détail).

\section{Citoyens observateurs : images et prises de souveraineté}

\section{Spectacles urbains et droit de regard}

«La Révolution a pour monument... le vide... » : c'est Michelet qui exprime sans doute le mieux la manière dont la Révolution tente, en particulier à travers les fêtes, de changer le rapport du pouvoir au temps et à l'espace ${ }^{125}$. Une fois célébrées, les fêtes disparaissent et s'effacent invariablement. Or ce vide et cet invisible sont éminemment politiques. Telles des fictions momentanées, les fêtes explorent l'utopie de l'espace transparent, libéré des opacités, des entraves mais aussi du marquage visuel des dispositifs de reconnaissance et de surveillance d'Ancien Régime. Pendant l'été 1790, certains se félicitent que les fêtes populaires se déroulent « sans aucune surveillance de police", affirmation fausse mais sincère du point de vue de l'expérience vécue, marquée par le sentiment que désormais, la sûreté est protégée par l'œil des simples citoyens, capables de balayer l'espace public du regard et de participer à la surveillance collective. Les grands angles des images des fêtes de la Révolution participent à cette fiction d'ouverture, jouant parfois le rôle de "révélateurs ", au sens photographique du terme : les nombreuses gravures dévoilant l'intérieur et les cachots de la Bastille en même temps qu'elles célèbrent les fêtes, traduisent cette fonction d'exploration. Jouant sur le contraste du clair-obscur, la gravure Vue de la Décoration et illumination faite sur le terrein [sic] de la Bastille (...) montre cette reconquête sur deux plans superposés. Au fond, des Parisiens dansent à la lumière des lampions sur les vestiges des tours de la forteresse. Au premier plan, alors la fête bat son plein, des curieux s'enfoncent dans les sombres entrailles des anciens cachots, éclairés par de simples falots (fig. 34). En permettant aux gens ordinaires qui achètent ces images de découvrir eux aussi les lieux 
autrefois secrets et invisibles, les estampes équivalent à une conquête, une prise de souveraineté sur des territoires qui, par l'effet de cette soudaine intrusion, deviennent soumis au droit de regard de l'ensemble des citoyens.

Fig. 34

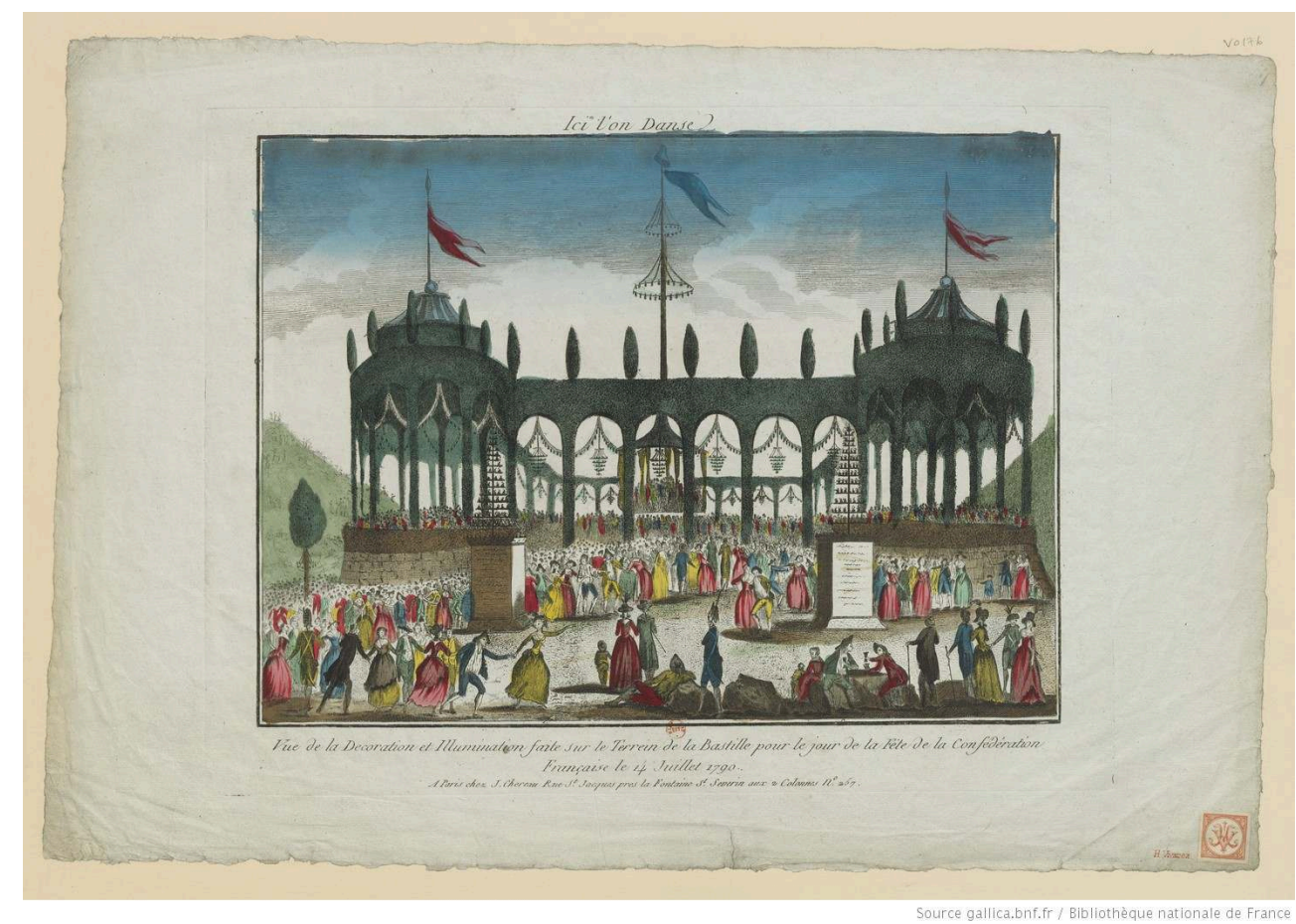

anonyme, Vue de la Décoration et Illumination faite sur le Terrein de la Bastille pour le jour de la Fête de la Confédération Française le 14 Juillet 1790 : à Paris chez J. Chereau rue St Jacques près la Fontaine St Séverin aux 2 colonnes n² 257, vue d'optique, estampe, coul. ; 30 × 40 cm, 1790, BNF.

Les fêtes et leurs images inventent ainsi un "grand spectacle de la transparence », qui différencie autant le projet révolutionnaire des secrets de l'Ancien régime que de l'opacité des nouveaux conspirateurs ${ }^{126}$. Contrairement aux vues parisiennes ordonnées et sans habitants prisées par la bourgeoisie des Lumières, les images des fêtes de la Révolution font voir autrement l'espace urbain, vu comme un monde plein, prolongé jusqu'aux faubourgs. Le véritable citoyen n'est donc pas seulement celui qui prend les armes ou dispose du droit de vote. C'est aussi celui qui réussit à « ouvrir les yeux » et à se libérer des signes extérieurs de domination qui, dans l'esprit de l'empirisme, impriment leurs effets sur le caractère ${ }^{127}$. Le désir de disparition des masques, et des artifices révèle l'utopie d'une fête dans laquelle on ne saurait tricher, son image aspirant à traduire, sans filtre, l'expérience vécue.

Sans être réellement fondées ni documentées, ces images gagnent un nouveau statut un peu magique : celui de preuves et de témoignages visuels ${ }^{128}$. Lors des fêtes, l'œil alerte, mobile et actif de l'«observateur " émancipé doit contribuer à l'exercice actif de la citoyenneté. Le libre regard citoyen s'invente ainsi comme un des organes essentiels d'une anthropologie de l'émancipation. Or parmi l'ensemble des spectacles qui tentent de modeler du commun dans la cité en crise, les fêtes et leurs images prennent une place centrale.

Les titres des images des fêtes ont parfois eux-mêmes valeur d'accréditation ou de témoignage : «cette fête vraiment nationale, s'est passée dans le Champ de Mars près 
Paris, sur un terrain de 400 toises de long, sur 150 de large, les fédérés étaient au nombre d'environ 18000 : l'enceinte contenait au moins 300 mille spectateurs sans compter la Garde nationale qui faisait le service ", précise l'auteur anonyme du Pacte fédératif des Français le 14 juillet $1790^{129}$. Cet effet de véracité quasi-naturaliste correspond au besoin d'informations fiables, rares en temps de crise politique, mais il n'est bien entendu qu'une illusion. Beaucoup d'images des fêtes ne sont pas réalisées d'après les observations de leurs auteurs, mais d'après des descriptions écrites. Cependant, les contemporains de la Révolution française n'ont pas un rapport aussi naïf à ces médias que l'on postule souvent : protagonistes consentants d'un jeu dans lequel leur regard exercé est reconnu comme instance critique, ils ne se contentent pas d'assister aux fêtes. Ils les regardent, les observent, les scrutent parfois puis en évaluent la portée esthétique et politique. Les images des fêtes font partie des supports de cette nouvelle instance critique que l'on appellera ensuite l'« opinion publique ».

Nombre d'images se présentent de fait comme de vrais reportages tirés de l'expérience immédiate des témoins voire des protagonistes de l'événement: une estampe publiée chez Chéreau après les travaux préparatoires au 14 juillet 1790 affirme que « ceux qui ont vu le Champ de Mars il y a peu de jours et qui le revoient aujourd'hui sont surpris de la métamorphose qui $s^{\prime} y$ est opérée $»^{130}$. Parce qu'elles ont pour fonction d'authentifier ou même de reproduire la réalité des faits, les images des fêtes de la Révolution donnent ainsi à la figure du spectateur une place centrale dans l'événement lui-même, dont il devient, par le simple fait d'acheter et de regarder l'estampe, un témoin.

Le droit au regard implique que les fêtes où l'on voit mal ou presque rien sont critiquées. «L'œil, au Champ de Mars, embrassait donc une trop vaste enceinte ; il s'y perdait et n'apercevait rien d'une vue distincte. Pour voir trop d'objets, on n'en voyait aucun... C'était un champ trop étendu pour des hommes de cinq à six pieds. La proportion entre le spectacle et les spectateurs était entièrement rompue » affirme le comte d'Écherny ${ }^{131}$. Probablement effectué par un Britannique, un dessin contemporain attribué à un certain Byron livre un panorama grandiose, enthousiaste, dans lequel le regard, balancé de scène en scène, tend à se perdre. Au milieu de voisins occupés à boire, chanter ou manger, les spectateurs les plus éloignés ou les plus attentifs tentent suivent le défilé à l'aide de longues vues ${ }^{132}$. Les myopes et malvoyants sont nombreux dans les images des fêtes, incarnant ceux qui ne peuvent ou qui ne veulent pas voir, comme empêchés par l'opacité qu'entraîne l'incroyance révolutionnaire, ou dépendants du luxe et des artifices visuels. Dans l'espace idéal de la fête, tout est donc fait pour que le spectacle soit vu et partagé par tous. Ce sont les dispositifs circulaires qui correspondent le mieux à l'idéal du peuple observant et agissant, uni dans un même regard commun: "il faut que rien ne se donne à la domination, mais tout à la fraternité ; la forme circulaire semble donc la meilleure car ici chaque citoyen se trouve toujours en face du peuple. (...) Il faut qu'ici chacun se trouve acteur et spectateur en même temps", assure le député Lequinio en 1795, alors que depuis cinq ans, les estampes célèbrent la magie circulaire du Champ de Mars ${ }^{133}$. Les plans d'architecte les plus inventifs comme Jean-Jacques Lequeu se multiplient, recherchant la visibilité optimale : comme pour l'Assemblée des députés, celle du peuple réuni doit, dans l'idéal, correspondre à la forme de l'ellipse ou du cercle, censée faciliter le partage sensible (fig. 35) ${ }^{134}$. Dans sa Chronique du Mois de janvier 1793, Condorcet fait des amphithéâtres de nouveaux temples dans lesquels les fêtes auront notamment pour fonction de « signaler et éviter les trahisons et les conspirations ». Lieu de la surveillance autonome 
du peuple, la fête est ainsi conçue comme un moment d'épiphanie du « vrai » peuple en Révolution ${ }^{135}$. Lorsqu'il peint la fête de l'Unité (10 août 1793), Pierre Antoine Demachy fait de la convergence des regards la preuve que la fête socialise et unifie, au-delà des différences sociales ${ }^{136}$. Les nombreuses images des feux d'artifices montrent combien le spectacle partagé rassemble les populations, jusqu'à ce que, dans l'obscurité entrecoupée d'éclairs, les corps individuels ne fusionnent dans un plus grand corps commun, uni par l'impression du feu céleste. Parce qu'elles se passent de médiation et qu'elles testent une autonomie de la représentation, ces expériences collectives publiques, qui se privatiseront à la fin des années 1790 dans les séances de magnétisme animal, vont plus loin que les recherches de figuration colossales ou herculéennes du peuple ${ }^{137}$.

Fig. 35

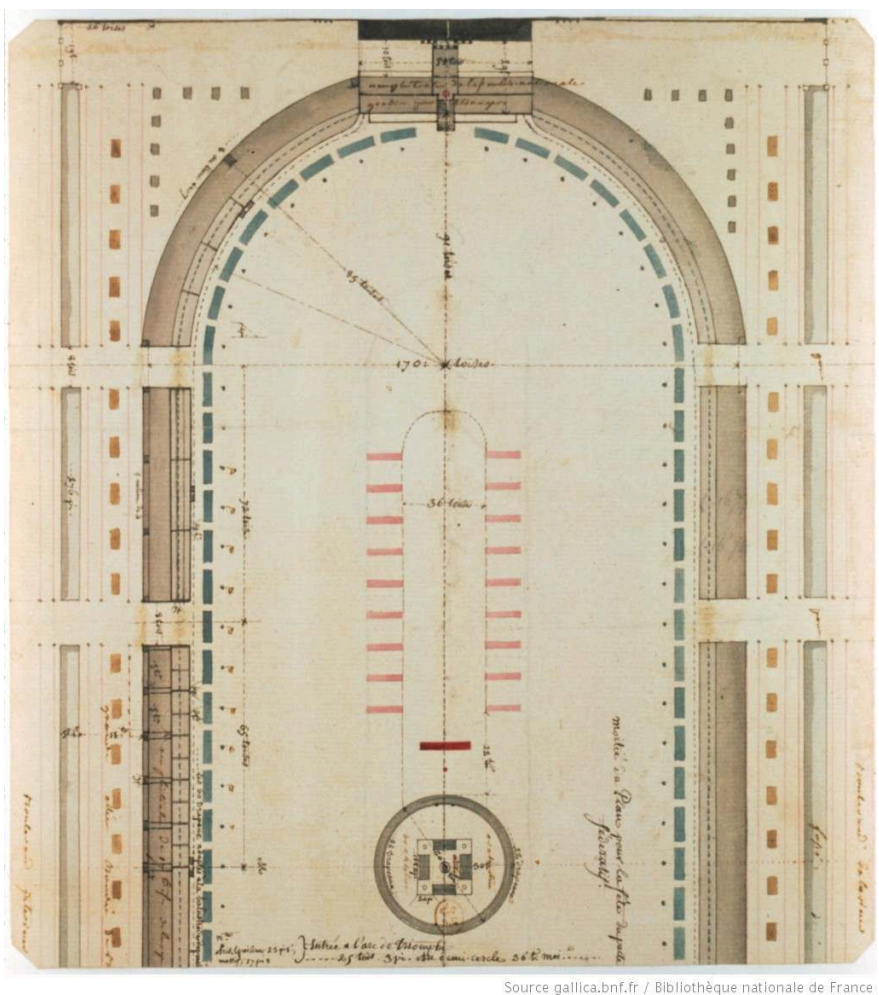

Jean-Jacques lequeu, Moitié du plan pour la fête du Pacte Fédératif, dessin, plume, aquarelle, 30 × 27,5 $\mathrm{cm}$, Paris, 1791

Abolir le spectateur passif, faire du citoyen un observateur critique et vigilant : tel est l'objectif d'une partie de la pédagogie révolutionnaire. Imbus des théories optiques faisant de la vue le résultat d'un rayon émis par l'œil sur l'objet du regard, et non d'une réception passive à un stimulus extérieur, certains révolutionnaires s'efforcent de stimuler l'exercice actif et critique de la vue, qui devient un outil déterminant de l'émancipation ${ }^{138}$. Comme dans certains outils de pédagogie scolaire, recourant à la visualité, les fêtes font partie d'une réflexion plus vaste sur l'efficacité des dispositifs visuels et de la vue dans l'élaboration du savoir politique commun ${ }^{139}$. La vue d'ensemble des fêtes, pensées comme des métonymies de la Révolution, de ses idées et de son histoire, doit permettre de synthétiser, à bonne distance, l'expérience collective par le biais d'un panorama ou d'un tableau synoptique, jugés plus efficaces pour régénérer la sensibilité que les écrits ou les paroles ${ }^{140}$. De la Vue perspective du Champ de Mars (...), 
publiée en grand format après la Fête de la Fédération, prise depuis le dos des spectateurs dessinés en train de regarder et de montrer le défilé des gardes nationaux, se dégage le sentiment d'avoir soi-même assisté à l'événement (fig. 36). Les fêtes sont ainsi considérées comme des institutions civiles visant à « faire aimer » la Révolution à l'aide d'une politique des affects et de la raison sensible, participant de la construction d'une nouvelle « faculté de juger »"

Fig. 36

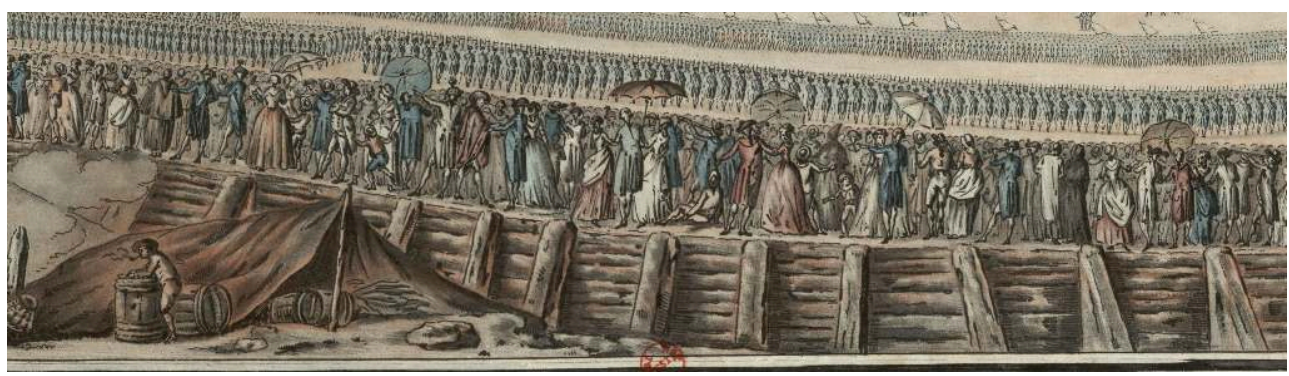

Jacques Le roy (dess.), Jean-Baptiste chapuy (grav.), Vue perspective du Champ de Mars, jour du serment civique prononcé par la nation françoise assemblée à Paris le 14 juillet $1790 . . .$, eau-forte, outils, col. au repérage ; 30 × 52 cm (tr. c.) au Cabinet littéraire, Paris, 1790 (détail)

Fig. 37

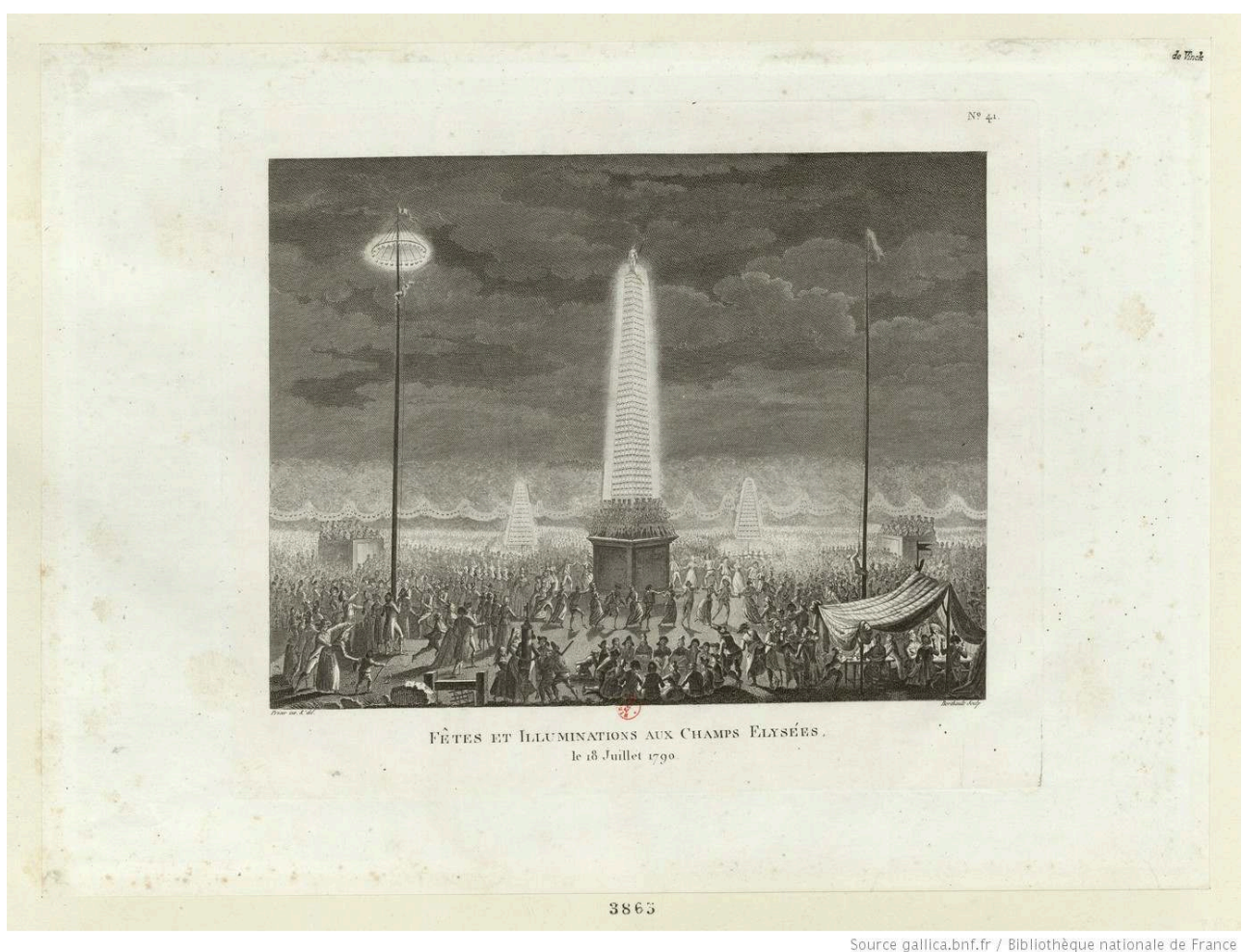

Jean Louis prieur (dess.), berthault (grav.), Fêtes et illumination aux Champs-Elysées : le 18 juillet 1790 Paris, eau-forte, burin, $24 \times 29 \mathrm{~cm}, 1802$

Dans sa gravure sur les fêtes et illuminations populaires aux Champs-Elysées, organisées le 18 juillet 1790, Berthault célèbre la réciprocité des gestes et des regards, qui efface la barrière entre acteurs et spectateurs (fig. 37). Dans l'estampe anonyme intitulée Bal et illumination aux Champs Elysées (1790), la beauté des lumières, qualifiée de 
"spectacle ravissant ", résulte, selon l'auteur de la lettre, de l'ouvrage d'un "grand peuple " et même du "vrai peuple»: la participation directe des couches les plus modeste est source de beauté et de bonheur collectif (fig. 38). Repris des clichés sur l'iconographie des fêtes d'Ancien Régime, le motif des parents qui montrent la fête à leurs enfants, ou de l'anonyme qui désigne du doigt un élément du spectacle, doivent guider l'œil, donnant aux images des fêtes le statut de récits visuels. Dans la Vue du char qui a servi à la cérémonie de la fête dédiée à l'Être suprême le 20 prairial l'an deuxième de la République et exposée au jardin national ${ }^{142}$, un homme dessine le char (fig. 39). Cette mise en abyme du dessinateur dessinant l'événement, récurrent dans les estampes depuis 1789, induit un jeu de regards complexe qui dévoile les ressorts de la représentation, que l'on peut observer en train de se construire. Au-dessous de la gravure, la lettre insiste encore sur le rôle de la vue dans la performativité du dispositif : «Sur ce char éclatant, Français, fixe tes yeux/Ce tableau te soumet les trésors de la France ».

Fig. 38

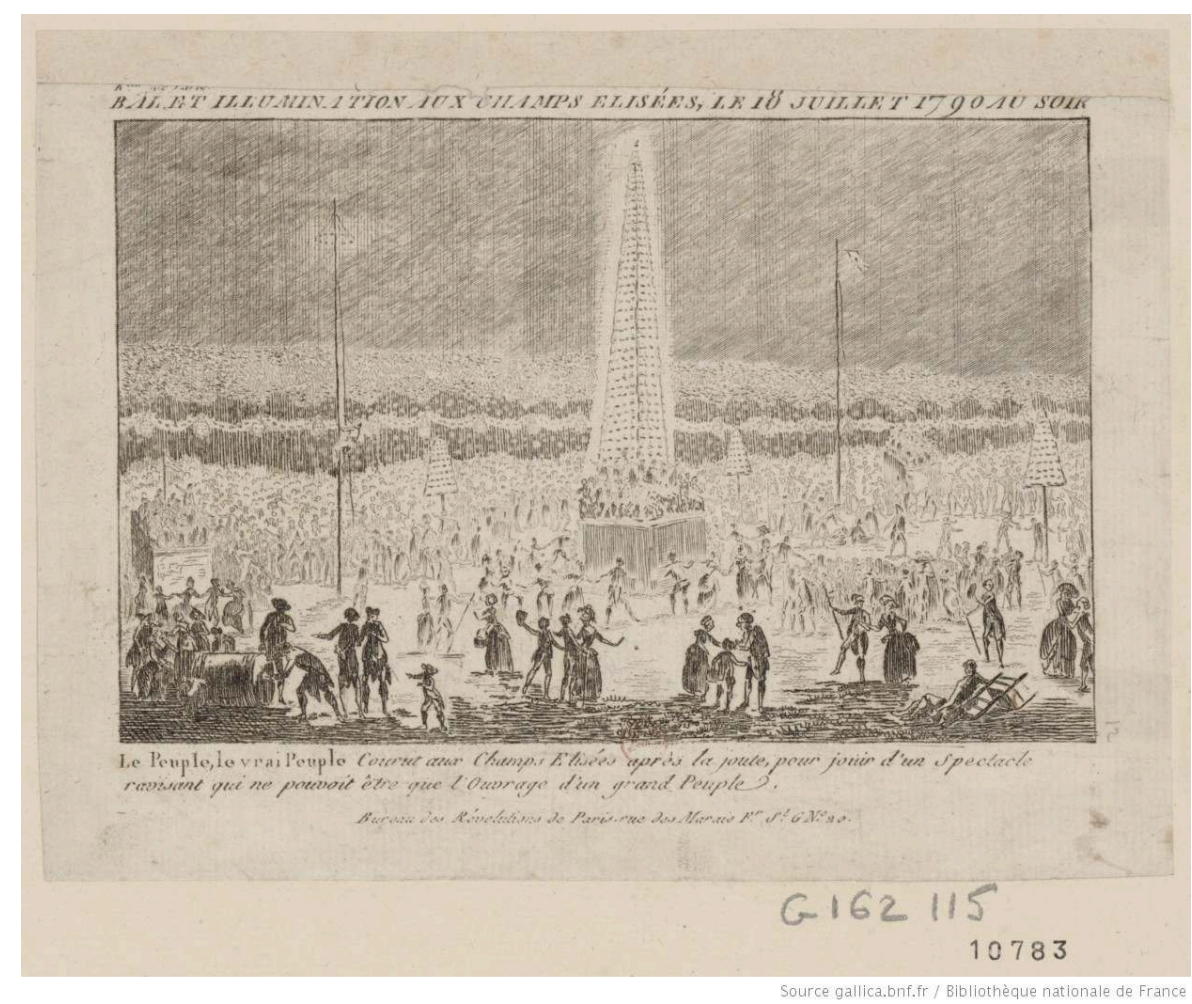

anonyme, Bal et illumination aux Champs Elisées, le 18 juillet 1790 au soir (...), eau-forte ; 9,5 x $15 \mathrm{~cm}$ (im.), Paris, 1790, BNF. 
Fig. 39

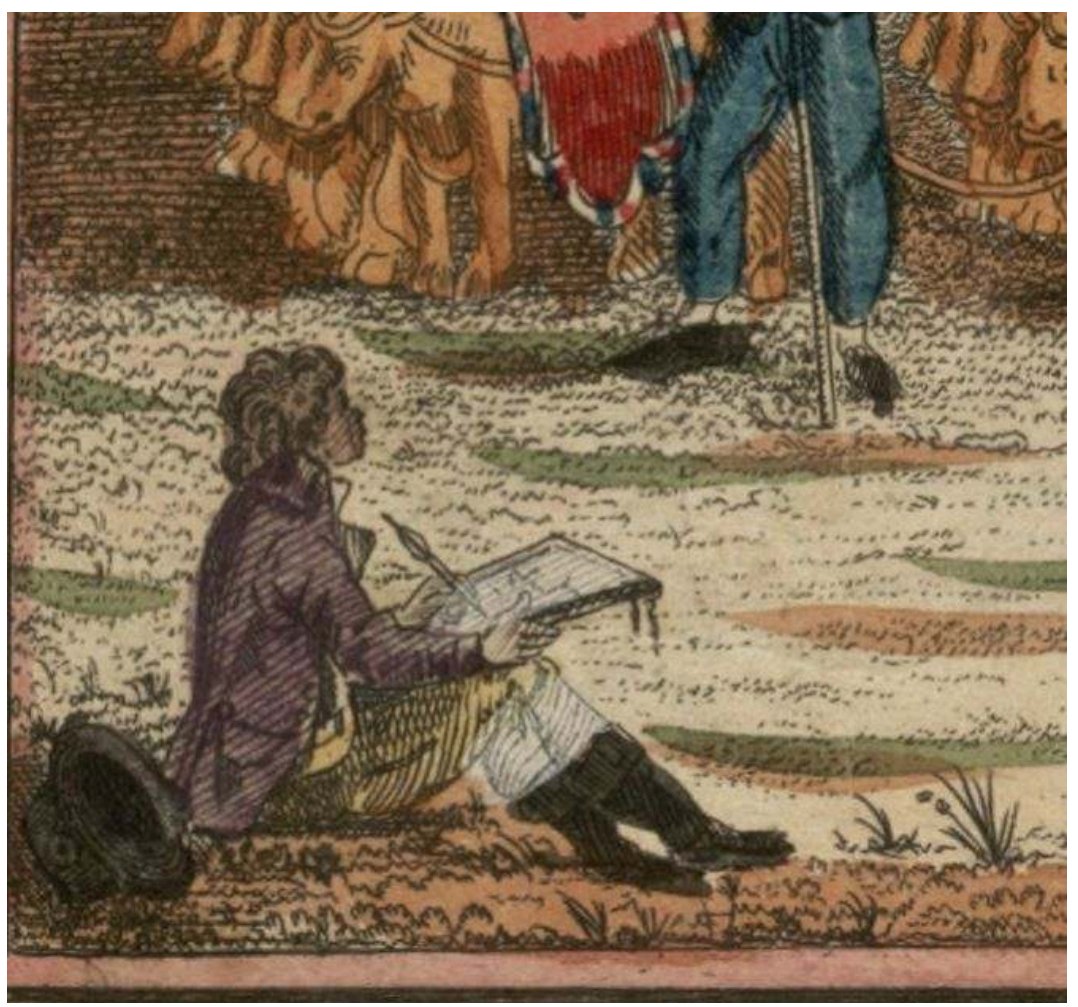

ANONYME, Vue du char qui a servi à la cérémonie de la fête dédiée à l'Être suprême le 20 prairial l'an deuxième de la République et exposée au jardin national, eau-forte, roulette, coul. ; 26,5 × 33,5 cm, Paris, 1794 (détail).

Les fêtes visent ainsi à déployer une véritable pédagogie de l'attention, sollicitant l'œil actif et critique des citoyens définis comme des "observateurs", des citoyens impliqués, qui utilisent leur vision comme une instance de jugement critique. De très nombreux discours prononcés lors des fêtes invitent les spectateurs à "fixer ", «attacher » ou « porter » leurs regards vers les dispositifs censés délivrer le sens. De plus en plus précises au fur et à mesure que les techniques s'affinent, valorisant la gravure sur cuivre au détriment de la gravure sur bois, le dessin et l'aquarelle à la peinture, de plus en plus tournées vers la recherche de la "vérité » et du détail " authentique » ou " d'après nature », plus focalisées qu'avant sur les faits saisis comme sur le vif, ces images invitent l'œil à « saisir » les détails, impliquant le "regardant ", selon le terme de l'époque, dans une attitude vigilante et critique. Les organisateurs de la fête « sans-culottide » célébrée à Valenciennes à l'automne 1793, précisent quelle est exactement la nature de cette observation. Après avoir ressenti la douce émotion devant la vision des trois couleurs, "l'œil satisfait» des participants se charge d'énergie et "dévor[e] l'effigie du tyran], suivant l'« œil animé et furieux » du Génie tutélaire ${ }^{143}$. Mais cette fonction critique du regard citoyen culmine dans les représentations de l'arrivée des œuvres d'art saisies en Italie à Paris, savamment mise en scène les 27 et 28 juillet 1798 ( 9 et 10 thermidor an VI) : dans l'estampe qu'ils consacrent à l'événement, Berthault et Girardet placent le fameux Quadrige de la basilique Saint-Marc au milieu de l'image. Tout autour, les spectateurs s'extasient, admirent les chevaux de bronze, les montrent du doigt et se mettent à discuter: représentés comme des experts ordinaires, ces simples citoyens accèdent grâce à la fête 
au statut de l'amateur d'art, une figure associée à l'exercice de la pensée critique depuis les années 1750 (fig. 26) ${ }^{144}$.

\section{Specta(c)teurs : la fête et la nouvelle cité}

Pour le député Merlin de Douai, le spectacle ne suffit pas. Les fêtes et leurs images doivent surtout éviter de susciter l'admiration, qui fait perdre aux spectateurs leur faculté de juger et les soumet au retour des idoles: « le 14 juillet ne fut qu'un spectacle, et quel spectacle? On ne vit guère que trois choses, une tête mitrée sur un autel, un corps couronné sur un autre autel, un cheval blanc portant encore un autre autel ; ajoutez, si vous voulez, devant ces autels, des adorateurs les pieds dans la boue et la tête dans les brouillards (...) ${ }^{145}$. Soucieux de nouer de nouveaux liens avec le peuple après l'exécution de Robespierre (28 juillet 1794), Merlin tord la réalité, tant les fêtes policées de la nouvelle République conservatrice réduisent déjà les spectateurs à l'obéissance et à la passivité. Exécutée en 1795, la gravure intitulée Le Porte-Drapeau de la Fête civique, montrant un sans-culotte bien domestiqué, résume ce que l'on attend désormais des citoyens ordinaires : intégrer les éléments du décor (fig. 40). Néanmoins, le regard de cet homme porte loin: cette instrumentalisation révèle un idéal persistant depuis les années 1750 , qui passe par la participation de tous et par l'abolition de la frontière entre spectateurs et acteurs. Selon cette conception radicale, il peut y avoir du spectacle dans la fête, mais la fête ne saurait se réduire au spectacle.

Fig. 40

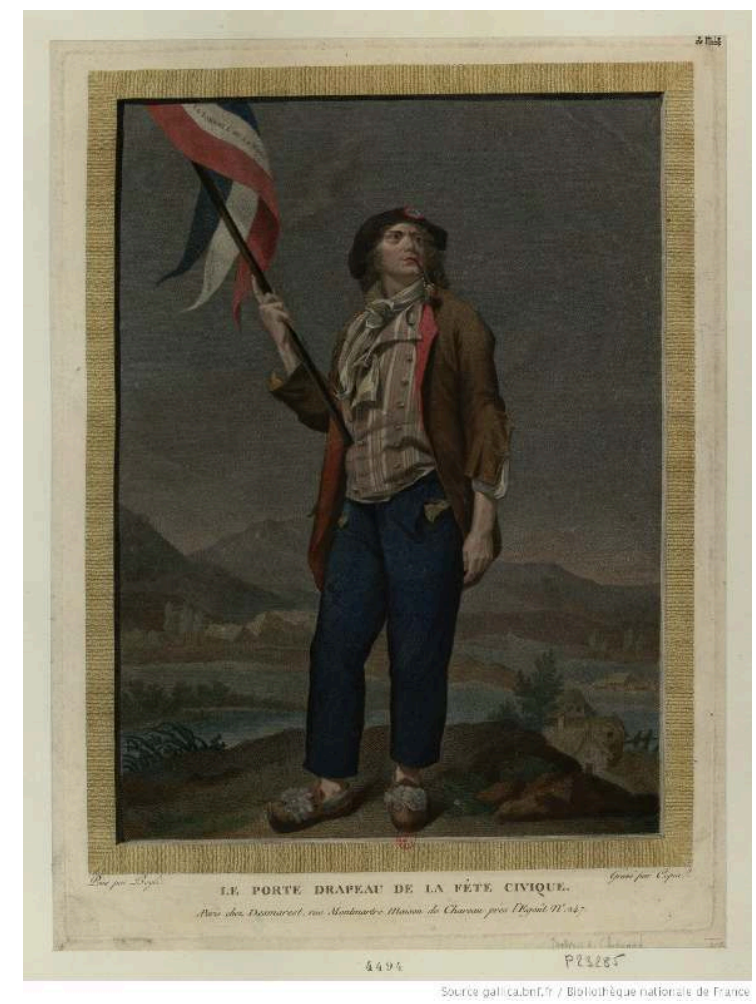

Boyı (dess.), copIA (grav.), Le porte-drapeau de la fête civique, eau-forte, col. ; 38 × 27,5 cm, Paris, chez Desmarets, 1795. 
54

$$
\begin{aligned}
& \text { Eugène Béricourt: dans son tableau éponyme représentant la Fête de la Réunion (10 } \\
& \text { août 1793), les personnages sont acteurs, observateurs et spectateurs en même temps, } \\
& \text { tournant le dos à celui qui regarde l'estampe, de ce fait lui-même impliqué dans le } \\
& \text { rituel collectif qui se déroule autour de la Fontaine de la Régénération (fig. 41). Le } \\
& \text { spectacle peut même disparaître : le } 15 \text { avril 1792, libérés des galères de Brest, les } \\
& \text { soldats mutins de Châteauvieux, défilent à Paris lors de la fête donnée en leur honneur, } \\
& \text { dans un sentiment d'osmose avec la foule : «Ici les acteurs et les témoins, souvent } \\
& \text { confondus, formaient tour à tour le cortège : il y eut peu d'ordre, mais beaucoup } \\
& \text { d'accord : on ne sacrifia point à la vanité d'offrir un coup d'œil superbe; on ne chercha } \\
& \text { point à se donner en spectacle ; (...) la chaîne du cortège se rompit bien des fois, mais } \\
& \text { les regardans [sic]en remplissaient les lacunes : tout le monde voulait être de la fête de } \\
& \text { la liberté »146. }
\end{aligned}
$$

Cet ideal-type est paradoxalement le mieux figuré par lartiste contre-révolutionnaire

Fig. 41

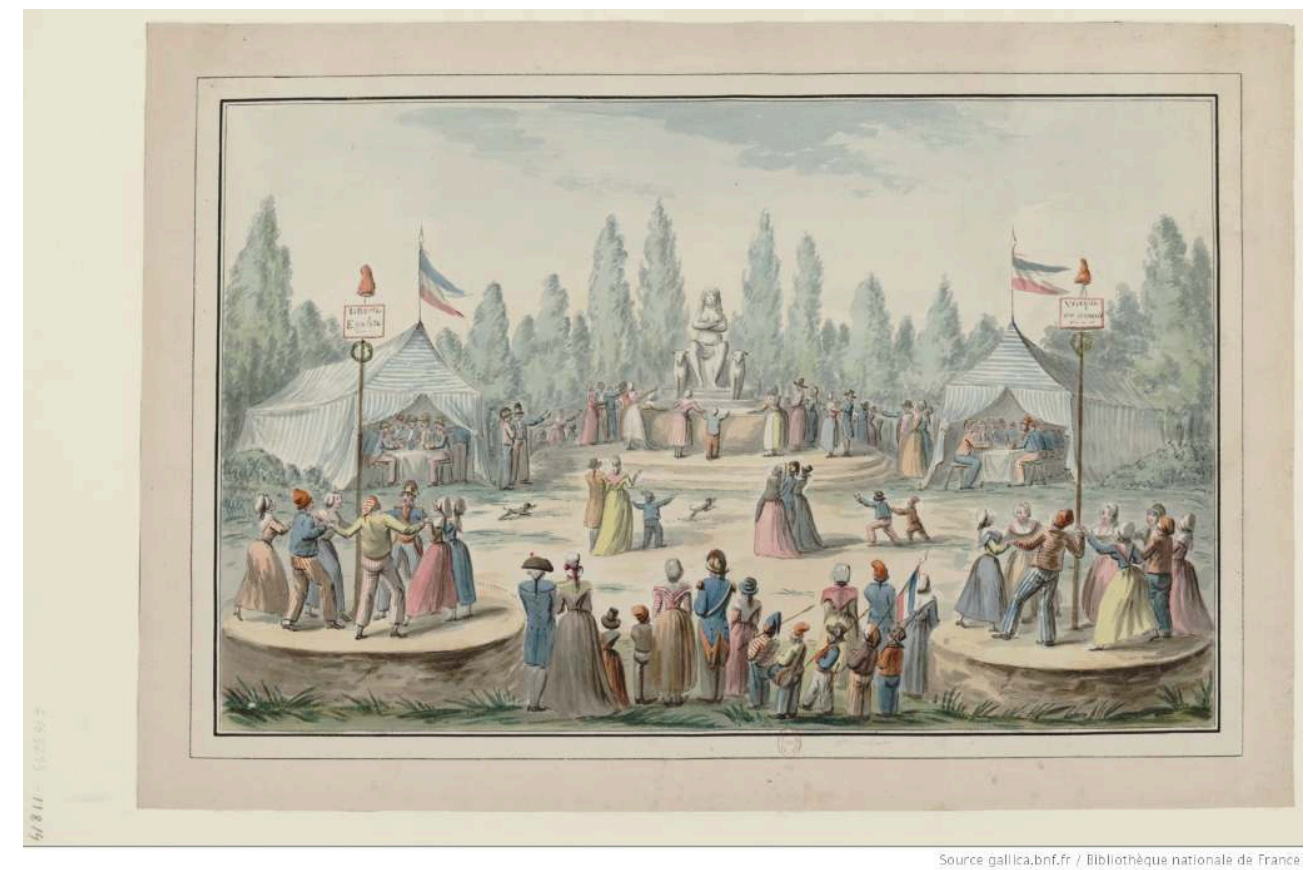

Eugène béricourt, Fête révolutionnaire, dessin à la plume, lavis, aquarelle, 26,5 × 43 cm, Paris, 1793

Même si elles sont utilisées comme des armes politiques, les critiques virulentes contre la fête de l'Être Suprême, organisée au printemps 1794, révèlent à quel point celle-ci est ressentie comme une erreur politique, mais aussi esthétique, qui semble menacer le rapport critique et instable à la représentation du pouvoir que les révolutionnaires avaient tenté de redéfinir depuis $1789^{147}$. Devant la difficulté de représenter l'irreprésentable, les scénographes des fêtes de l'Être Suprême n'ont d'ailleurs d'autre choix que de recourir aux allégories complexes et abstraites, ou de recycler les anciens gestes, symboles et décors, donnant l'impression de déjà-vu: assez répétitives, les images de cette fête laissent le sentiment que la machine festive tourne à vide et surtout que ce qui se joue n'implique plus personne ${ }^{148}$. Moins accessible, la fête doit être expliquée, d'où la diffusion d'estampes à visée pédagogique ${ }^{149}$. La représentation s'éloigne des réalités : la croyance en la magie de la fête s'évanouit. 

elles simulent la mobilisation des populations face aux ennemis de la Révolution ${ }^{150}$ Dans la tradition des jeux de guerre comme les «bravades" provençales, ces fêtes peuvent aussi reconstituer des combats, surtout après la déclaration de guerre (20 avril 1792). Dans de vastes spectacles mimés, appelées des "pantomimes ", organisés dans des lieux symboliques, «rejouent » ainsi le siège de Lille, la prise de la Bastille ou des Tuileries, ces performances réactualisant en quelque sorte à chaque fois l'héroïsme et le martyre des partisans de la Révolution, suscitant l'enthousiasme, l'admiration et la compassion des spectateurs.

Le 26 juin 1793, Lakanal précise la fonction que peuvent remplir ces actualisations du passé : il propose que les citoyens instruits s'«exercent aussi aux représentations historiques pour donner ou rappeler à leurs concitoyens dans les fêtes nationales, la connaissance des époques les plus importantes de l'histoire des hommes et de la Révolution française $»^{151}$. Fondés sur l'imitation et la reconstitution d'événements réellement arrivés, parfois joués in situ par les protagonistes mêmes, proposant parfois de vastes fresques de l'histoire immédiate, ces spectacles muets signifient cependant tout autre chose : ils proposent à celles et ceux qui les regardent de revivre, parfois par procuration, les moments héroïques ou traumatiques du passé récent. À Paris, le 10 août 1793, cinquante-et-une femmes sont ainsi rémunérées pour incarner des héroïnes populaires ou figurer dans la reconstitution des principaux événements de la Révolution ${ }^{152}$. À Paris comme ailleurs, les autorités ne lésinent pas sur les moyens : au Champ de Mars, une forteresse éphémère est édifiée pour rejouer le bombardement de Lille de 1792. C'est d'ailleurs dans cette ville que le 30 décembre 1793, la prise de Toulon est célébrée par une grande fresque dans laquelle un général coordonne lui-même la reconstitution militaire. Monté dans les ruines du quartier Saint-Sauveur, le décor fait de bois et de carton, doit "frapper et fixer tous les regards", d'autant que les effets spectaculaires ne sont pas minces : du bastion forcé et incendié par les assaillants surgit une montagne, symbole du nouvel ordre politique ${ }^{153}$. Lors de la Fête de la Liberté (27 et 28 juillet 1796), les reconstitutions sont encore plus impressionnantes: sur une vaste scène de 60 mètres de large sur 20 de haut, c'est l'histoire récente de la Révolution qui est mimée par les populations, à travers les épisodes de la Prise de la Bastille, la chute du Trône en 1792, l'élimination de Robespierre puis l'établissement de la Constitution de 1795. Dans certaines des fêtes organisées en France entre janvier et juillet 1794 pour célébrer l'abolition de l'esclavage, la séance pendant laquelle le décret a été voté est par ailleurs rejouée en présence de gens de couleur ${ }^{154}$. 
Fig. 42

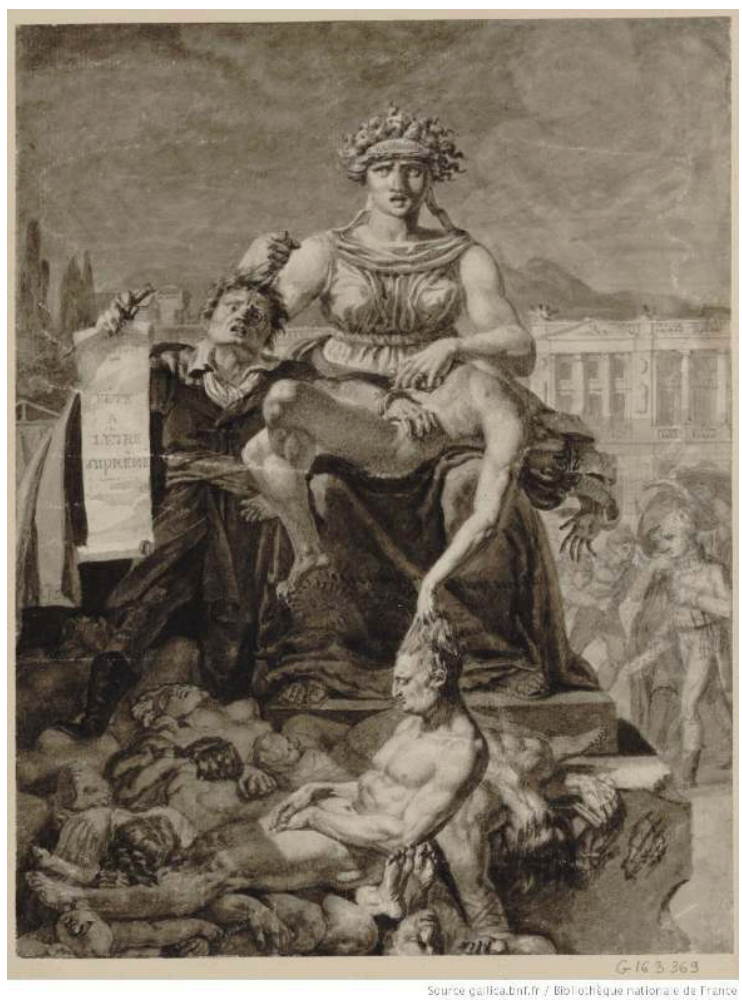

pierre paul prudhon (Att. À), Fête de l'Être Suprême, Dessin au crayon noir, lavis, gouache, $35 \times 26,5$ cm, Paris, BNF, vers 1794-99.

Ciel est noir, déchiré par un éclair. Portant le masque de condamné (peut-être Robespierre?), armé d'un couteau, tient encore une affiche portant l'inscription «Fête à l'Être Suprême» (fig. 42). De l'autre main, il agrippe le corps nu d'une victime de la Révolution, elle-même représentée sous les traits de la Discorde, qui le tire par les cheveux. Frappés d'horreur, les yeux révulsés de cet homme gagné par la folie semblent implorer la pitié aux hommes du futur qui les contempleront à travers le temps, et par-delà le papier. En organisant cette confrontation, Pierre Paul Prudhon (1758-1823) semble interpeller le spectateur du Consulat, sommé de regarder le passé récent bien en face et d'en tirer les leçons: représenté à l'arrière-plan, le jeune Bonaparte, protégé par Minerve, annonce le nouvel ordre à venir. L'évocation de la fête révolutionnaire alors honnie par excellence doit alerter le citoyen, défini par l'exercice actif de son regard. Produit au crépuscule de la Révolution, ce dessin fait métaphore.

La multiplication et les nouvelles fonctions des fêtes traduisent ce que Haim Burstin qualifie de « protagonisme » et qui touche à la fois les acteurs et les spectateurs, que ces derniers soient, ou non, présents lors des fêtes : au cœur de la crise révolutionnaire, l'aspiration de certains groupes ou individus à s'engager et à faire reconnaître la légitimité de leur action, transforme les régimes habituels de la «représentation » publique, aboutissant à une amplification de la participation directe aux événements, mais aussi à la mise en scène de celle-ci ${ }^{155}$. Or si ce recours au spectacle de l'action peut augmenter la radicalité et parfois stimuler la violence, lorsqu'il est pris en charge par les rituels comme les fêtes, il peut au contraire contribuer à apaiser les tensions et recoudre les plaies collectives ${ }^{156}$. Ces invitations à traverser le papier tentent

Images Re-vues, Hors-série 6 | 2018 
d'instaurer une confiance dans le pouvoir de l'image "vraie», comme si, malgré la médiation de l'artiste, celle-ci assurait la présence et l'aura de la fête elle-même ${ }^{157}$. Vue ainsi, l'image n'est plus la représentation coupée du réel ni une simple illustration de ce qui se joue dans l'ordre des pratiques. Conçu comme un «trait d'union» entre les hommes, le dessin peut ainsi, dans la gamme des actions possibles, lui aussi faire événement. Dans l'idéal des révolutionnaires, le spectateur peut, quant à lui, arrêter de s'abriter derrière la médiation de l'image et lui aussi faire montre d'histoire.

\section{NOTES}

1. Ludivine BANTIGNY, La France à l'heure du monde. De 1981 à nos jours, Paris, Seuil, 2013, chapitre 1 ; Steven KAPLAN, Adieu 89, Paris, Fayard, 1993, p. 358 et suiv.; Patrick GARCIA, Le Bicentenaire de la Révolution française. Pratiques sociales d'une commémoration, Paris, CNRS éditions, 2000, p. 247 et suiv.

2. Mikhaïl BAKHTNE, L'œuvre de François Rabelais et la culture populaire au Moyen Age et sous la Renaissance, Paris, Gallimard, 1970 ; Yves-Marie BERCÉ, Fête et révolte. Des mentalités populaires du XVIe au XVIIIe siècle, Paris, Fayard, 1976 ; Daniel FABRE, La fête en Languedoc, Toulouse, Privat, 1977 ; Patrick CHAMPAGNE, « La fête au village », Actes de la recherche en sciences sociales, vol. 17, 1977, n¹, p. 73-84.

3. Guy DEBORD, La société du spectacle, Paris, Buchet/Chastel, 1967 ; Michel FOUCAULT, Surveiller et punir. Naissance de la prison, Paris, Gallimard, 1975.

4. Mona Ozouf, La fête révolutionnaire, Paris, Gallimard, 1976.

5. Jean-Jacques RouSSEAU, Lettre à D'Alembert, Oeuvres complètes, t. I, Paris, Gallimard, 1995.

6. Jules MICHELET, Histoire de la Révolution française, tome 2, Paris, Chamerot, 1847, p. 163.

7. Louis de CAHUSAC, Antoine Gaspard BOUCHER D'ARGIS, «Fêtes ", L'Encyclopédie, 1751, tome 6, p. 576-598.

8. Eugène BÉRICOURT, Procession burlesque de révolutionnaires chargés d'objets de culte, dessin à la plume, lavis, aquarelle, couleur ; 27 x 42,5 cm, Paris, 1793.

9. Phlippe MURAY, Après l'histoire, Paris, Gallimard, 1999.

10. Susan MASLAN, Revolutionnary Acts. Theater, Democracy, and the French Revolution, Baltimore, The John Hopkins University Press, 2005.

11. Yves-Marie BERCÉ, Fête et révolte. Des mentalités populaires du XVIe au XVIIIe siècle, Paris, Fayard, 1976.

12. Roger CHARTIER, «Le monde comme représentation », Annales. Economies, Sociétés, Civilisations, vol. 44, n6, 1989, p. 1505-1520 ; Christian-Marc BOSSENO, "Les signes extérieurs » : diffusion, réception et image de la culture révolutionnaire française dans l'Italie du Triennio (1796-1799), thèse de doctorat sous la direction de Michel Vovelle, Université Paris 1, 1995, dact. ; du même auteur: «Iconographie des fêtes révolutionnaires italiennes (1796-1799)», dans Michel voveLLE (dir.), Les images de la Révolution française, Paris, Publications de la Sorbonne, 1988, p. 157-164.

13. Peter BRown, La société et le sacré dans l'Antiquité tardive, Paris, Le Seuil (1998), 2002, p. 226 ; Paul VEYNE, «Conduites sans croyance et œuvres d'art sans spectateurs », Diogène, n¹43, 1988, p. 3-22. 
14. David FREEDBERG, Le pouvoir des images, Paris, Gérard Montfort, 1998 ; Jean-Claude PASSERON, Le raisonnement sociologique. L'espace non-poppérien du raisonnement naturel, Paris, Nathan, 1991, p. 285-286 ; Walter BENJAMIN, L'œuvre d'art à l'heure de sa reproductibilité technique (1936), Paris, Allia, 2003.

15. Mona ozouf, op. cit.

16. Dictionnaire de l'Académie française, $4 \mathrm{e}$ Edition (1762), t. 2.

17. Louis de CAHUSAC, Antoine Gaspard BOUCHER D'ARGIS, art. cit.; Dictionnaire de l'Académie française, 4e Edition (1762) : «Jour consacré particulièrement au service de Dieu, en commémoration de quelque Mystère, ou en l'honneur de quelque Saint, \& durant lequel il n'est pas permis de travailler; 5. (...) Signifie aussi une réjouissance publique qui se fait en des occasions extraordinaires, telles que sont les naissances, les mariages \& les entrées des Rois. »

18. Alain CABANTOUS, Entre fêtes et clochers: profane et sacré dans l'Europe moderne (XVIIe-XVIIIe siècles), Paris, Fayard, 2002.

19. C.-M. BossÉNo, "Acteurs et spectateurs des fêtes officielles parisiennes ", dans Fêtes et Révolutions, Paris, éd. V. Jouffre et B. de Andia, 1997.

20. Voir aussi ANONYME, Procession des Etats généraux à Versailles le 4 mai 1789, eau-forte ; 17,5 x 12 cm, Paris, 1789 ; ANONYME, Vue de la procession des Etats généraux, à Versailles, le 4 mai 1789, eau-forte, outils, monochr. bistre ; 28,5 x $45 \mathrm{~cm}$, Paris, chez Basset, 1789; ANONYME, Ordre du Cortege pour la Translation des Mânes de Voltaire le lundi 11 Juillet 1791, eau-forte, col., 42 x $55 \mathrm{~cm}$, chez Basset, 1791.

21. Anonyme, Costume de cérémonie de Messieurs les députés des 3 ordres aux États généraux (...), eauforte, roulette, col. ; 22 x 27,5 cm, Paris, chez Basset, 1789 .

22. Raymond Augustin VIEILH DE VARENNES, Collection entière des drapeaux de l'armée nationale parisienne, Paris, 1790.

23. Abel POITRINEAU, «La fête traditionnelle », dans Jean EHRARD, Paul VIALLANEIX (dir.), Les fêtes de la Révolution, Paris, SER, 1977, p. 14.

24. Philippe de CARBONNIÈRES, «Iconographie de la Fête de la Fédération », dans Pascal DUPUY (dir.), La Fête de la Fédération, Rouen, PURH, 2012, p. 86.

25. Daniel RocHE, La culture des apparences. Une histoire du vêtement (XVII-XVIIIe s.), Paris, Fayard, 1990.

26. David GARRIOCH, La fabrique du Paris révolutionnaire, Paris, La Découverte, 2013.

27. Louis MARIN, Politiques de la représentation, Paris, Kimé, 2005.

28. Jean-Marie APOSTOLIDÈs, Le Roi-Machine. Spectacle et politique au temps de Louis XIV, Paris, Editions de Minuit, 1981.

29. Hélène VISENTIN, « Des tableaux vivants à la machine d'architecture dans les entrées royales lyonnaises (XVI ${ }^{\mathrm{e}}$-XVII ${ }^{\mathrm{e}}$ siècles) », Dix-septième siècle, 3/2001 ( ${ }^{\circ}$ 212), p. 419-428.

30. Odile RAMETTE, L'architecture éphémère de la décennie révolutionnaire, Paris-Lille, Corda, 1979 ; Guillaume MAZEAU, Corday contre Marat. Deux siècles d'images, Versailles, Artlys, 2009, Introduction. 31. Guillaume MAZEAU, «Le ciel nocturne, écran de la Révolution », dans Philippe BOURDIN (dir.), Les nuits de la Révolution française, Clermont-Ferrand, Presses Universitaires Blaise Pascal, 2013, p. 251-268.

32. Élise PAVAGEAU, "Fêtes, arts et pédagogie sous le Directoire ", Mémoire de Master 1, Université Paris-1 Panthéon Sorbonne, 2016, p. 46.

33. Alice de BOURGoInG, Célébrer la République. Une histoire politique et matérielle de la fête de l'Unité et de l'Indivisibilité, le 10 août 1793, mémoire de Master 2 sous la direction de Jean-Luc Chappey, 2016, p. 67.

34. Ibidem, p. 92.

35. Michel VOvelLE, op. cit., p. 159-160.

36. Jean Georges WILLE, Mémoires, Paris, Duplessis, 1857, t. II, p. 388-389. 
37. Jean-Marie APOSTOLIDÈs, op. cit.; Bernard GUENÉE et François LEHOUX, Les Entrées royales françaises de 1328 à 1515, Paris, CNRS, 1968 ; Lawrence M. BRYANT, The King and the City in the Parisian Royal Entry Ceremony : Politics, Ritual, and Art in the Renaissance, Genève, Droz, 1986.

38. AnONyme, Arrivée des députés de l'Assemblée nationale au Champ de Mars au cours de la Fête de la Fédération, le 14 juillet 1790, 1 est. : eau-forte ; diam. 6,5 cm, Paris, 1790.

39. ANONYME, Vue Perspective d'une Fête donnée à Florence, sur l'Arno, à l'occasion du Mariage d'Henri IV avec Marie de Médicis donnée par le Grand-Duc de Toscane en 1600, coul. ; 23 x $31 \mathrm{~cm}$, Paris, chez Chéreau, 1790.

40. Christian Marc BosséNo, «Iconographie des fêtes révolutionnaires italiennes (1796-1799), dans Michel vovelle (dir.), Les images de la Révolution française, Paris, Publications de la Sorbonne, 1988, p. 158.

41. Frances A. YATES, L'art de la mémoire, Paris, Gallimard, 1987.

42. Supplément au Journal de Paris, 13 décembre 1790, p. 2.

43. Claude MAZAURIC, «La fête révolutionnaire manifestation de la politique jacobine, Rouen, 1793. An II ", dans Louis TREHARd et Paul VIALLANEIX (dir.), Les fêtes de la Révolution, op. cit., p. 182.

44. Mona ozouf, op. cit.

45. F. GRIJZEnhout, « Le temple et la table, la fête patriote 1781-1787 », A.H.R.F., n 277, 1989, pp. 185-196.

46. Louis-Marie de LA RÉVELLIÈRE-LÉPEAUX, Réflexions sur le culte, sur les cérémonies civiles et sur les fêtes nationales (...) lues à l'Institut le 12 floréal, an 5 de la République, dans la séance de la classe des sciences morales et politiques, Paris, Jansen, 1797.

47. Jean-Luc CHAPPEY, «Révolution, régénération, civilisation : enjeux culturels des dynamiques politiques », Pour quoi faire la Révolution, Marseille, Agone, 2012, p. 115-148.

48. BILLAUD-VARENNE, Moniteur Universel, 2 floréal an II (21 avril 1794), séance du $1^{\text {er }}$ floréal an II (20 avril 1794), p. 267 ; Le Dernier coup porté aux préjugés et aux superstitions, Paris, 1789, p. 182, cité par Françoise BRUNEL, art. cit.

49. Edouard POMMier, L'art de la liberté : doctrines et débats de la Révolution française, Paris, Gallimard, 1991, p. 276 ; François-Xavier LANTHENAS, Motifs de faire du 10 août un jubilé fraternel, une époque solennelle de réconciliation générale entre tous les républicains, en consacrant une déclaration des devoirs de l'homme, des principes \& maximes de la morale universelle, Paris, de l'imprimerie nationale, 1793.

50. Pierre Alexandre wiLle fils (del.), Jean DUPLESSIS BERTAUX (grav.), La Fête de la Réunion : Dédiée à tous les Bons Citoyens. Ces jours de fête et de Réunion fraternelle s'ouvroient par une tréve universelle, oubli total du passé, purification entiere En présence de toute la Gréce, l'ennemi embrassoit son ennemi, et sans deshonneur, il ne leur étoit plus permis de se hair, eau-forte, col. ; 50,5 x 65 cm, Paris, 1795.

51. Jean-Baptiste LESUEUR, "Laboureur à la fête de l'agriculture » et "Conducteur des Boeufs attellés [sic] au char / sur lequel étoit la charue [sic] d'or. / fête de l'agriculture an 5.". \» (détails) dans Citoyens participant à des fêtes du Directoire, dessin à la gouache, $35.5 \times 53 \mathrm{~cm}$, fin du XVIIIe siècle, Musée Carnavalet.

52. Leora AUSLANDER, Cultural Revolutions The Politics of Everyday Life in Britain, North America and France, Oxford \& New York, Berg, 2009; un exemple de papier-peint inspiré de la Fête de la Fédération: Jean-Baptiste HUET, La Fête de la Fédération, toile imprimée : impr. à la plaque de cuivre sur coton, col. Rouge, 97 x $90 \mathrm{~cm}$, Paris, Manufacture Oberkampf, 1790.

53. ANONYME, Fête nationale le 14 juillet 1790, eau-forte, 24 x $37 \mathrm{~cm}$, Paris, BNF, 1790.

54. Philippe de CARBONNIÈRES, art. cit.; voir Jean-Baptiste Félix MASSARD, Premiere frise de l'arc de triomphe elevé au Champ de Mars pour la Fédération du XIV juillet MDCCXC du coté de la Seine : presenté l'Assemblee nationale : [estampe] / dessiné au Champ de Mars et gravé a l'eau-forte par Felix Massard ; et terminé par son frere ainé, eau-forte, roulette ; 19,5 x $70 \mathrm{~cm}$ (élt d'impr.), Paris, chez Massard, 1790, BNF. et J-B LUCIEN (d'après Moitte), Hommage à la deuxième législature, eau-forte au pointillé, Musée 
Carnavalet, 1790 ; ANONYME, Autel de la patrie, fête de la Fédération le 14 juillet 1790, eau-forte, outils, monochr. bistre ; $11 \times 18 \mathrm{~cm}$, Paris, 1790 .

55. Charles thévenin, La Fête de la Fédération le 14 juillet 1789 au Champ de Mars, huile sur toile, $127 \mathrm{x}$ $183 \mathrm{~cm}$, Paris, Musée Carnavalet, 1796.

56. Philippe BORDES, «David, brissotin enragé » dans Régis MICHEL (dir.), David contre David, actes du colloque de 1989, paris, La Documentation française, 1993, t. I, p. 131-132.

57. Amy FREUND, Portraiture and Politics in Revolutionary France, University Park, Pennsylvania State University Press, 2014.

58. Antoine LilTi, Figures publiques : l'invention de la célébrité (1750-1850), Paris, Fayard, 2014.

59. ANONYME, éventail brisé en bois de santal ajouré, colorié, sépia, bois, hauteur $28.3 \mathrm{~cm}$, Paris, vers 1790, Musée Carnavalet.

60. ANONYME, eau-forte, burin, pointillé ; 8 x 11,5 cm, Paris, 1796.

61. Fr GRIJZENHOUT, « La fête révolutionnaire aux Pays-Bas... », art. cit., p. 112.

62. Mona ozouf, La fête révolutionnaire, op. cit., p. 51

63. Jean- Paul MARAt, L'Ami du Peuple, $\mathrm{n}^{\circ} 23,13$ mai 1790 ; Révolutions de Paris, $\mathrm{n}^{\circ} 53$.

64. Journal de la Confédération, $\mathrm{n}^{\circ} 2,3$ juillet 1790.

65. Joseph CLARKE, Commemorating the Dead in Revolutionary France. Revolution and Remembrance, 1789-1799, Cambridge, Cambridge University Press, 2007 ; Emmanuel fUREIX, La France des larmes. Deuils politiques à l'Âge romantique (1814-1840), Seyssel, Champ Vallon, 2009.

66. ANONYME, eau-forte, col. ; 20,5 x 34,5 cm, Paris, 1791.

67. Guillaume MAZEAU, Corday contre Marat. Les discordes de l'histoire, Versailles, Artlys, 2009.

68. Bernard GAINOT, « Rites et contexte dans les cérémonies funèbres en l'honneur des généraux de la République (1796-1800), dans Natalie SCHOLz et Christina SCHRÖER (dir.), Représentation et pouvoir. La politique symbolique en France (1789-1830), Rennes, PUR, 2007, p. 85.

69. Voir aussi ANONYME, Fête au Champ de Mars pour la fondation de la République, eau-forte ; $25 \times 37,5$ cm, Paris, 1796 ; L. F. LABROUSSE (grav.), Pompe funèbre en l'honneur du général Hoche, au Champs de Mars à Paris le 10 vendemiaire an 6.me : enterré au fort Marceau le 1.er vendemiaire an 6.me, eau-forte, outils ; 12 x $16 \mathrm{~cm}$, Paris, 1797.

70. Michel VOVELLE, op. cit., p. 216.

71. ANONYME, Serment des fédérés au cours de la Fête de la Fédération, le 14 juillet 1790 à Paris, eau-forte, outils, ovale $10 \times 12,5 \mathrm{~cm}$, Paris, BNF, 1790.

72. Mona ozouf, La fête révolutionnaire, op. cit., chap. X, p. 317-340.

73. Antoine DE BAECQUE, «Les corps du carnaval politique », dans Le corps de l'histoire. Métaphores et politique (1770-1800), Paris, Calmann-Lévy, 1993, p. 309.

74. Antoine DE BAECQUE, Les éclats du rire. La culture des rieurs au XVIIIe siècle, Paris, Calmann-Lévy, 2000 ; Pierre SERNA (dir.), La politique du rire. Satire, caricatures et blasphèmes, XVIe-XXIe siècles, Ceyzérieux, Champ Vallon, 2015.

75. ANONYME, Fête de la Fédération, papier, eau-forte, gouache, bois (éventail), 28.1 x $14.2 \mathrm{~cm}$, Paris, 1790, Musée Carnavalet.

76. Jacques RANCIÈRE, Le partage du sensible, Paris, La Fabrique, 2000.

77. Nicolas MARIOT, «Qu'est-ce qu'un « enthousiasme civique » ? Sur l'historiographie des fêtes en France après 1789 ", Annales. Histoire, Sciences Sociales, Paris, Ed. de l'EHESS, 2008/1, p. 113-139.

78. Moniteur Universel, 28 septembre 1794 (7 vendémiaire an III), discours du 26 septembre 1794 (9 vendémiaire an III).

79. ANONYME, Révolution française : illuminations à l'Hôtel de Ville, la nuit. Fête de la Fédération, 14 juillet 1790. 7ème arrondissement, 17.8 x $24.4 \mathrm{~cm}, 1790$, Musée Carnavalet.

80. Mona OzOUF, « Du mai de la liberté à l'arbre de la liberté », dans Pierre NORA (dir.), Les Lieux de mémoire, Paris, Gallimard, 1984 ; ANONYME, eau-forte, 34 x 22 cm, Paris, 1789. 
81. Sur l'importance du son dans les fêtes: Maxime KACI, «Chanter la politique: partitions nationales et modulation septentrionale (1789-1799) ", Annales historiques de la Révolution française, 362, 2010, p. 79-100. Robert BRÉCY, La Révolution en chantant, Paris, éd. Van de Velde, 1988 ; Laura MASON, Singing the French Revolution. Popular culture dans Politics, 1787-1799, Ithaca and London, Cornell University Press, 1996.

82. Jean DUPLESSI-BERTAUX, Liberté des barrières. Barrière de la Conférence. 1er mai 1791, Dessin à la plume et lavis à l'encre de Chine sur papier gris ; 5,3 x 7,9 cm, Paris, 1791 ; voir aussi ANONYME, Barriere des Champs Elisées, Premier May donné à la Ville de Paris par l'Assemblé Nationale qui suprime [sic] tous les Droits d'entrées aux Barrières, Paris, M.d Layrie, eau-forte, 31 x 50,5 cm, vers 1791.

83. Martine воттеUX, «Fête et Révolution. Des célébrations aux commémorations ", Les Annales de la Recherche urbaine, vol.43, $n^{\circ} 1,1989$, p. 45-54.

84. Mona ozouf, op. cit. Martine SIN BLIMA, La fête révolutionnaire. Politisation, 1789-1794, mémoire de maîtrise sous la direction de Michel Vovelle, Univ. Paris-1 Panthéon-Sorbonne, 1991, p. 8.

85. Annie JOURDAN, Les Monuments de la Révolution française. Le discours des images dans l'espace parisien (1789-1804), Amsterdam, Université d'Amsterdam, 1993.

86. Moniteur Universel, 8 novembre 1793.

87. Anouchka WASAK, «Grandes émotions météorologiques collectives », dans Alain CORBIN, JeanJacques COURTine et Georges VIGARELlo (dir.), Histoire des émotions, t. 2, Paris, Seuil, 2016, p. 79-97. 88. ANONYME, Revue du général La Fayette d'une partie de la Garde nationale parisienne (...), eau-forte, col. ; 21,5 x 31,5 cm, Paris, 1790 .

89. Olivier RITZ, Les Métaphores naturelles dans le débat sur la Révolution, Paris, Garnier, 2015.

90. Dessin à la plume, lavis, aquarelle, couleur, 18 x 22,5 cm, Paris, BNF, 1794.

91. Claude соснет (dess.), Pierre Gentot (grav.), Vue d'un rocher élevé dans le centre du camp de la Fédération tenu sous les murs de la ville de Lyon le 30 mai 1790, eau-forte, burin ; ov. 24 x $20 \mathrm{~cm}, 1790$; ANONYME, Vue du camp fédératif de Lyon, gravure sur bois ; $11 \mathrm{x} 18 \mathrm{~cm}, 1790$; Thomas Charles NAUDET, Fête de l'Être Suprême au Champ de Mars le 20 prairial an II (8 juin 1794), Aquarelle, gouache et pastel sur traits de plume et mine de plomb, 46,8 x $73 \mathrm{~cm}$, Paris, 1794, Musée Carnavalet.

92. ANonymE, Cerémonie de la Confédération Nationale au Champ de Mars le 14 Juillet 1790, au Moment où tous les Français ont juré sur l'Autel de la Patrie d'être à jamais unis par les liens indissolubles de la fraternité : s'il s'etoit trouvé parmi nous un seul homme de chaque nation, au moment ou la famille des Français à juré la liberté, et que cet homme, quelqu'il fût, retournat chez ses compatriotes, bientot tous les tyrans auroient disparue, nous avons donné a l'Univers le signal de la liberté. Qu'on ne nous parle plus de ces fêtes tant vantées chez les anciens, estampe à l'eau-forte, 30 x $40 \mathrm{~cm}$, Paris, J. Chereau, 1790

93. ANONYME, Montagne élevée au champ de la réunion: Pour la Fête de l'Etre Suprême le 20 prairial l'An 2.me, eau-forte, 70,5 x 50,5 cm, Paris, chez Basset, 1794.

94. Edmund BURKE, Recherche philosophique sur l'origine de nos idées du sublime et du beau, Paris, J. Vrin, 1973, p. 69.

95. Odile RAMETTE, op. cit., p. 119-121.

96. Werner SZAMBIEN, "Les architectes parisiens de l'époque révolutionnaire", Revue de l'Art Année 1989 Volume 83, Numéro 1 p. 36-50 ; Odile RAMETTE, op. cit., p. 58 ; Claude MAZAURIC, «La fête révolutionnaire manifestation de la politique jacobine, Rouen, 1793. An II », dans Jean EHRARD et Paul Viallaneix (dir.), op. cit., p. 181-190.

97. Philippe BORDES, "La Révolution française, une question de style », dans Emmanuel FUREIX (dir.), Iconoclasme et révolutions de 1789 à nos jours, Ceyzérieu, Champ Vallon, 2014, p. 94-110.

98. Bénédicte SAVOY, Patrimoine annexé: les biens culturels saisis par la France en Allemagne autour de 1800, Paris, Editions de la Maison des Sciences de l'Homme, 2003, p. 345 et suiv.

99. Le ministre de l'intérieur aux administrations centrales et municipales de toute la république, Paris, le 3 ventôse an 6.

100. Eau-forte, roulette, monochr. bistre ; 10,5 x 9 cm, Paris, entre 1792 et 1795. 
101. Guillaume MAZEAU, «Violence politique et transition démocratique : les attentats sous la Révolution française », La Révolution française [En ligne], 1| 2012, mis en ligne le 29 avril 2013, Consulté le 30 mai 2017. URL : http://lrf.revues.org/380.

102. Olivier RITZ, op. cit., chap. 1 «Un 14 juillet sous la pluie»; BAXMANN, Die Feste der Franzöischen Revolution. Inszenierung von Gesellschaft als Natur, Berlin, 1989.

103. Yann LIGNEREUX, Les rois imaginaires : une histoire visuelle de la monarchie de Charles VIII à Louis XIV, Rennes, PUR, 2016, p. 264.

104. Florence SORKINE, Propagande et mécénat royal : les fêtes louis-quatorziennes à Versailles et leurs représentations. 1661-1682, thèse de doctorat, littérature française, Université Paris 3 Sorbonne nouvelle, 1993, dact. ; Marine RoussiLlon, « Les carrousels : configurer l'espace social de la noblesse », Papers on French Seventeenth Century Literature, 2011, p. 377-390.

105. Louis Sébastien MERCIER, Le Nouveau Paris, Brunswick, 1800, p. 70-71.

106. Révolutions de Paris, ${ }^{\circ} 145$, du 14 au 21 avril 1792, p. 99.

107. Rapport sur les rapports des idées religieuses et morales avec les principes républicains et sur les fêtes nationales, 7 mai 1794 (18 floréal an II).

108. Louis Sébastien MERCIER, op. cit., p. 72.

109. Confédération nationale, ou récit exact et circonstancié de tout ce qui s'est passé à Paris, le 14 juillet 1790, à la Fédération, Garnéry, 1790, p. 61.

110. Guillaume MAZEAU, "Trikolore", dans Rolf REICHARDT (dir.), Lexicon der RevolutionsIkonographie, à paraitre chez Rhema éditions, p. 1940-1959.

111. anonyme, Pompe funèbre au Champ de la Fédération le 20 7.bre 1790, en l'honneur des soldats citoyens morts à Nancy, Paris, bureau des Révolutions de Paris, 1790.

112. Michel VOVELLE, op. cit., p. 217.

113. Eugène BÉRICOURT, Préparatifs de la fête de la Fédération en juillet 1790, plume, lavis, aquarelle, coul. ; 20 x 35,5 cm, Paris, 1790.

114. Dessin au crayon noir, lavis, gouache, 35 x 26,5 cm, Paris, BNF, vers 1794-99.

115. ANonyme, Ordre du Cortege pour la Translation des Manes de Voltaire le lundi 11 Juillet 1791, eauforte, col. ; 42 x $55 \mathrm{~cm}$, Paris, chez Basset, 1791.

116. Pierre-Gabriel Berthault, Transfert des cendres de Voltaire au Panthéon le 11 juillet 1791, eauforte, 12,4 x $16.7 \mathrm{~cm}$, Paris, vers 1791 ; ANONYME, Translation des restes de Voltaire au Panthéon, eauforte ; 8 x 14,5 cm, Paris, 1791 .

117. Jean-Luc CHAPPEY, «Révolution, régénération, civilisation : enjeux culturels des dynamiques politiques ", dans Jean-Luc CHAPPEY, Bernard GAINOT, Guillaume MAZEAU, Frédéric RÉGENT et Pierre SERNA, Pour quoi faire la Révolution, Agone, 2012, p. 115-148.

118. Cité par Mona ozouf, «La fête révolutionnaire. Le renouvellement de l'imaginaire collectif ", dans Jean EHRARD et Paul VIALLANEIX (dir.), op. cit., p. 304-305.

119. EMMANUEL, Appel à l'honneur français, ou projet d'une fête pour célébrer dignement la mort de Louis XVI, 1796.

120. J.C. LE FRANÇOIS (dess.), Jean-Baptiste CLOQUET (grav.), Vue générale de la Fédération française : prise à vôl d'oiseau au-dessus de Chaillot, eau-forte, coul. ; 31,5 x 47,5 cm, Paris, 1790.

121. ANONYME, Vüe du côté oriental De la montagne élevée au Champ de la réunion Pour la fête célébrée en l'honneur de l'être Suprême, eau-forte, roulette, col. ; 25,5 x 37,5 cm, Paris, chez Coustellier, 1794 ; Noël BYron (dess.), La fête de la Fédération au Champ de Mars en 1790, dessin, Paris, Musée Carnavalet, 1790.

122. Jacques Guilhaumou, « Nous/vous/tous : la fête de l'Union le 10 août 1793 », Mots, $\mathrm{n}^{\circ} 10$, mars 1985, p. 91-108.

123. Voir aussi ANONYME, Vue du jardin national et des décorations, Le jour de la fête célébrée en l'honneur de l'Etre Suprême le Decadi 20 Prairial l'an 2.e de la République Française, estampe à l'eauforte et au burin, 29,5 x 41,5 cm, Paris, Chéreau, 1794. 
124. ANONYME, Robespierre brûlant l'Athéisme, le Fanatisme et dévoilant la Vérité à la Fête de l'Être Suprême le 20 prairial, projet d'éventail (détail), fin XVIII siècle, musée Carnavalet.

125. Jules MICHELET, Histoire de la Révolution française, 1847, préface.

126. Antoine DE BAECQUE, Le corps de l'histoire. Métaphores et politique (1770-1800), Paris, CalmannLévy, 1993, p. 257-302.

127. Guillaume MAZEAU, «Révolution et construction de l'espace public. L'iconoclasme à Paris en 1790 », dans Emmanuel FUREIX (dir.), op. cit., p. 81-93.

128. Sur le nouveau statut cognitif des images: Lorraine DASTON et Peter GALISSON, Objectivité (2007), Paris, Presses du réel, 2012.

129. ANONYME, estampe à l'eau-forte, $9,5 \times 15 \mathrm{~cm}$, Paris, Bureau des Révolutions de Paris, 1790 .

130. ANONYME, Ceux qui ont vu le Champ de Mars il y a peu de jours et qui le revoyent aujourd'hui sont surpris de la métarmorphose qui s'y est operée. Cette plaine immense à été transformée tout à coups en un vaste et superbe cirque au milieu duquel s'eleve une montagne sur laquelle doit être placé l'autel de la Fédération, eau-forte, coul. ; 29,5 x $38 \mathrm{~cm}$, Paris, chez Chéreau, 1790.

131. COMTE D'ESCHERNY, Correspondance d'un habitant de Paris avec ses amis de Suisse et d'Angleterre sur les événements de 1789, 1790 et jusqu'au 4 avril 1791, Paris, 1791, p. 319 et 322.

132. George Gordon Noël BYRon (dess.), La fête de la Fédération au Champ de Mars en 1790, dessin, Paris, Musée Carnavalet, 1790.

133. Joseph Marie LEQUINIO, Des fêtes nationales, Paris, Imprimerie nationale, 1795, p. 12 ; MEUNIER (dess.), GAUCHER (grav.), Plan général du Champ de Mars, et du Nouveau cirque : ou la nation française a prêté le serment fédératif sur l'Autel de la patrie le 14 juillet 1790, jour de l'an[n]iversaires de la prise de la Bastille, 1790.

134. Jean-Jacques LEQUEU, Moitié du plan pour la fête du Pacte Fédératif, dessin, plume, aquarelle, $30 \mathrm{x}$ $27,5 \mathrm{~cm}$, Paris, 1791 ; voir aussi Jean-Philippe HEURTIN, L'espace public parlementaire. Essais sur les raisons du législateur, Paris, PUF, 1999.

135. La chronique du mois, ou Les cahiers patriotiques, Paris, imprimerie du cercle Social, 1793, p. 27.

136. Pierre Antoine DEMACHY, La Fête de l'Unité sur la place de la Concorde (23 thermidor an I- 10 août 1793), huile sur toile, $48 \times 75 \mathrm{~cm}, 1794$.

137. Yann LIGNEREUX, «Hercule sans-culotte. Un figure de l'iconoclasme révolutionnaire en France ((XVII-XIXe s.), dans Emmanuel FUREIX (dir.), op. cit., p. 56-67 ; Lynn HUNT, « Hercules and the Radical Image in France », Representations, $\mathrm{N}^{\circ} 2$, Spring 1983, p. 95-117.

138. Gérard SIMON, Le Regard, l'être et l'apparence dans l'optique de l'Antiquité, Paris, Le Seuil, 1988.

139. Isabelle SAINT-MARTIN, Voir, savoir, croire. Catéchismes et pédagogie par l'image au XIX siècle, Paris, Champion (Histoire cuturelle de l'Europe), 2003.

140. Pauline PUjo, "Tableaux synoptiques et récits historiques: La référence aux modèles étrangers dans le cours d'histoire des Écoles centrales (1795-1802)», La Révolution française [En ligne], $4 \mid 2013$, mis en ligne le 10 juin 2013, Consulté le 08 juillet 2017. URL: http:// lrf.revues.org/834.

141. Sophie WAHNich, La Révolution française: un événement de la raison sensible (1787-1799), Paris, Hachette, 2012 ; Guillaume MAZEAU, «Émotions politiques : la Révolution française », dans Alain CORBIN, Jean-Jacques COURTINE, Georges VIGARELlo (dir.), Histoire des Émotions, t.2, Paris, Seuil, p. 115 et suiv.

142. ANONYME, eau-forte, roulette, coul. ; 26,5 x 33,5 cm, Paris, 1794 ; DALIGNY, Fête du 20 prairial (Fête au Grand Camp près de Lyon), dessin à la plume, aquarelle, 28,5 x $37 \mathrm{~cm}$, Lyon, 1794 (détail).

143. Plan de la dernière fête sans-culottide, célébrée à Valenciennes, l'an deuxième de la République française, p. 12.

144. Charlotte GUICHARD, Les amateurs d'Art à Paris au XVIII ${ }^{\mathrm{e}}$ siècle, Seyssel, Champ Vallon, 2008.

145. Moniteur Universel, 28 septembre 1794 (7 vendémiaire an III), discours du 26 septembre 1794 (9 vendémiaire an III). 
146. Révolutions de Paris, $\mathrm{n}^{\circ} 145$, p. 100.

147. Odile RAMETTE, L'architecture éphémère de la décennie révolutionnaire, 1789-1799, Lille, 1979, p. 46 ; Françoise BRUNEL, "L'Être Suprême et les divisions de la Montagne avant Thermidor ", dans Michel VovelLE (dir.), L'Être Suprême, Arras, Noroit, 1991, p. 21-26.

148. Alain LotTin, «Les manifestations de l'Être Suprême dans le Nord: l'exemple de Bailleul et de Lille », dans Michel vovelLE (dir.), L'Être Suprême, Arras, Noroit, 1991, p. 31-33.

149. ANONYME, L'Athéisme ayant disparu, la Sagesse apparoit au Peuple Français : Allégorie de la Fête à l'Etre-Suprême, eau-forte, outils, 11,5 x 34,5, Paris, chez Joubert, 1794.

150. ANONYME, A la double aristocratie portons enfin les derniers coups: C'est en nous confédérant tous que nous sauverons la patrie, eau-forte, outils, monochr. bistre ; ov. 18 x 14,5 cm (im.), 24 x 33,5 cm, Paris, 1790.

151. Projet de décret pour l'établissement de l'Instruction nationale, Paris, 1793.

152. Alice de BOURGOING, op. cit.

153. Ibidem, p. 48.

154. Caroline CROUIN, «Étude scénographique des fêtes en faveur de l'abolition de l'esclavage en France (février - juillet 1794)», Annales historiques de la Révolution française [En ligne], 339| janvier-mars 2005, mis en ligne le 15 mars 2008, consulté le 17 février 2017. URL: http:// ahrf.revues.org/2123; DOI : 10.4000/ahrf.2123.

155. Haïm BURSTIN, « Le protagonisme comme facteur d'amplification de l'événement : le cas de la Révolution française ", L’Evénement, Aix-en-Provence, PUUA, 1986, p. 65-74.

156. Guillaume MAZEAU, "La violence évitée. Citoyens ordinaires face à l'assassinat de Marat ", Revue d'Histoire moderne et contemporaine, $\mathrm{n}^{\circ} 57,2010 / 1, \mathrm{p}$. 57-68.

157. Sur l'utopie du naturalisme artistique pendant la Révolution : Guillaume MAZEAU, « Portraits de peu. Le physionotrace au début du XIX ${ }^{\mathrm{e}}$ siècle », Revue d'histoire du XIXe siècle [En ligne], 45 | 2012, mis en ligne le 31 décembre 2015, consulté le 09 juillet 2017. URL : http://rh19.revues.org/ 4334 ; DOI : $10.4000 /$ rh19.4334.

\section{RÉSUMÉS}

Est-il possible de redécouvrir les fêtes de la Révolution française ? Ces événements ont surtout été étudiés à travers des sources écrites et en fonction du modèle idéal typique de la "fête révolutionnaire", lui-même associé à la subversion totale de mai $68 \mathrm{ou}$, au contraire, au rituel folklorisé du Bicentenaire (1989). Cet article propose de se dégager de ces "déjà-vus". Pour cela, il faut revenir aux images et aux sources visuelles de l'anthropologie politique de la Révolution française. Les fêtes apparaissent alors pour ce qu'elles furent : des spectacles publics, des performances visuelles dans lesquelles s'éprouvèrent les nouveaux mécanismes de représentation politique et sociale, ainsi que les nouvelles manières de se "sentir" citoyen.

Is it possible to throw a new glance on French Revolution festivals? This events have been mainly studied through written sources, which stressed the influence of the utopian model of the "revolutionnary festival", relying upon collective emancipation or, on the contrary, folkloric rituals symbolized by the Bicentenary(1989). This article claims that such events should be studied through images and fully included in the political antropology of the French Revolution, based on visual culture and experience. If we see them as public spectacles and collective 
performances, the French Revolution festivals reveal their functions in a context of collective crisis: the helped to shape new forms of citizenship and collective representation.

INDEX

Mots-clés : Révolution française, fêtes révolutionnaires, visualité, représentation politique

Keywords : French Revolution, festivals, visuality, political representation

\section{AUTEUR}

\section{GUILLAUME MAZEAU}

Maître de conférences en histoire moderne

Centre d'Histoire du XIX ${ }^{\mathrm{e}}$ siècle, Université Paris-1 Panthéon Sorbonne Associé à l'Institut d'Histoire du Temps Présent.

A publié Le Bain de l'Histoire (2009), Pour quoi faire la Révolution (2012), Un révolutionnaire malgré lui (2016) et va publier La Révolution française. Une histoire au présent, Fayard, 2019. 